\title{
WestVirginiaUniversity
}

THE RESEARCH REPOSITORY @ WVU

Graduate Theses, Dissertations, and Problem Reports

2007

\section{Fine particle separation in a riser with flow modifications}

\author{
Bryan M. Wimer \\ West Virginia University
}

Follow this and additional works at: https://researchrepository.wvu.edu/etd

\section{Recommended Citation}

Wimer, Bryan M., "Fine particle separation in a riser with flow modifications" (2007). Graduate Theses, Dissertations, and Problem Reports. 4349.

https://researchrepository.wvu.edu/etd/4349

This Thesis is protected by copyright and/or related rights. It has been brought to you by the The Research Repository @WVU with permission from the rights-holder(s). You are free to use this Thesis in any way that is permitted by the copyright and related rights legislation that applies to your use. For other uses you must obtain permission from the rights-holder(s) directly, unless additional rights are indicated by a Creative Commons license in the record and/ or on the work itself. This Thesis has been accepted for inclusion in WVU Graduate Theses, Dissertations, and Problem Reports collection by an authorized administrator of The Research Repository @ WVU. For more information, please contact researchrepository@mail.wvu.edu. 


\title{
Fine Particle Separation in a Riser with Flow Modifications
}

\author{
Bryan M. Wimer
}

Thesis submitted to the
College of Engineering and Mineral Resources
at West Virginia University
in partial fulfillment of the requirements
for the degree of
Master of Science
In
Mechanical Engineering
Eric K. Johnson, Ph.D., Chair
Bruce Kang, Ph.D.
Gary Morris, Ph.D.
Department of Mechanical and Aerospace Engineering

Morgantown, West Virginia

2007

Keywords: Coal Preparation, Fluidization, Separation Technology 


\section{$\underline{\text { Abstract }}$ \\ Fine Particle Separation in a Riser with Flow Modifications}

\section{Bryan M. Wimer}

Fine particle separation is of great interest in industry. Coal and mineral processing industries are currently very interested in particle separation for its potential in cleaning coal matter. A circulating fluidized bed riser system has been constructed to investigate possible separation of coal containing pyrite from clean coal. The system was constructed to operate using compressed air in which an air-solid mixture would pass through the riser and the solids would enter in to a dense, product, or filter collection bin. Several different variables were investigated during the project such as the collection ring wall height, particle entrance size into the riser, and mass flux of particles into the riser. By changing the particle entrance into the riser, and changing the ratio of nozzle flow and particle mass flux, a jet style flow could be achieved. The objective of this investigation was to observe how changing the flow field in a circulating fluidized bed would affect particle separation.

The first experiment was conducted using a mixture of sand and steel shot with particles sizes between 250 and 500 micron. Results from using the sand and steel shot proved to be very promising as more than $90 \%$ of the steel shot could be collected from the sand. The results were then used to determine the experimental conditions that were to be used while separating pyrite laden coal particles from clean coal. There was approximately $1 \%$ initial pyrite in the mixture and size ranges for the particles were between 105 and 210 micron. The results using the run-of-mine coal were not as promising as those of the sand and steel shot as a maximum of $25 \%$ of the pyritic laden coal could be separated from the cleaner coal. A third experiment was then performed in which chunks of pure pyrite were crushed and then added into clean coal and run through similar separation conditions to the run-of-mine coal. The mixture contained $4 \%$ pyrite, and both the pure pyrite and clean coal size ranges were between 105 and 210 micron. The results from this test proved to be very good as up to $77 \%$ of the pure pyrite could be recovered from the clean coal. 


\section{Acknowledgements}

I, Bryan Wimer, would like to thank several people for their help and support throughout my tenure at West Virginia University. They have helped me along my journey with knowledge and support.

I would first like to thank Dr. Eric Johnson for taking me in as a graduate student, and giving me a project to work on. His guidance through my two years as a graduate student has been very helpful, and will be used throughout my engineering career.

I would also like to thank Dr. Bruce Kang and Dr. Gary Morris for being on my graduate committee and providing the assistance they have.

Dr. Frank Saus also needs to be recognized for letting us use space in the NRCCE high bay and keeping the area clean of Femi's stuff as much as possible. Frank also was in control of funding for the project and helped to ensure that I had everything needed to complete the project.

I finally must thank Jordan Musser and Olufemi Olijade. Jordan has been very helpful in so many different ways. Jordan helped me in several situations when my brain had shut down, and also did all of the re-programming of the data acquisition system so that it was easier to use. Enough thanks can never be extended to him. Femi must be thanked for always helping when materials were needed that were not easily found. Femi also must be thanked for helping to provide coal for this project, and spending long hard hours helping Jordan and I to grind coal (Even though he gave me pre-cleaned coal).

I must also thank my Lord and Savior Jesus Christ for being the Rock of my life. He has been the same yesterday, today, and forever, and for that, I am grateful. 


\section{$\underline{\text { Table of Contents }}$}

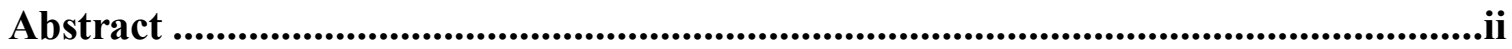

Acknowledgements ........................................................................................ iii

Table of Contents ...................................................................................................iv

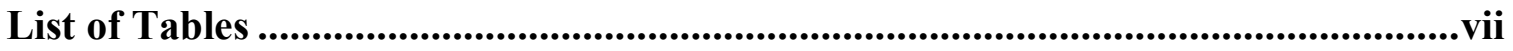

List of Figures......................................................................................................viii

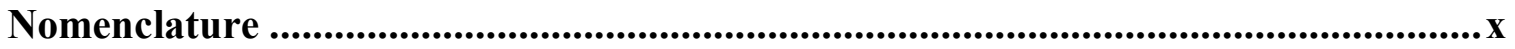

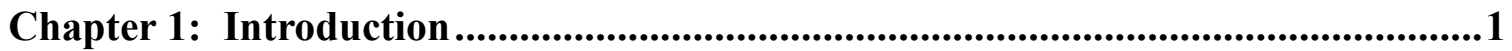

1.1 Coal Pollution Control..........................................................................................1

1.1.1 Pre-Combustion vs. Post-Combustion ....................................................... 2

1.1.2 Preference of Pre-Combustion Cleaning .................................................. 3

1.2 The Need for Particle Separation in Coal Cleaning ...........................................3

1.3 Current Cleaning Techniques .....................................................................5

1.3.1 Wet Separation Techniques ........................................................................ 5

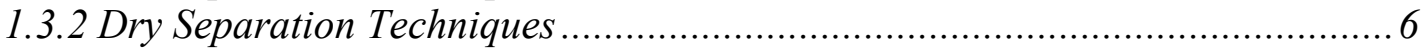

1.4 Object of This Research ........................................................................................ 7

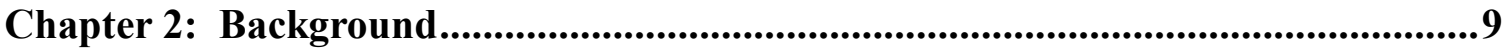

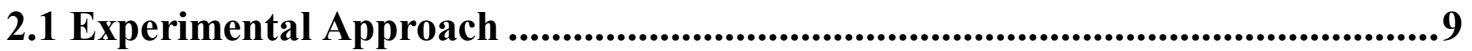

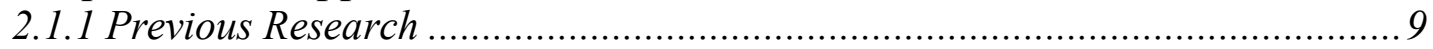

2.2 Small Coal Particle Problem ...................................................................................11

2.2.1 How Pyrite is Found in Coal.................................................................. 11

2.2.2 Crushing of Coal to Liberate Pyrite ......................................................... 12

2.3 Flow In a Riser......................................................................................13

2.4 Different Flow Regimes in a CFB..............................................................14

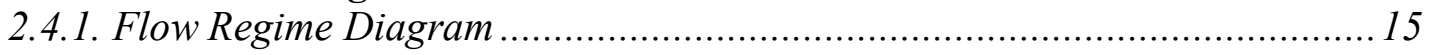

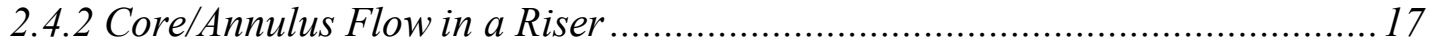

2.4.3 Experimental Flow Regime Operation................................................ 18

2.5 Concentric Jet Flow ...................................................................................... 19

2.6 Lift Forces .......................................................................................................28

2.7 Modification of the Flow Field/Conclusions .............................................. 32

3.1 Initial System ..............................................................................................33

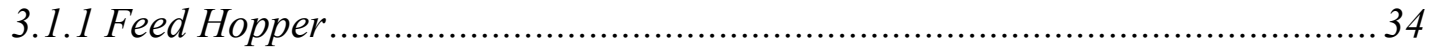

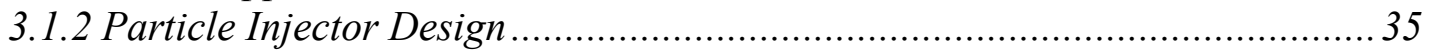

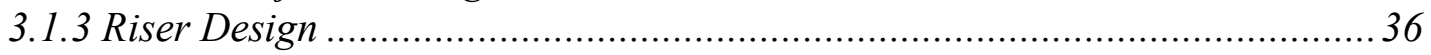

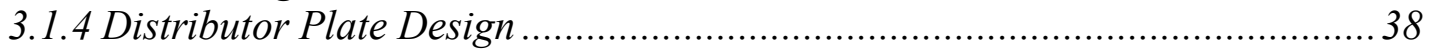

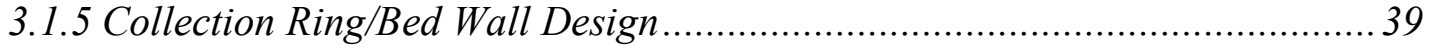

3.1.6 Dense Particle Collection Bin Design ...................................................... 40

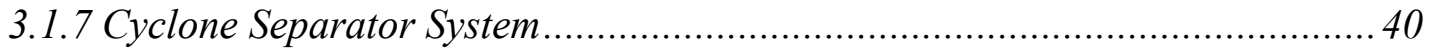

3.1.8. Design of the Light Particle (Product) Collection Bin .................................. 44

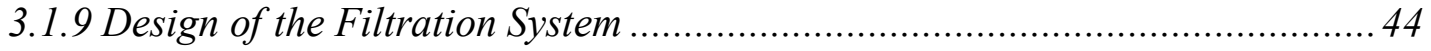

3.1.10 Design of the System Frame ............................................................... 45 
3.2 Modifications to the Initial System ...........................................................................46

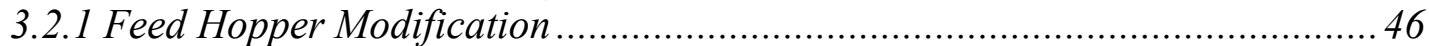

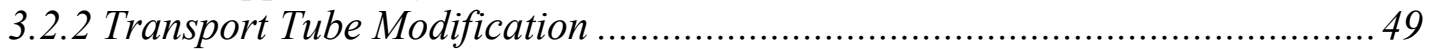

3.2.3 Collection Ring/Bed Wall Height Modifications ........................................... 49

3.2.4 Design of the Particle Entrance into the Riser...........................................51

3.2.5 Modifications of the Paper Filtration System ……....................................52

3.3 Instrumentation ........................................................................................................5 54

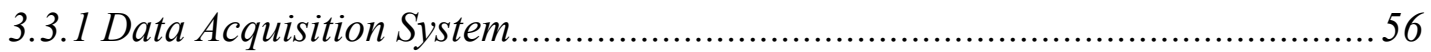

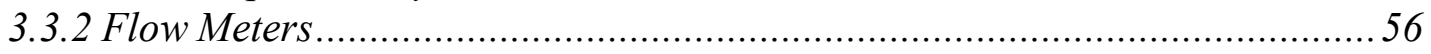

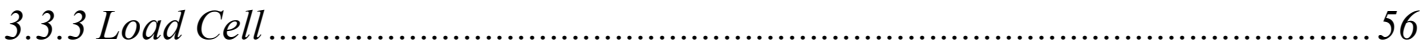

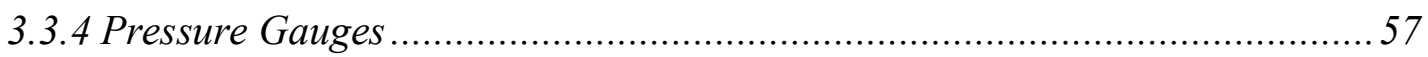

3.3.5 Inductively Coupled Plasma - Optical Emission Spectroscopy Machine .........57

3.3.6 Scanning Electron Microscope (SEM) ....................................................58

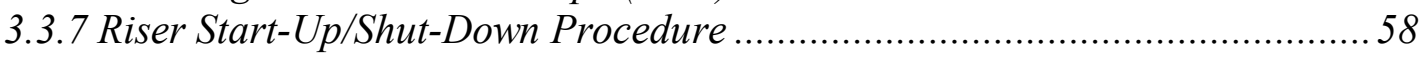

Chapter 4: Selection of Test Conditions ........................................................................59

4.1 Test Matrix Selection....................................................................................................59

4.1.1 Basic Riser Geometry/Variable Selection …….........................................59

4.1.2 Selection of Sand and Steel Shot Test Matrix............................................59

4.1.3 Selection of Pyritic Coal/Clean Coal Test Matrix ..........................................61

4.1.4 Selection of Pure Crushed Pyrite/Clean Coal Test Conditions.......................63 63

4.2 Experimental Gas Velocities.............................................................................63

4.2.1 Terminal Velocity Equation.................................................................64 64

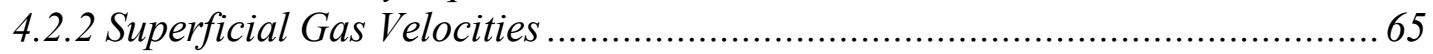

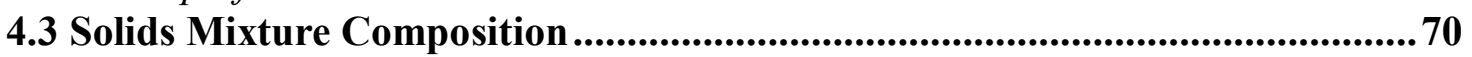

4.4 Selection of Mass Flux Values ......................................................................................70

4.5 Selection of Transport and Fluidization Air Flows ..............................................72

4.6 Experimental Uncertainty ..............................................................................74

Chapter 5: Sand and Steel Shot Separation Projects.....................................................75

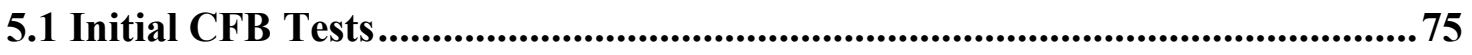

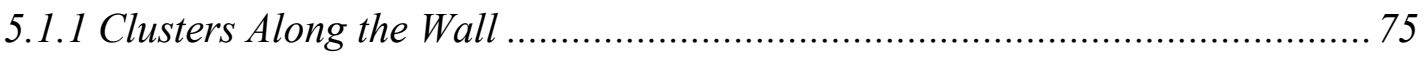

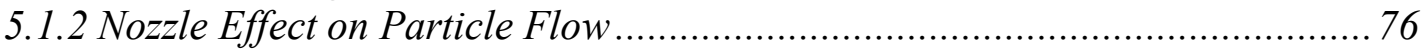

5.1.3 Effect of the Collection Ring Wall Height .................................................... 78

5.2 Introduction to the Sand and Steel Shot Separation Project ...............................78

5.3 Separation by Density of Steel Shot from Sand .....................................................79

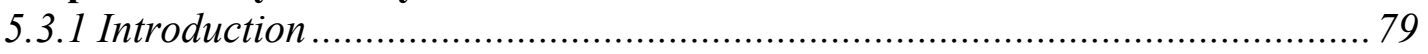

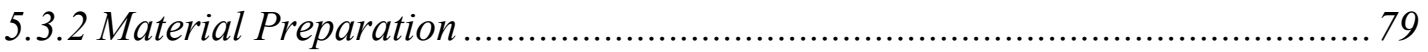

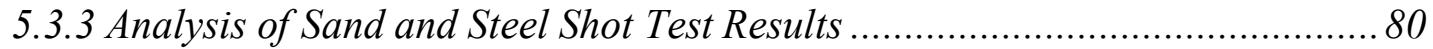

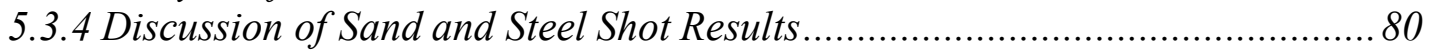

Chapter 6: Separation of Pyrite Laden Coal from Clean Coal ....................................87

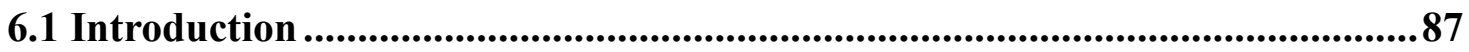

6.1.2 Preparation of Materials and Test Conditions.........................................8 87

6.2 Analysis of Coal Test Runs ....................................................................................88

6.3 Discussion of Coal Test Results ......................................................................89

6.4 Coal Particle Size Distribution ........................................................................105 
Chapter 7: Separation of Crushed Pyrite From Coal ............................................106

7.1 Separation of Pure Crushed Pyrite from Coal .................................................. 106

7.2 Problems with the Kingwood Coal Used..................................................... 106

7.3 Added Pyrite ..................................................................................................107

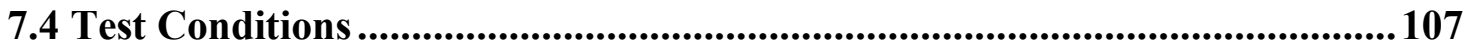

7.5 Analysis of Results ............................................................................................ 107

7.6 Discussion of Results from Separating Pure Pyrite from Coal Tests............. 108

7.6.1 Results from Optical Microscope ................................................................ 108

7.6.2 Sink-Float Analysis ..................................................................... 110

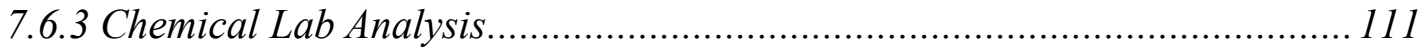

7.7 Conclusions from Pure Pyrite from Clean Coal Separation Tests..................112

Chapter 8: Conclusions and Recommendations...................................................113

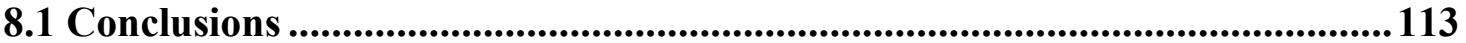

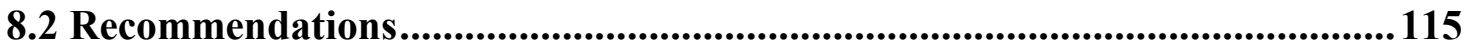

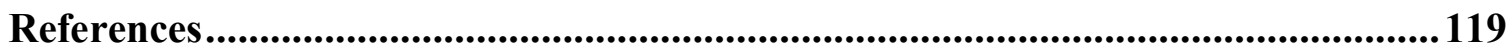

Appendix A

Appendix B .................................................................................................................. 123

Appendix C ................................................................................................................... 129

Appendix D................................................................................................ 133

D.1 Riser Start Up/Shut Down Procedure ......................................................133

D.1.1 Riser Start-up Procedure ................................................................... 133

D.1.2 Riser Shutdown Procedure ............................................................... 133 


\section{List of Tables}

Table 2.6.1 Properties of the Spheres used in Eichhorn experiments .......................29

Table 3.1.7.a Cyclone Dimensions and Cut Diameters for Cyclone System..............42

Table 4.1.a. Experimental System Setup/Modifications ..........................................59

Table 4.1.b Sand and Steel Shot Test Matrix ...........................................................60

Table 4.1.c Clean Coal/Pyritic Coal Test Matrix ......................................................62

Table 4.1.d Clean Coal/Pure Pyrite Test Matrix........................................................63

Table 5.3.a Results of Sand and Steel Shot Separation Tests ...................................81

Table 6.3.a Experimental Results for Coal Test Runs .................................................97

Table 7.6.a Sink-Float Results from Separation of Pure Pyrite from Coal............. 110

Table 7.6.b Analytical Chemical Lab Results from ............................................... 111

Separation of Pure Pyrite from Coal ............................................................................... 111 


\section{$\underline{\text { List of Figures }}$}

Figure 2.4.1.a Basic Flow Regime Diagram.............................................................16

Figure 2.4.2.a Particle Velocity Profile in a CFB in Core/Annulus Flow Regime..... 17

Figure 2.5.a. Levy and Lockwood experimental mean axial gas velocity profile ......21

Figure 2.5.b. Mean Particle and Fluid Velocity Profiles for a Loading Ratio of .3...24

Figure 2.5.c. Simulated Particle Velocity Profile for a Loading Ratio of 1.8 ...........25

Figure 2.5.d. Particle mass flux Results in a Axisymmetric Particle Laden Jet........26

Figure 2.5.e Particle Velocity Profiles of Powder Exiting a Pipe.............................26

Figure 2.6.2 Lift Coefficient as Influenced by Distance from the Center-Line..........30

Figure 2.6.3 Lift Coefficient as Influenced by Shear Parameter .............................31

Figure 3.1.a. Schematic of the Riser System..........................................................33

Figure 3.1.b. Pneumatic Flow Chart for the Riser System ..........................................34

Figure 3.1.2.a. Diagram of the Pneumatic Particle Injector .....................................36

Figure 3.1.3.a. Picture of the Modified Riser System ................................................37

Figure 3.1.4.a Distributor Plate and T-Shaped Particle Entrance into Riser ...........39

Figure 3.1.7.a. Cyclone Dimensions and Schematic ............................................41

Figure 3.1.7.b. Experimental Set up - Two Stage Cyclone ........................................43

Figure 3.2.1.a Modified Feed Hopper ............................................................................48

Figure 3.2.2.a. Modified Transport Tube ...................................................................49

Figure 3.2.3.a Collection Ring/Distributor Wall Extensions....................................50

Figure 3.2.4.a Particle Entrance Nozzles ..........................................................52

Figure 3.2.5.a. Modified Paper Filtration System ..................................................53

Figure 3.3.a Air Supply and Flow Meter System ......................................................54

Figure 3.3.b Instrumentation Location................................................................55

Figure 4.2.2.a Terminal Velocity vs. Particle Size of Sand and Steel Shot ................67

Figure 4.2.2.b Terminal Velocity vs. Particle Size of Coal and Pyrite........................68

Figure 4.2.2.c Corrected Terminal Velocity vs. Particle Size of Coal and Pyrite .....69

Figure 5.1.1.a Cluster and Stream formations of sand and steel shot mixture

traveling down along the riser wall..........................................................................76

Figure 5.1.2.a Beginning of Turbulent Particle Flow/End of Cluster Flow................77

Figure 5.3 4.a Dense Particle Mass Fraction for Sand and Steel Shot Runs.............81

Figure 5.3.4.b Dense Particle Collection Efficiency for Sand and Steel Shot Runs .. 82

Figure 5.3.4.c Dense Mass Fraction vs. Mass Flux for Sand and Steel Shot .................

Tests ............................................................................................................................883

Figure 5.3.4.d Dense Collection Efficiency vs. Mass Flux for Sand and Steel Shot

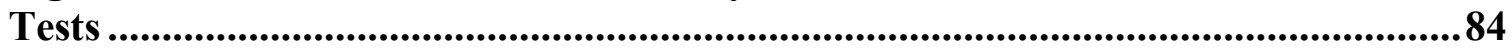

Figure 5.3.4.e Dense Particle Mass Fraction as a Function of Nozzle Size.....................

(Regular Flow) ...........................................................................................................85

Figure 5.3.4.f Dense Particle Collection Efficiency as a Function of Nozzle Size

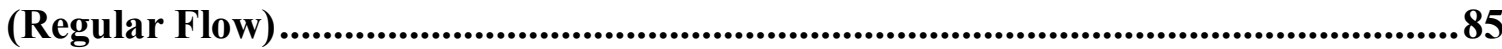

Figure 5.3.4.g Dense Particle Mass Fraction as a Function of Nozzle Size

(Concentric Jet Flow) ........................................................................................86

Figure 6.3.a Percent Sulfur Change Comparison for Gas Flow Rates......................99

Figure 6.3.b Product Percent Change in Sulfur vs. Mass Flux.....................................

(0.3048 meter Collection Ring Wall Height)........................................................100 
Figure 6.3.c Product Percent Change in Sulfur vs. Mass Flux

(0.381 meter Collection Ring Wall Height)

Figure 6.3.d Percent Sulfur Change Comparison for Repeatability Tests.

Figure 6.3.e Percent Change in Sulfur Comparison for Ring Wall Heights

Figure 6.3.f Percent Change in Percent Sulfur Comparison for Nozzle Sizes ........104

Figure 6.4.a Particle Size Analysis and Distribution ................................................... 105

Figure 7.6.a Pure Pyrite from Product Collection Bin..............................................109

Figure 7.6.b Pure Pyrite from Dense Collection Bin ............................................110

Figure B.1 Dense Particle Mass Fraction as a Function of Collection Ring Wall

Height (Regular Flow)

Figure B.2 Dense Particle Mass Fraction as a Function of Collection Ring Wall

Height (Concentric Jet Flow).

Figure B.3 Dense Particle Collection Efficiency as a Function of Collection Ring Wall Height (Regular Flow).

Figure B.4 Dense Particle Collection Efficiency as a Function of Collection Ring

Wall Height (Concentric Jet Flow)

Figure B.5 Dense Particle Mass Fraction as a Function of Nozzle Size - .3048 meter

Ring Wall Height - (Concentric Jet Flow) ........................................................125

Figure B.6 Dense Particle Mass Fraction as a Function of Nozzle Size - .381 meter

Ring Wall Height - (Regular Flow)...........................................................................125

Figure B.7 Dense Particle Collection Efficiency as a Function of Nozzle Size - $\mathbf{3 0 4 8}$

meter Ring Wall Height - (Concentric Jet Flow) ..........................................126

Figure B.8 Dense Particle Collection Efficiency as a Function of Nozzle Size - .381

meter Ring Wall Height - (Regular Flow) .

Figure B.9 Dense Particle Collection Efficiency as a Function of Nozzle Size - .381

meter Ring Wall Height - (Concentric Jet Flow) ...............................................127

Figure B.10 Picture of Sand and Steel Shot Mixture before Separation..................127

Figure B.11 Picture of Sand and Steel Shot from Product Bin - Post Separation.. 128

Figure B.12 Picture of Sand and Steel Shot from Dense Bin - Post Separation .....128

Figure C.1 Initial Carbon Coated Coal Sample 1 (x250) ......................................129

Figure C.2 Initial Carbon Coated Coal Sample 2 (x250) ......................................... 129

Figure C.3 Dense Bin Carbon Coated Coal Sample 1 (x250) ...................................130

Figure C.4 Dense Bin Carbon Coated Coal Sample 2 (x250) .................................. 130

Figure C.5 Product Bin Carbon Coated Coal Sample 1 (x250) ................................ 131

Figure C.6 Product Bin Carbon Coated Coal Sample 2 (x250) .............................. 131

Figure C.7 Coal Spectrum Overlay for Initial, Dense, and Product Samples......... 132 


\section{$\underline{\text { Nomenclature }}$}

\section{Symbol}

A

a

$A_{f}$

$A_{r}$

B

b

$\mathrm{C}_{\mathrm{LS}}$

D

$d_{\text {cut }}$

$d_{p}$

$D_{R}$

$F_{L}$

G

g

$g_{c}$

$\mathrm{H}$

$\Delta \mathrm{H}$

$\mathrm{H}_{\mathrm{R}}$

$\mathrm{k}$

$\mathrm{K}_{\mathrm{s}}$

$\mathrm{m}_{\mathrm{p}}$

$\mathrm{N}$

O

$\Delta \mathrm{P}$

Q

R

$r$

$\mathrm{Re}_{\mathrm{G}}$

$\mathrm{Re}_{\mathrm{p}}$

$\mathrm{Re}_{\mathrm{t}}$

$\mathrm{Re}_{\mathrm{tr}}$

$t_{\text {flight }}$

$\mathrm{U}_{0}$

$\mathrm{U}_{1}$

u

$\mathrm{U}_{\mathrm{fd}}$

$\mathrm{u}_{\mathrm{cen}}$

$u_{r}$

\section{Meaning}

Cyclone inlet height

Particle radius

Frontal area of particle

Archimedes number

Cyclone dust outlet width

Cyclone inlet width

Lift coefficient for sphere

Cyclone diameter

Particle diameter collected with $50 \%$ efficiency (Equation 25)

Particle diameter

Riser Diameter

Lift force

Solids mass flux into the riser

Acceleration of gravity

Collection gap width

Cyclone total length

Inlet velocity heads lost in cyclone

Riser Height

Number of variables

Shear parameter

Mass of particle

Number of turns gas makes in cyclone

Cyclone gas outlet diameter

Pressure drop

Volume flow rate

Pipe radius

Radial coordinate,

Number of basic dimensions

Shear Reynolds number

Particle Reynolds number

Reynolds number at terminal velocity

Reynolds number at transport velocity

Particle time of flight

Superficial gas velocity in riser

Cyclone gas inlet velocity

Gas velocity

Upper bound of gas velocity for fast fluidization

Gas velocity to center of sphere

(Yamamoto, et al.)

Gas velocity in radial direction 


$\begin{array}{cc}\mathrm{U}_{\mathrm{tf}} & \begin{array}{c}\text { Lower bound of gas velocity for fast } \\ \text { fluidization }\end{array} \\ \mathrm{u}_{\mathrm{z}} & \begin{array}{c}\text { Gas velocity in axial direction } \\ \mathrm{u}_{\theta}\end{array} \\ \mathrm{V} & \begin{array}{c}\text { Gas velocity in tangential direction } \\ \text { Relative velocity between gas and particle } \\ \text { (Yamamoto, et al.) }\end{array} \\ \mathrm{v} & \text { Particle velocity } \\ \mathrm{v}_{\mathrm{r}} & \text { Relative velocity between gas and particle } \\ \mathrm{V}_{\mathrm{pt}} & \text { Particle terminal velocity } \\ \mathrm{W} & \text { Cyclone inlet width } \\ \mathrm{W} & \text { Relative velocity to front of sphere } \\ & \text { (Saffman) }\end{array}$

\section{Greek}

$\mu$

$\rho_{\mathrm{g}}$

$\phi$

$\omega_{\mathrm{h}, 0}$

$\omega_{\mathrm{h}, \mathrm{r}}$

$\eta_{\mathrm{h}}$

$\eta_{\text {cyclone }}$

Viscosity of gas

Gas density

Relative velocity between gas and particle

Initial heavy particle mass fraction

Recovered heavy particle mass fraction

Heavy particle collection efficiency

Cyclone efficiency 


\section{Chapter 1: Introduction}

\subsection{Coal Pollution Control}

One of the most important areas in controlling environmental pollution is developing cleaner burning coal fired power plants. The main solutions to the problems encountered involve finding a way to clean the coal either before it enters the plant, or after the combustion products exit the boilers. One of the chief goals of cleaning the coal is to separate out the polluting species by various methods, including wet and dry particle separation, and gas cleaning.

Separation of particles is a technology that has long been employed by many industries. Doctor (1983) states the mineral processing and coal preparation industries hold the area of fine particle separation in particularly high respect. The particles to be separated are considered small individual pieces of coal. Many of the separation methods used to separate these particles have significant disadvantages associated with them. The procedures they employ to separate fine particles sometimes require chemicals or water to aid in the process of separation (Doctor 1983). This leads into disposal of the chemicals or waste water, which are most generally hazardous to the environment. There is, however, an alternative on the horizon as newer developments have been made in the area of dry particle separation.

One such manner of dry separation is a circulating fluidized bed (CFB) riser system. A CFB riser system was built by Jeremy Regester, Robert Almond, and Dr. Eric Johnson on the campus of West Virginia University. Their previous work has shown that a dry separation method of fine particles is possible when using the system. 


\subsubsection{Pre-Combustion vs. Post-Combustion}

Coal is commonly used as an energy source but also has some considerable drawbacks. Coal frequently contains significant amounts of inorganic sulfur, in the form of pyrite, which can be potentially hazardous to the environment. The material being considered can be thought of as coal that contains either a small amount of pyrite, or a large amount of pyrite, since completely separating pyrite particles from coal is very difficult. Coal and pyrite particles, and their structure, will be discussed further in Section 2.2.1. When coal is used as an energy source in power plants, harmful contaminants could potentially be released into the atmosphere during combustion. For this thesis, the main concern is separating pyrite from run-of-mine coal. There are two different methods in which pyrite can be cleaned from coal. Coal can either be sent to a preparation plant where contaminates will be removed before combustion, or during a flue gas cleaning procedure after the exhaust gases have exited the boilers. Herhal (1990) states when run-of-mine coal is sent to a preparation plant it goes through a process of being crushed to liberate impurities in the coal, such as the pyrite, which are then separated by mechanical means. The alternative cleaning method to this is to clean the gases expelled from the plant boilers after the coal has been combusted. This is generally known as flue gas desulfurization. Holt (1977) states that flue gas desulfurization is used when the flue gases from combustion are scrubbed with a limestone, or dolomite, slurry to remove sulfur dioxide $\left(\mathrm{SO}_{2}\right)$ that is harmful to the environment. 


\subsubsection{Preference of Pre-Combustion Cleaning}

Both pre-combustion and post-combustion cleaning methods have advantages and disadvantages. Despite the potentially environmentally harmful drawbacks of precombustion cleaning, it remains preferable to post-combustion cleaning. Both Holt (1977) and Herhal (1990) state that physical coal cleaning before combustion is more cost effective that using post-combustion cleaning. They also state that pre-combustion cleaning methods have more potential to clean the coal more thoroughly.

Herhal (1990) states that removing the impurities in the coal produces a higher BTU value per weight of the coal, since the lower energy producing contaminates are removed. By removing the polluting particles lying in the coal, a cleaner burn will also be found in the boilers, thus reducing wear on the plant equipment. One downfall of precombustion physical cleaning is that is cannot remove the organic sulfur found in the coal. It would be preferable to have both pre- and post-combustion cleaning to eliminate as much of the pollutants as possible, but the pre-combustion cleaning process is more effective at removing such pollutants.

\subsection{The Need for Particle Separation in Coal Cleaning}

There is a great interest in particle separation technology in the field of coal preparation. It is of the utmost importance to be able to efficiently separate pyritic laden coal from clean coal. Speight (2005) states that sulfur is found in coal in three different forms: organically bound sulfur, inorganically bound sulfur, and inorganic sulfates. Inorganically bound sulfur is generally what is known as pyritic coal. According to Komnitsas (2001) the main concern with pyrite in coal is that it will oxidize and will inherently form acids. 
Chen and Yang (2003) state China is the largest coal producing and coal consuming country in the world. Over $80 \%$ of the coal used in China is burned directly without sufficient cleaning. Chen and Yang (2003) also state up to $85 \%$ of the sulfur dioxide emissions in China come from this contaminated coal being combusted. Up to $33 \%$ of the coal used in China for energy is cleaned before combustion, leaving a large amount of polluted coal to be burned, thus causing harmful emissions and environmental hazards. The main reason for the lack of coal cleaning in China is due to the deficiency of water that is needed in most cleaning processes. Most of the coal producing regions in China are in arid regions, where water is simply not available.

Another area that has a need for coal cleaning is the Tula coal region near Moscow, Russia. Komnitsas (2001) states that there are over 150 large coal waste sites where coal beneficiation plants are located. These waste sites usually contain coal that has a very high sulfur content which needs to be cleaned. Without the removal of the pyritic coal there is a great concern for the generation of acidic runoff and acid in the water found nearby. Cleaning the sulfur from this coal would allow it to be used, thus leaving less coal being moved to the waste sites.

Another area of concern is in the Eastern United States. Lutrell (1998) states that studies have found that only $30-50 \%$ of the pyritic sulfur found in coal used in the Eastern U.S. can be efficiently removed by conventional coal cleaning processes. This leads again to the concern of environmental dangers that can be found with coal pollution. Considering these factors, it is of vast importance to be able to effectively separate the harmful impurities from the clean coal. 


\subsection{Current Cleaning Techniques}

It is clear to see that coal must be cleaned before use as an energy source. There are some dry methods of coal cleaning, but both these and the wet separation techniques have their own drawbacks. Most of these methods can clean the coal of ash, trace elements, and still burn while recovering most of the energy value left; however, most of these methods can not clean pyrite laden coal as efficiently.

In a coal preparation plant, there are typically four stages that coal will go through to be thoroughly cleaned. Doctor (1983) states that depending on the plant, that coal will normally will be crushed first so that it may be easily handled while allowing the desirable size range to be produced. Second, the coal will be screened allowing it to be separated into the desired size ranges while removing foreign objects. Third, the coal will have the impurities removed by means of physical cleaning. These cleaning methods will be discussed further in Section 1.3.1 and 1.3.2. Last, the coal will be dewatered so that excess moisture can be removed so as to make the combustion process as efficient as possible.

\subsubsection{Wet Separation Techniques}

Conventional wet cleaning methods are efficient, and generally cause other forms of environmental risks, such as contaminated water used in jig or froth flotation. Doctor (1983) says that jigging is when pulses of air are moved upwards through a coal filled bath which will then separate the materials by density. Froth flotation is another wet separation technique in which advantage is taken of the wetting properties of coal and its impurities. The coal is put into a bath in which air is blown through, causing the clean coal to float to the top. Doctor (1983) states froth flotation is not dependent on the 
specific gravity of the material used; therefore it is not as an effective method of cleaning pyrite from the coal. Another procedure used to clean impurities from coal is hydrocyclones. Hydrocyclones, also known as dense medium cyclones, have a vortex of water formed within them that takes advantage of high centrifugal forces to help separate the denser impurities from the coal.

The greatest risk with wet coal cleaning methods is contaminating water while washing the coal. This water must then be disposed of, giving it potential to contaminate outside water resources. According to Chen and Yang (2003), cleaning one ton of coal requires up to 3 to 5 tons of water. This leaves a very large amount of polluted water to be dealt with once the cleaning process is complete.

Almond (2005) states that when density based coal cleaning methods are implied, such as jigging or shaking tables, that as the particle sizes become very fine the efficiency of cleaning decreases. This also creates a problem due to the need for coal to be crushed down to a fine size for pyrite to be liberated and properly separated from the clean coal.

\subsubsection{Dry Separation Techniques}

To avoid the drawbacks of polluted waste water that is common with wet coal cleaning methods, newer dry coal cleaning methods have been developed. Almond (2005) states there are several advantages to dry separation methods opposed to those of wet methods. One such advantage is that no de-watering process is needed. This means no waste water results from cleaning, thus helping prevent environmental damage.

Although dry separation methods have several advantages, there are some drawbacks. One drawback is that dry coal cleaning methods are generally not as efficient in separating pyrite laden coal particles as are wet methods. Dry separation methods also 
frequently require the coal be dried before it enters into the system; meaning a drying process would generally be needed as well. Another setback is air pollution, in the form of dust, may be created with dry separation methods. This could also create environmental concerns.

For coal preparation plants to be effective, a generally high cleaning capacity is needed. Currently, there are not many dry separation and cleaning methods widely used in industry. Despite this Chen and Yang (2003) state one such dry cleaning method has been put into effect in China. The areas producing much of China's coal is located in a very arid region where water is not readily available. To clean the coal before combustion, dense medium air fluidized beds are being investigated as an alternative to wet cleaning methods. The current air fluidized beds can separate particles between 50-6 millimeter sizes. This particle size allows rather large quantities of coal to be cleaned, though much of the pyrite will remain embedded in the coal. Although particles of this size will generally not have pyrite liberated from them, several other dense medium fluidized beds are being investigated that will allow fine particles to be separated as well. Currently a 700,000 ton/year beneficiation plant such as this has been put into operation for testing in China.

\subsection{Object of This Research}

This particular research project uses a Circulating Fluidized Bed (CFB) riser system to investigate the separation of pyritic laden coal from clean coal, and pure pyrite particles from clean coal by means of density differences. It was desired to observe how modifying the flow field in the riser of the CFB would affect the separation of fine particles. The particles were injected into the riser through different size air jets that 
would change the flow field as desired. Sand and steel shot particles were used in preliminary tests to see the effects of the modified flow fields. The results from the tests were then used to set the design modifications and conditions for the tests performed using coal mixtures. 


\section{Chapter 2: Background}

\section{$\underline{\text { 2.1 Experimental Approach }}$}

A Circulating Fluidized Bed (CFB) riser system is usually found in power plants to combust and gasify coal. However, they can also be used as a way to separate particles. The CFB riser used for the experiments performed is a prime candidate for the desired coal particle separation. This research project is a continuation of work previously documented by Regester (2004) and Almond (2005). The work previously completed by Regester and Almond focused on basic particle separation and which geometry for the riser would best accommodate it. For this project a nozzle style inlet, for particle entrance into the riser, was used to see how it affected the separation efficiency for coal. Different size nozzles were installed to observe, as the particle flow became more of a jet style flow, if the pyritic laden coal could be split from the clean coal. Other factors included in the study were the mass flow rate of coal into the CFB, the height of the CFB's bed collection ring wall height, and the split of flow between the nozzle/distributor plate.

\subsubsection{Previous Research}

The first stages of research on the CFB riser were completed by Jeremy Regester in 2004, in the NRCCE building's high bay on the Evansdale campus of West Virginia University. Regester (2004) completed exploratory work using the riser to separate particles by density. Several different variables were considered in the separation process such as the outlet geometry of the riser, the dense bin collection gap width, and the height of the riser. 
Regester found that with a riser height of 14 feet and a 90 degree swept outlet geometry that the separation process was most efficient. It was also found that the collection gap size had little or no effect on the separation process when high mass flux values were passed through the system. A mixture of sand and steel shot was run through the system to investigate if and how efficiently the two could be separated. With the experimental set up used, Regester found that he could attain favorable heavy particle mass fraction and collection efficiencies, but the particle mass flow rates remained rather low.

Systems and processes other than circulating fluidized beds are generally used in industry to separate pyritic coal from clean coal. Lutrell (1998) states an experimental system using basic coal cleaning devices was set up at the Federal Energy Technology Center in Pittsburgh, Pennsylvania. The system combined an enhanced gravity separator to clean the froth product from an advanced flotation column and Multi-Gravity Separator (MGS). Illinois No. 6 coal with 2.2\% pyritic sulfur content was the coal used for the test procedures. Combining the processes achieved separation efficiency of $83.6 \%$ when separating the pyritic coal from clean coal for 2 to 6 millimeter sizes. Although this system is efficient, it also contains the same waste water problems as other wet separation systems.

Chen and Yang (2003) report that at China University of Mining and Technology the Mineral Processing Research Center has been working on coal beneficiation with a dense air fluidized bed since 1984. A plant has been developed that can operate with coal sizes of $+6 \mathrm{~mm}$ at up to 50 tons/hour. This system is just one example of different fluidized beds that are currently being investigated for particle separation. 


\subsection{Small Coal Particle Problem}

For density based particle separation, there is a need for the particles to have relatively different densities. For this type of separation to take place, each individual particle must be either heavy or light. The problem with separating pyritic laden coal from clean coal lies in the fact that the coal must be crushed to very fine particle sizes to free the pyrite. To fully liberate pyrite from coal, it usually must be crushed or pulverized down to sizes below 200 micron (Stiller 2007).

Crushing coal to this size allows a significant quantity of the pyrite to be released from the coal, which in turn permits it to be separated by gravitational means. This would mean all coal would need to be crushed down to a fine size for cleaning, which is time and cost consuming. Another problem lies in the health and fire hazards associated with having fine airborne coal particles.

\subsubsection{How Pyrite is Found in Coal}

This research contains two different experiments that investigate separating pyrite from coal. In these experiments, there are two different ways of describing how the pyrite and coal mixtures are to be separated.

In the first experiment, as delivered run-of-mine coal is used. With run-of-mine coal there are pyrite particles found embedded within the coal, but they are very hard to liberate. When coal is crushed to a fine size, a few individual pyrite particles could be released, but most will remain embedded in the larger coal particles. When performing the first experiment, the pyrite particles being separated from the clean coal are actually coal particles that contain large amounts of pyrite. The clean coal is actually a piece of 
coal that contains a small amount of pyrite. These could also be referred to as "dirty" and "clean" coal.

For the second experiment, whole pieces of pure pyrite approximately $3 / 4$ inches were crushed and screened to the same size as the coal used for the test runs. The pyrite was then added into the clean coal and mixed up. By doing this, the coal and pyrite were completely separated from one another and not bound together, as was the case in the first experiment. This allowed the system to simulate separation of pyrite from run-ofmine coal if the pyrite particles could be liberated completely from the coal when crushed. When analyses of all coal test runs were completed, samples were sent to a chemical analytical lab to check the results. The lab checked for total percent of sulfur in the samples. Since pyrite is comprised of primarily sulfur, this was an accurate way to check the samples.

\subsubsection{Crushing of Coal to Liberate Pyrite}

When run-of-mine coal is sent to a preparation plant, it is crushed down to a more manageable size, also allowing it to be cleaned more easily. When the coal is crushed to a smaller size, many of the impurities are liberated. Although many of the polluted particles are freed, only some of the pyrite particles are completely broken away from the rest of the coal, leaving the rest embedded within. The Kingwood coal used in this research was crushed down to below 210 micron to try and release as many pyrite particles from the coal as possible, as would be done in a preparation plant. It was found that only a small amount of the pyrite could actually be broken away from the rest of the coal. It was also later discovered that the Kingwood coal received has already been pre- 
cleaned, having a sulfur content of $1 \%$. This meant it would be even harder to liberate the pyrite from the coal.

\subsection{Flow In a Riser}

Flow characteristics which lead to particle separation in a circulating fluidized bed have been observed in previous research. In prior work, it has been noted that particles in a CFB will travel upwards in the center of the riser, some of which will exit out the top. The particles that do not exit the top of the riser will move towards the wall and travel downwards. Some of these particles are then re-entrained in the flow and move upwards again, thus creating a circulating pattern (Johnson, et al 2005). While traveling in this circulating pattern, there are approximately three basic flow regimes at which a CFB can operate. Fan and Zhu (1998) have observed these, one which is of great interest - the fast-fluidization regime.

A mixture of transport gas and solids enter the system via an inlet port in the bottom of the riser. Below the particle inlet is a distributor plate that allows the air flow to be distributed evenly as it enters the riser. The air flow from the distributor plate then mixes with the flow from the inlet port as it moves upwards in the riser. It is here that the air flow coming from the distributor plate and the inlet port will combine to form the mass average gas velocity in the riser.

As the particles enter the riser via the inlet port they will travel upwards. The lighter, or smaller, particles will continue climbing in the center of the riser, and will eventually exit out the top into a cyclone system and then into a collection bin if the corresponding gas velocity is high enough. The heavy, or dense, particles will move towards the outside walls of the riser due to the Saffman/lift forces and begin to form 
clusters. The Saffman/lift forces will be discussed further in Section 2.6. Once these clusters are formed, the large heavy particles will begin to travel down the outside walls of the riser back towards the distributor plate. This is caused by a velocity profile, described by Moran and Glicksman (2001), which has a higher average value towards the center of the riser, and a lower value at the walls of the riser. This will be discussed further in Section 2.4.2.

The lower velocity value at the wall is not high enough to sustain the particles upward movement, which allows them to fall along the riser wall. Some of these particles will then become re-entrained in the flow due to turbulent gas coming from the distributor plate. The lighter particles will then begin to travel up the riser again, while the more dense particles will pass by the distributor through a small gap along the riser wall and enter the dense collection bin.

\subsection{Different Flow Regimes in a CFB}

A Circulating Fluidized Bed (CFB) operating with an air-solid mixture may operate in one of three flow regimes. The flow regimes are dilute, dense, and the regime this experiment is concerned with - core/annulus or fast fluidization (Regester 2004). There is also a transition regime that can occur between the fast fluidization and dilute flow regimes, although it is not always classified as one.

Fan and Zhu (1998) state the dense flow regime is characterized by the solid mixture concentration in the riser becoming high enough that it disrupts the air flow moving upwards in the riser. This disruption causes the flow to form a bubbling action of the air flow and particles in the riser. Dilute Flow occurs when the solids mixture in the riser is reduced to a minimal amount in which it flows directly out the top of the riser 
without re-circulating back to the bottom. The core/annulus flow regime occurs in between the dense and dilute flow regimes. It is commonly characterized by the solids rapidly moving upwards in the riser then re-circulating back to the bottom along the wall, and then being re-entrained in the core flow once again.

\subsubsection{Flow Regime Diagram}

To predict the flow regime in which a system is operating, several equations can be used which are found in Fan and Zhu (1998). With these equations, a flow regime diagram can be created which takes into account the flow rates of the gas velocity in the riser, mass flow of particles into the riser, and shows the different regimes and boundaries in which the system can be operating. These equations are used to determine the boundaries for the different flow regimes for a generic CFB system. To truly define the boundaries, equations need to be tailored to the specific system being used.

To find the boundaries, the Reynolds number for transport velocity must be calculated. This equation is based on the Archimedes number and is defined as:

$$
\operatorname{Re}_{\mathrm{tr}}=2.28 \mathrm{Ar}^{0.419}
$$

From Fan and Zhu (1998) the particle terminal velocity of the particle may now be found using:

$$
U_{p t}=.072 \frac{d_{p}^{1.6}\left(\rho_{p}-\rho_{g}\right) g}{\rho_{g}^{0.4} \mu^{0.6}}
$$

Using the particle terminal velocity, the particle Reynolds number may then be found by using the relation:

$$
\operatorname{Re}_{t}=\frac{\rho U_{p t} d_{p}}{\mu}
$$


Upon finding these values, two main equations found in Fan and Zhu (1998) can be used to find the boundaries between the dense and core/fast fluidization, and the fast fluidization/dilute operating regimes. To find the lower bound of the superficial gas velocity for the regime boundaries, the following equation is used:

$$
U_{t f}=39.8 \sqrt{g d_{p}}\left(\frac{G}{\rho U_{t f}}\right)^{0.311} \operatorname{Re}_{t}^{-0.078}
$$

To find the upper bound gas velocity to divide the fast fluidization and dilute regimes, the following equation from Fan and Zhu (1998) is used:

$$
U_{f d}=21.6 \sqrt{g d_{p}}\left(\frac{G}{\rho U_{f d}}\right)^{0.542} A r^{0.105}
$$

The equations for $U_{t f}$ and $U_{\text {fd }}$ may be plotted for various mass flux $\left(J_{p}\right)$ values into the system in units of $\mathrm{kg} / \mathrm{m}^{2} \cdot \mathrm{s}$. Upon plotting, two lines will be formed showing superficial gas velocity vs. the mass flow of solids into the riser. A basic diagram of this nature is shown from Almond (2005) below in Figure 2.4.1.a.

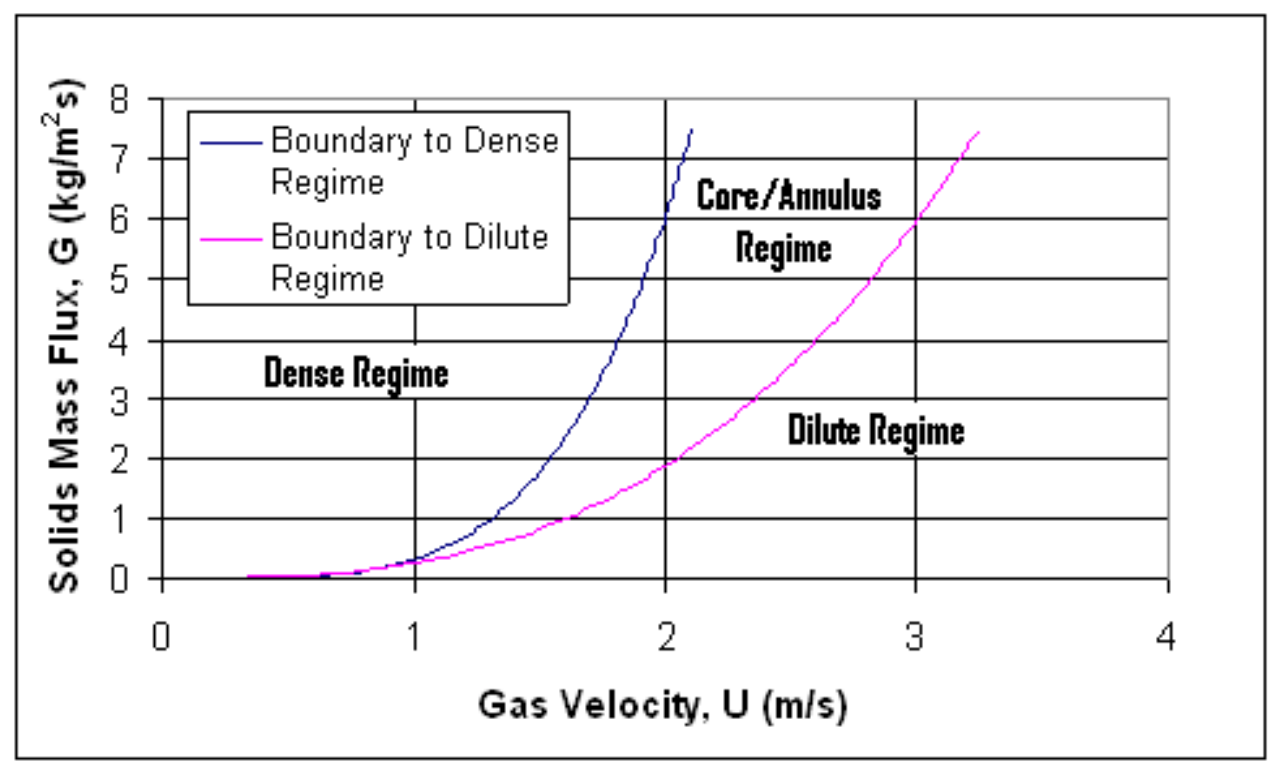

Figure 2.4.1.a Basic Flow Regime Diagram 


\subsubsection{Core/Annulus Flow in a Riser}

The ideal operating regime for this experiment is core/annulus flow. In the core/annulus, or fast fluidization regime, three different mechanisms can aid in the separation process. Regester (2004) states that with the process of particles circulating upwards in the riser and then downwards along the wall that gravitational force, radial forces, and cluster break-up phenomena all lead to better separation in the CFB.

Yang (1995) completed experiments at West Virginia University in which the particle velocity profile in the riser of a circulating fluidized bed was studied. This velocity profile shows that along the wall near the annulus there is a small downward flow, and an upwards flow in the middle of the riser, also known as the core. By aiming to operate in this flow regime, advantage can be taken of the velocity profile within the riser to maximize re-circulation due to the downward velocity found near the wall. A diagram of the particle velocity profile is show in Figure 2.4.2.a.

\section{Velocity Profile in a Circulating Fluidized Bed Riser} Operating in the Core/Annulus Flow Regime

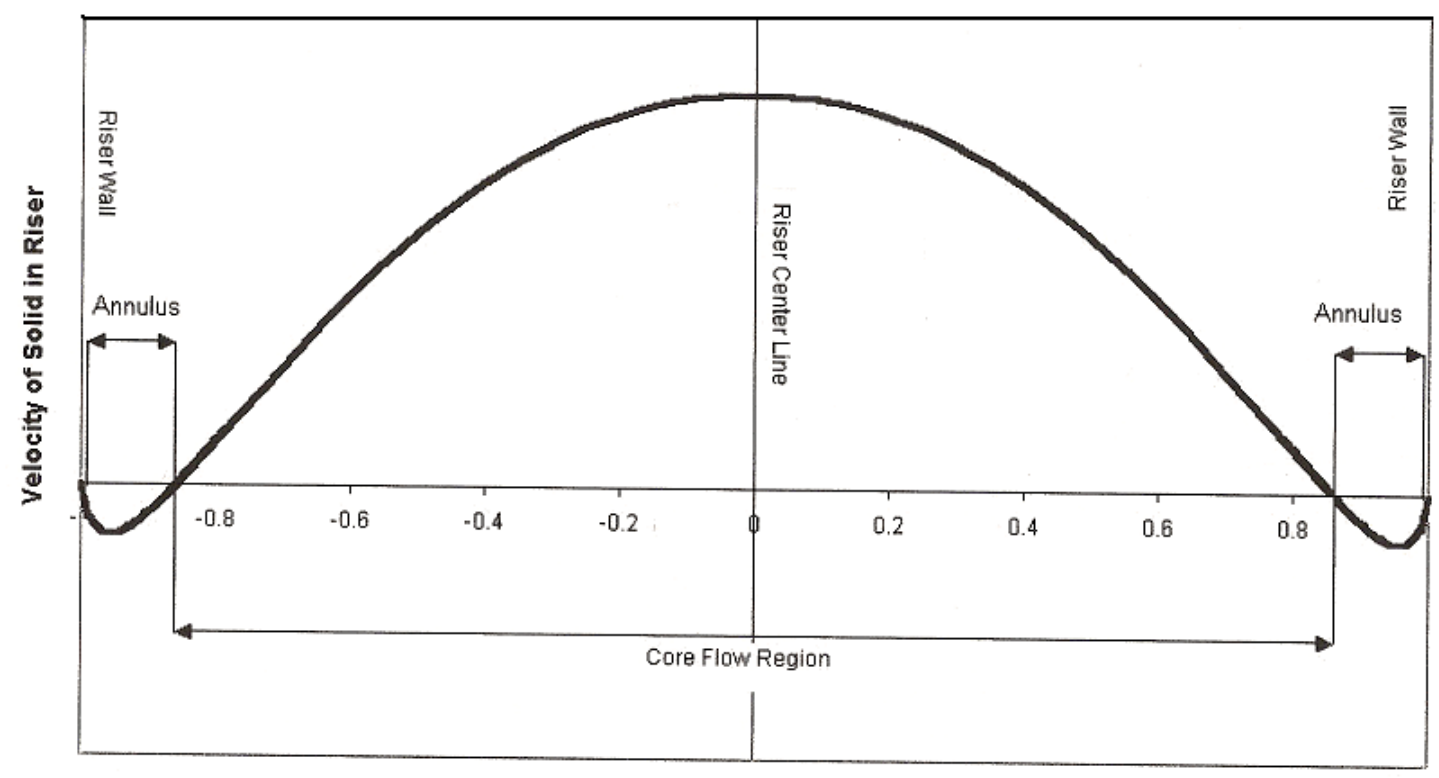

Figure 2.4.2.a Particle Velocity Profile in a CFB in Core/Annulus Flow Regime 


\subsubsection{Experimental Flow Regime Operation}

The aim for the current study was to operate in the upper end of the core/annulus flow regime. Regester (2004) had previously found that operating near the transition zone between core/annulus and dilute flow would provide the best results. Regester (2004) also states that when a circulating fluidized bed is operating in the core/annulus region, that the bottom section of the riser will have a dilute flow section, with the core/annulus regime visible above it. He also found that as mass flux decreases, that more of the riser will be filled with the dilute flow regime.

During the tests for the current research, it was noted that the riser system was operating in a core/annulus flow regime near the upper part of the riser, with a small dilute region below it. The bulk of material coming into the system traveled up the center

of the riser with no noticeable particles moving towards the riser walls; this was the dilute flow region. Visible clusters of material formed against the wall and were observed traveling down past the collection ring gap and into the dense particle collection bin. These clusters were visible approximately one meter above the distributor plate. Because of poor visibility through the riser walls it was difficult to see how high up the riser the clusters formed. However, some of the material coming down along the wall of the riser became re-entrained in the flow of particles traveling upward. The patterns of the particles observed have led to the belief that the system was indeed operating near the transition zones between core/annulus and dilute flow regimes. All particles for each of the three experiments exhibited the same behavior for all different test conditions used. 


\section{$\underline{2.5 \text { Concentric Jet Flow }}$}

The main purpose of the experimental test runs with the sand and steels shot was to see how a concentric jet style flow would affect separation. Nozzles were installed in various sizes to allow for this jet style flow to occur; they are described further in Section 3.2.4. The goal of obtaining the concentric jet flow with the nozzles is to investigate how the changed velocity profile will affect the separation process in the riser system. By changing the velocity profile to obtain a greater flow in the center of the riser, and a weaker flow towards the wall, it is hoped that the efficiency of separation will be increased. In particle-laden jet flow, the particles will disperse differently as they enter the riser. It is not known how the particle dispersion through a nozzle will affect the separation efficiency in a circulating fluidized bed. Several studies have been completed on the different effects of concentric jet flows and the effect they have on velocity profiles and particle dispersion, and will be discussed further.

Levy and Lockwood (1981) performed experiments in which sand particles of moderately large size: 215, 400, 540, 725, and 1060 microns. The particles were injected through a nozzle to study how velocity profile and particle dispersion occurred such as they would in a fluidized bed combustor. The gas velocities used were rather high, thus creating high Reynolds numbers as are found in this type of particle injection. Levy and Lockwood (198) found that three different flow regimes occurred, two of those being extreme cases of particularly large or particularly small sized solids. In the third case, medium sized sand particles were found to move with the mean gas flow and only partially responded to the turbulent fluctuations. This, in turn, reduced the kinetic energy of the turbulent eddies. 
Levy and Lockwood (1981) also discovered the particle fluctuating energy was somewhat independent from particle loading, which relates that the absorption of the turbulent energy is not related strongly to the loading. They also found that particle spreading in the jet flow was greatest for particles in the medium size range. Levy and Lockwood also state that from the axial velocity profiles found that the rate of spread of the gas jet must be related to the magnitude of the turbulent kinetic energy. This is of great concern as if the jet flow velocity increases, the particle spreading rapidly increases. As the particles spread, they will be bounded by the riser walls. This will therefore affect the particles clusters moving down along the riser wall if the particles spread too quickly after entering into the riser through the nozzle entrance. Levy and Lockwood's (1981) findings for the mean axial gas velocity are show in Figure 2.5.a. 


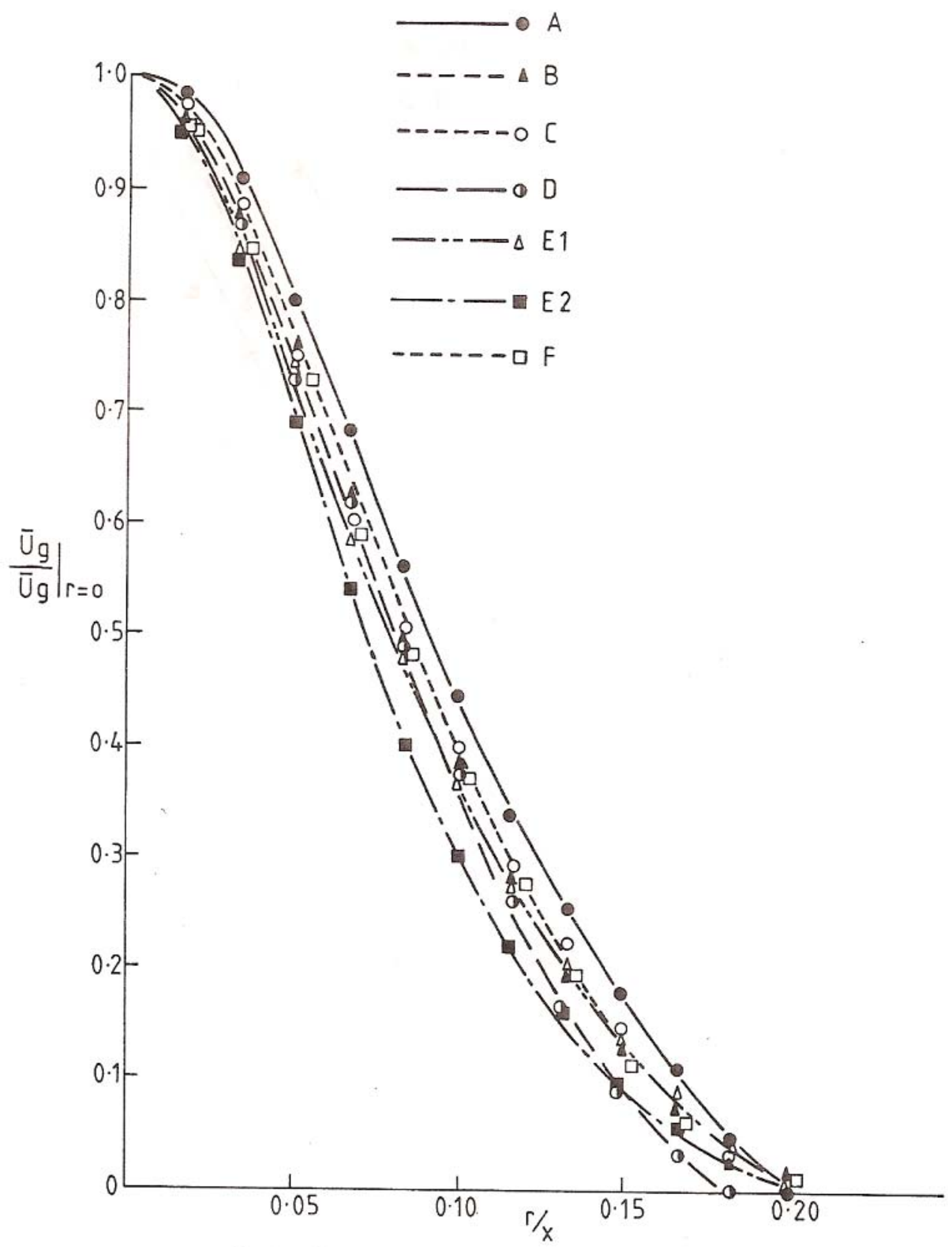

Fig. 3. (a) Experimental results: mean axial gas velocity.

Figure 2.5.a. Levy and Lockwood experimental mean axial gas velocity profile

Shuen (1985) completed experiments with turbulent, monodisperse, particle-laden jets to investigate the structure of the flow. An experimental apparatus was set up in which sand particles were injected downward into a screened enclosure from a nozzle diameter of $10.9 \mathrm{~mm}$, for a distance of ninety diameters. The jet exit particle velocities 
were between 18.5 and $24.2 \mathrm{~m} / \mathrm{s}$, while the jet exit gas velocities were found to be between 25.2 and $29.9 \mathrm{~m} / \mathrm{s}$. The jet exit mass flux for the particles was found to be between 6.60 and $19.0 \mathrm{~kg} / \mathrm{m}^{2} \mathrm{~s}$. A laser Doppler anemometer (LDA) was used to measure the mean and fluctuating gas velocities of the flow.

Different flow models had been used before to try to simulate what would occur in such situations. Locally homogeneous flow (LHF) and deterministic separated flow (DSF) models both provided inaccurate representations of what would occur, while a stochastic separated flow (SSF) model provided an accurate depiction of the flow structure. Basic boundary-layer assumptions for steady, axisymmetric, dilute, particleladen flow were used in all calculations. By using these assumptions, the SSF model could be solved using Lagrangian equations for the trajectories of the individual particles in the flow. It could also be determined how they would interact with the turbulence, and how that would affect the drag and dispersion of particles. As with most particle-laden flows, the particle was assumed to interact with an eddy in the turbulence for either the eddy's lifetime, or the time that it would take to cross an eddy.

Shuen (1985) and associates found that when the loading of particles into the jet flow are very high, the velocities of the gas decay much slower due to the momentum of the solid particles. They also found that the SSF and LHF models provided similar results. Since the LHF models rely on turbulent modulation, and the SSF models do not, it implies the effects of turbulent modulation are relatively negligible in these dilute flows.

Shuen and Faeth (1983) used data from previous experiments to investigate particle dispersion in a turbulent round jet. They found monodisperse fly ash particles 
did not have the same velocity as the gas they were mixed with when dispersed from an air jet, as previously suspected. This was found from particle trajectory calculations based upon the shape of the nozzle used. New particle velocity values were then calculated and compared to experimental values by using a stochastic dispersion model. The stochastic dispersion model calculations were made assuming the particles and the gas both had the same velocities at the nozzle entrance, and that the gas velocity changed as a function of the nozzle length. The assumptions proved to be valid as the predicted and measured values for the velocity profile of the particles and the gas matched, and were found to be very similar to those found later by Shuen and associates and published in their 1985 paper.

Lain and Garcia (2006) studied the four-way coupling process on particle-laden jet flows. A numerical simulation was completed first using Euler/Lagrange methodology. The simulations provided results very similar to those found when using their experimental set up. The experimental measurements taken were those of a particleladen jet that was loaded with glass spheres with an average density of $2450 \mathrm{~kg} / \mathrm{m}^{3}$. The diameter of the nozzle where the particles exited in the axisymmetric air jet had a diameter of $12 \mathrm{~mm}$.

Lain and Garcia (2006) found at the nozzle exit, particles had a lower mean velocity than the gas. This means the particles accelerate in the fluid taking momentum from the gas up to a distance of up to 10 diameter lengths downstream in the flow. Further on in the flow, the particles have a higher mean velocity than the gas. Lain and Garcia (2006) also noted that as the loading of the particles increased, the radial 
spreading of the jet decreased. This implies the mean velocity values of both the particle and gas increase downstream as the loading increases.

The highest loading ratio, the ratio of particles to transport gas, used in experiments was 0.9 , but a loading ratio of 1.8 was simulated using the previously noted methods. It was found the particle collisions and effects on the gas flow were in line with the previous results of the particle and gas average velocities being higher downstream when the loading ratios are higher. Figure 2.5.b shows the mean axial fluid velocity and the mean axial particle velocities for a mass loading ratio of 0.3 . In the figures the fluid velocity is plotted against the ratio of nozzle diameter to riser diameter.
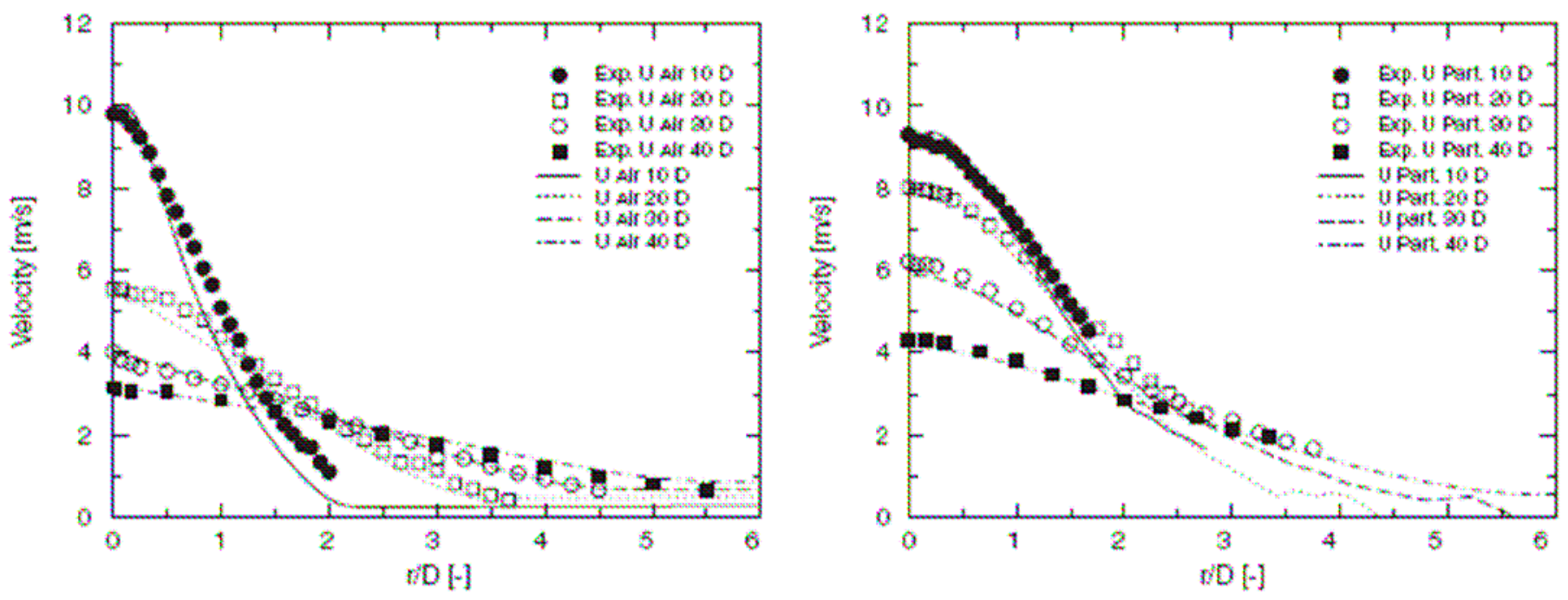

Figure 2.5.b. Mean Particle and Fluid Velocity Profiles for a Loading Ratio of .3

Figure 2.5.c. shows the simulated velocity profile for the particles with a mass loading ratio of 1.8 . 


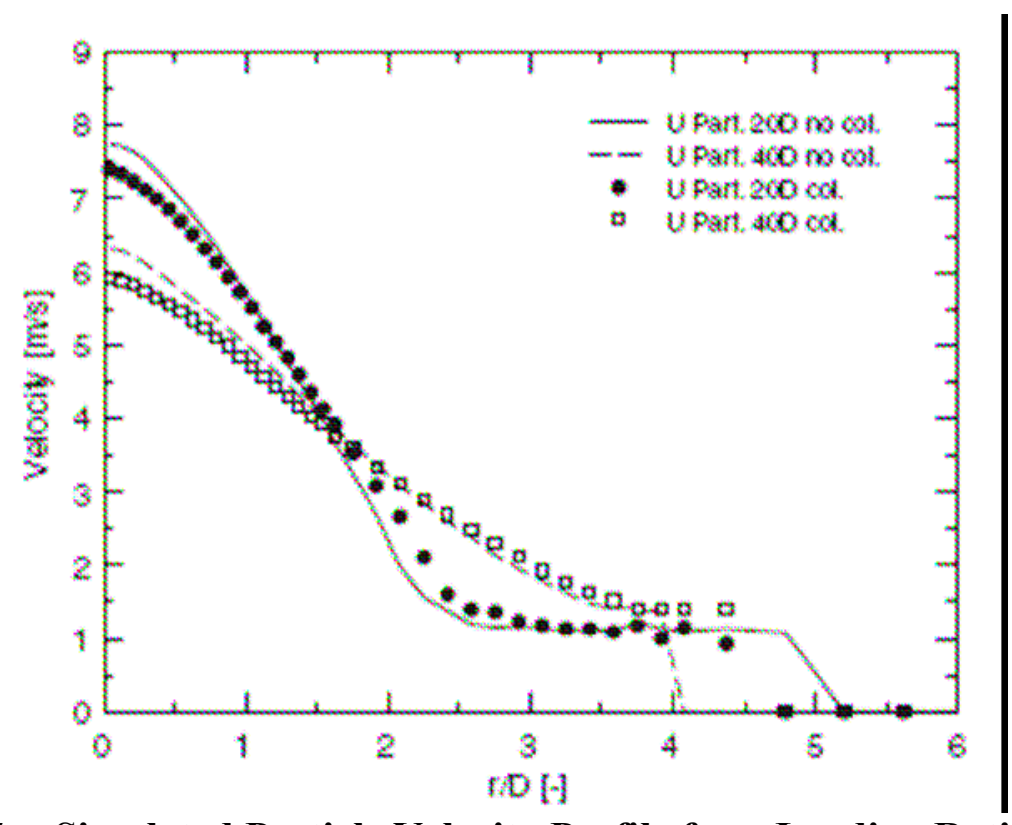

Figure 2.5.c. Simulated Particle Velocity Profile for a Loading Ratio of 1.8

Anjorin et al (2003) and associates completed experiments aimed at modeling the distribution and dispersion of powder particles from a pipe. Several measurements including particle concentration and velocity, axial and radial particle fluxes, and particle diameter were taken from a horizontal axisymmetric jet that was loaded with particles with a density of $2450 \mathrm{~kg} / \mathrm{m}^{3}$. The particle Reynolds number for the experiments was 26,856 , and the diameter of the nozzle exit was $12 \mathrm{~mm}$. These values fit very closely with those in the research project for particle separation being performed.

Anjorin et al (2003) found the particles exiting the pipe were still in a laminar style flow at a time interval of 0.1 seconds after leaving the nozzle in a cloud development. At a time interval of 0.4 seconds, it was found that the particle cloud had started to transition into the turbulent boundary layer. At 1.6 seconds after exiting the nozzle, the particles had entered into a fully turbulent flow pattern. Anjorin et al (2003) also found the particle mass concentration results show high levels of spherical particles were found at regions further from the central axis of the jet where lower particle 
velocities exist. Likewise, lower particle concentration levels were found near the jet axis where the particle velocities were much higher. Figure 2.5.d shows the particle mass flux using three different particle sizes and time intervals. Figure 2.5.e shows the particle velocity profiles at different lengths from the jet exit.
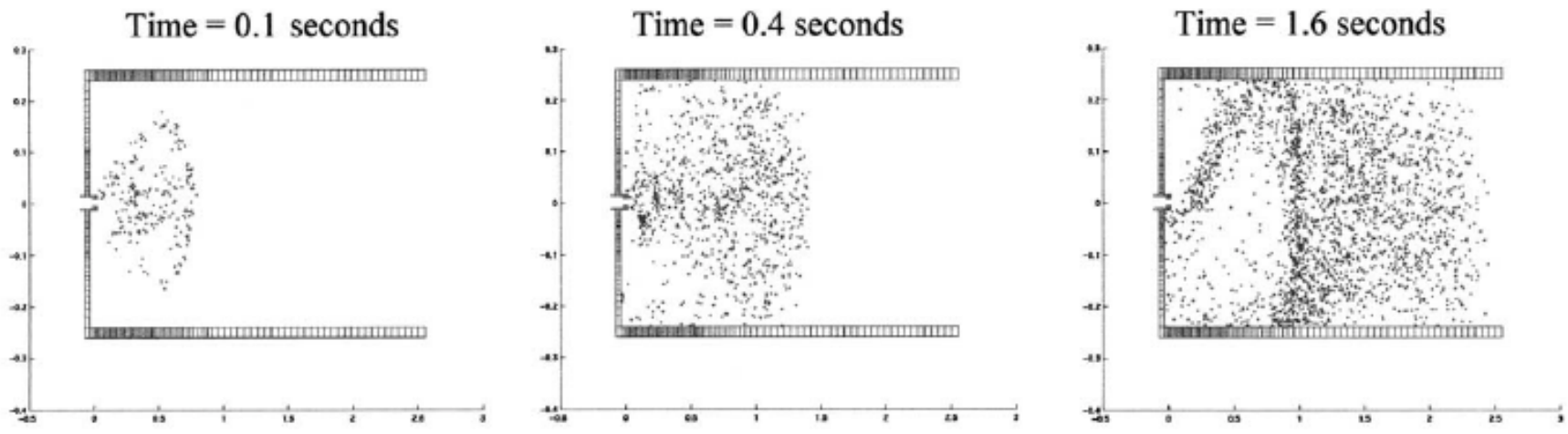

Figure 2.5.d. Particle mass flux Results in a Axisymmetric Particle Laden Jet

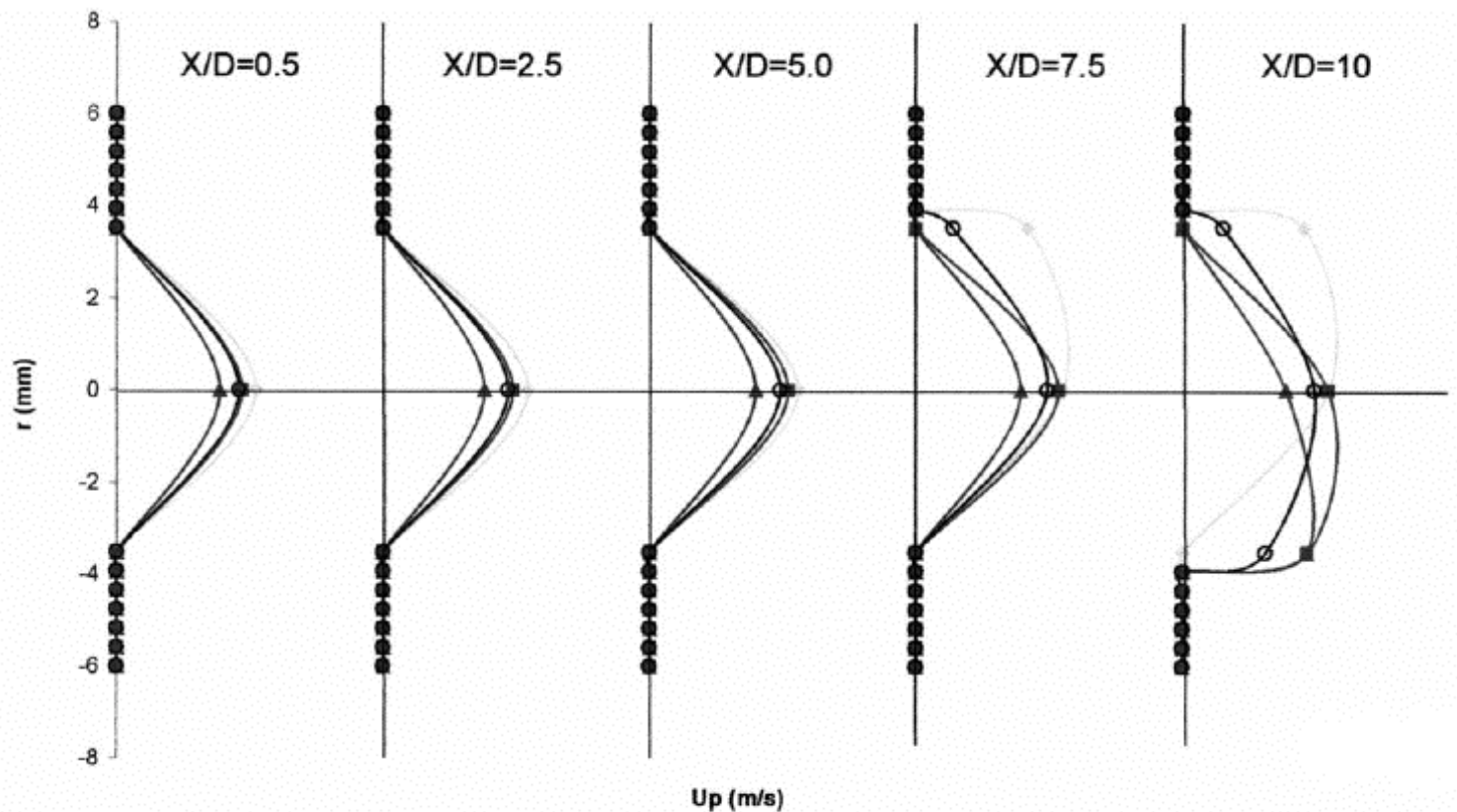

Figure 2.5.e Particle Velocity Profiles of Powder Exiting a Pipe 
With the findings in the previously mentioned studies, it is clear to see that by using a concentric jet style particle entrance into the riser, by installing nozzles, the velocity profile of both the gas and particles will be changed. This modified velocity profile should aid in the separation process and will be discussed further in Section 2.7 


\section{$\underline{\text { 2.6 Lift Forces }}$}

A main governing principal in the operation of a circulating fluidized bed is what is known as a lift, or Saffman force. The lift forces are what cause the particles to move towards the wall in a riser system as they move from the core to annulus flow regions. Eichhorn (1964) and associates performed experiments in which the lift and drag forces on a sphere in a confined Poiseuille (laminar) flow were studied. Eichhorn (1964) states the forces on a sphere in a flow can be resolved into two components, lift and drag. Eichhorn (1964) also states the lift force is a consequence of the velocity gradient and results from the pressure distribution on the sphere. Since the velocity gradient has such a large effect on the lift force, it will therefore be of great interest in the current research study.

For their experiments Eichhorn (1964) and associates suspended four small spheres, of different diameters, in a 0.419 inch diameter tube. The spheres were made of different types of plastic so they would have different densities. The tube was inclined to different angles and the flow rate was set to a laminar flow until the sphere rested a fixed distance from the wall. The weight of the sphere, in this case, is balanced out by the lift force caused by the velocity gradient. Knowing all other quantities about the sphere and the flow allowed the lift force to be measured.

Table 2.6.1 shows the sphere diameter and specific gravities that Eichhorn (1964) used in the experiments. 


$\begin{array}{cccc}\begin{array}{c}\text { Sphere } \\ \text { no. }\end{array} & \begin{array}{c}\text { Diameter } \\ \text { (in.) }\end{array} & \begin{array}{c}\text { Specific } \\ \text { gravity }\end{array} & \begin{array}{c}\text { Symool used } \\ \text { on gxaphs }\end{array} \\ 1 & 0.126 & 1.066 & 0 \\ 2 & 0.094 & 1.258 & \nabla \\ 3 & 0.062 & 1.144 & \Delta \\ 4 & 0.061 & 1.426 & 0\end{array}$

\section{Table 2.6.1 Properties of the Spheres used in Eichhorn experiments}

Eichhorn (1964) noted the angular velocity decreased with increasing Reynolds numbers.

Lower angular velocities of the particles will cause a less significant lift force to be

created. It is important to note this in the case of the particle separation project because

when high Reynolds numbers are used, the particles would travel higher up the riser

before moving to the walls.

Eichhorn (1964) also found the lift coefficient, which directly affects the lift force, is higher as the particle is moved farther from the center-line of the riser. This trend is shown from his paper in Figure 2.6.2. 


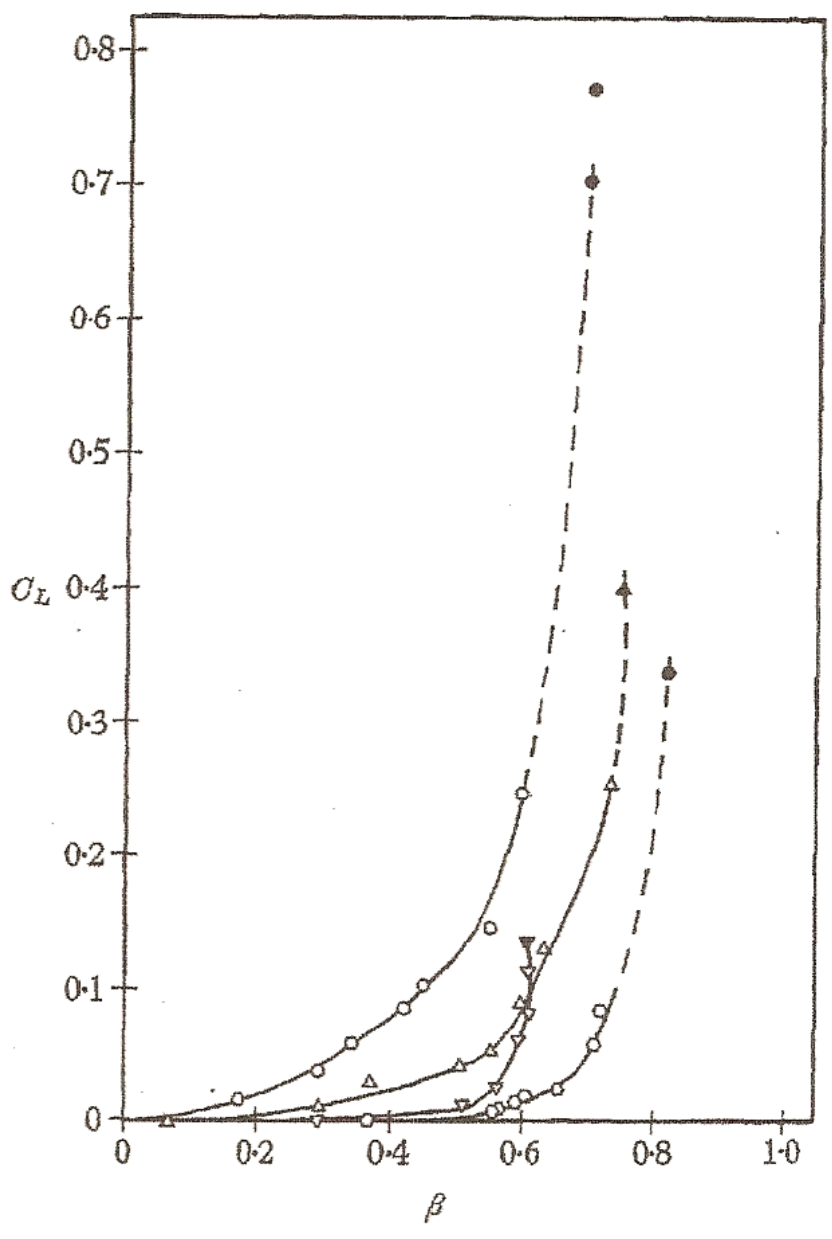

Figure 2.6.2 Lift Coefficient as Influenced by Distance from the Center-Line

Eichhorn (1964) also studied the lift coefficient as it is affected by the shear parameter.

The further from the center-line of the riser a measurement is taken, the higher the shear forces are acting on it. This means as the shear forces increase, the lift coefficient will also increase, thus creating a larger lift force. A diagram showing this trend from Eichhorn (1964) is shown in Figure 2.6.3. 


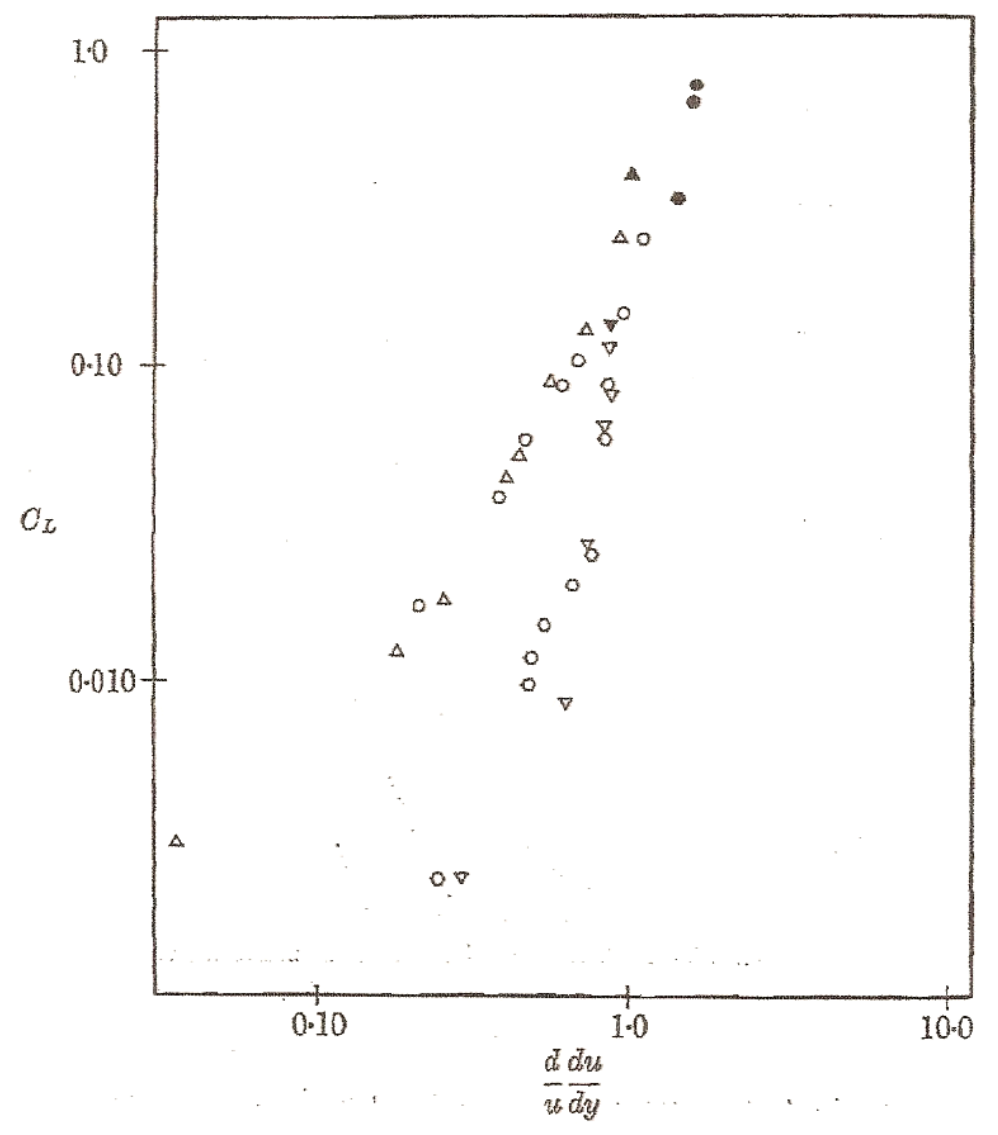

Figure 2.6.3 Lift Coefficient as Influenced by Shear Parameter

Eichhorn (1964) concludes the effects of Reynolds number and the particle/riser diameter ratio work opposite of each other. The lift coefficient will decrease as the Reynolds number increases. As the diameter ratio decreases, the lift coefficient will increase. This essentially means as the Reynolds number increases, the particles will travel higher in the riser before being moved to the walls by the lift force. This also means as the particles become smaller in size, the lift force will increase. In addition, it was shown as the particle density increases, the lift force will also increase. This is also of great interest due to the particle density differences found in the separation research being performed. 
If a dimensional analysis is performed on the lift equation, several key pi terms drop out. These pi terms are what will influence the lift force. For this project, two of the key pi terms that were are interested in are as follows:

$$
\frac{u}{V_{T}} \quad \frac{d_{p}}{u} \frac{d u}{d r}
$$

The first pi term essentially means that if the gas velocity is higher than that of the terminal velocity, then the particle will exit the riser. This will regulate the gas velocity in the riser. The second pi term is of interest as well. It essentially means that as the particle size is lower, that the lift force will be dependent on the gas velocity gradient (du/dr). As the particle sizes become smaller, also meaning lower gas velocities, it will take a larger velocity gradient to produce a larger lift force. By using the nozzles, this larger velocity gradient will be created. The larger velocity gradient will cause air flow around the particles to unsymmetrical. By creating a higher gas velocity on the side of the sphere closest to the core, a larger separation of gas from the sphere will occur on the side closest to the wall. This will in turn create an area of low pressure towards the wall side of the sphere, thus allowing the lift force to be created and moving the particle to the wall.

The influences these results have on the current research project will be discussed further in Section 2.7.

\subsection{Modification of the Flow Field/Conclusions}

One of the main test variables used for the circulating fluidized bed is to adjust the size of the inlet in which the particles would come in to the riser. Nozzles of different diameters are used to vary this inlet size. By using nozzles, an air jet style of concentric 
flow is created for the air-solid mixture to come into the riser. By varying the diameter of the nozzles, the gas and particle velocity flow fields are greatly modified.

Flow between the air-solids inlet mixture and the distributor plate are also varied. The mass flux values of the particles entering into the riser are to be changed as well. Both of these factors also change the particle and gas velocity profiles dramatically. It is hoped the particle separation process can be aided by taking advantage of the modified flow field velocity profile.

It is desired for the larger, heavier, particles to be pushed to the walls, thus allowing them to be collected in the dense particle collection bin. It is desired for the lighter, less dense, particles to travel upwards through the riser and exit the top, thus being collected in the light particle collection bin. As concluded from Section 2.5 and Section 2.6 as the Reynolds number increases, the lift force on the particles decreases. This is a desirable effect as when dealing with the higher Reynolds numbers the particles will be in the riser longer, thus giving them more time to circulate and separate properly. By creating more of a jet style of flow, the velocity profile should have more of a parabolic shape, and less of a bell style shape. Because of this, two different scenarios will occur during separation. One of the scenarios, as concluded in Section 2.6, is the lift force can be governed by the particle size. Essentially, the smaller particles will move towards the wall sooner, and the larger particles will move upwards in the riser towards the exit at the top - an undesirable effect. The second scenario, which is the more preferred effect, is that the lift force on the particles will be influenced more from density. This means the more dense particles will move towards the wall and the less dense particles will travel towards the exit at the top of the riser. 
Nozzles will be used to create an air-jet style of flow for the particles entering the riser. By doing so, the velocity profile of both the particles and transport gas will both be modified - aiding in the separation process by taking advantage of the lift forces that will be applied to the more dense particles. Having a larger lift force applied to the larger, denser, particles will allow them to move to the wall and pass into the dense bin, thus improving the collection efficiency of the CFB riser system. 


\section{Chapter 3: Experimental System}

\section{$\underline{\text { 3.1 Initial System }}$}

A Circulating Fluidized Bed (CFB) system was installed on the Evansdale campus of West Virginia University in the National Research Center for Coal and Energy. The CFB system was designed to investigate the potential of dry separation effectiveness of sand and steel shot. The CFB system contained a feed hopper, main riser section, cyclone separators, and collection and filter bins. A load cell, various pressure gauges, and two flow meters were the instrumentation used on the CFB. Various factors were investigated in the initial system to allow for the best efficiency and separation by Regester (2004). A schematic of the initial system taken from Almond (2005) is shown in Figure 3.1.a. An air flow diagram is also shown in Figure 3.1.b.

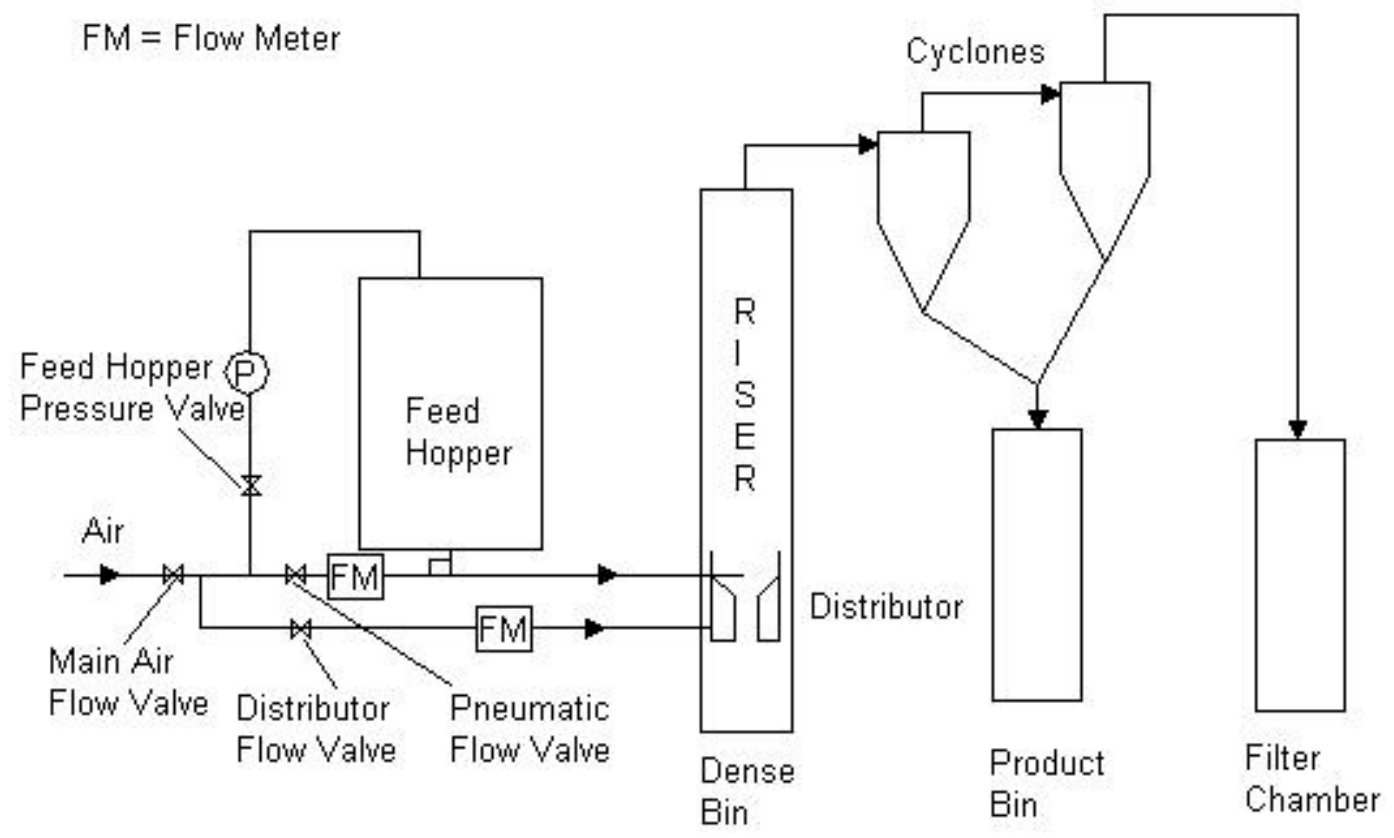

Figure 3.1.a. Schematic of the Riser System 
Flow Chart for CFB Riser System

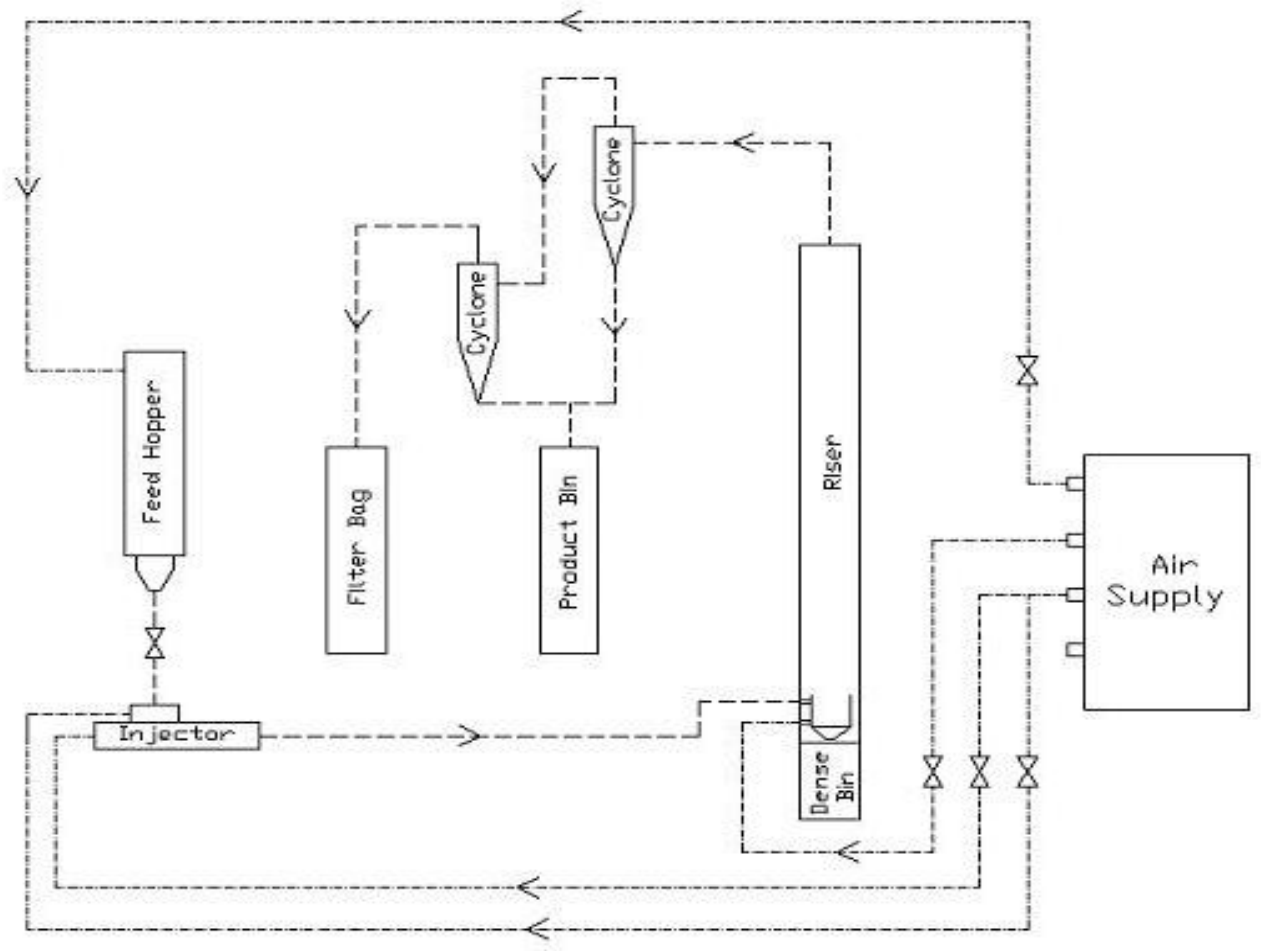

Solids Transport Line

Pneumatic Transport Line

Pneumatic Shutoff Valve

Figure 3.1.b. Pneumatic Flow Chart for the Riser System

\subsubsection{Feed Hopper}

The initial feed hopper, and product bin, for the system were two 2000 pound (907 kg) steel drums. One drum was used as a feed hopper for the solids mixture of sand and steel shot, while the other was used as a product bin for the mixture once the particles left the two-stage cyclones. Each hopper was 3 feet in diameter, 4 feet tall, and had a 1.5 foot tall conical section. These hoppers were later deemed inefficient and changed over to a smaller and more favorable design. The new feed hopper is discussed in Section

\subsection{1.}




\subsubsection{Particle Injector Design}

A pneumatic transport system was designed that carries the sand/steel shot or coal particles from the feed hopper to the riser without the need for a motorized screw feed or complex system. The pneumatic injector was constructed of various steel sections, and was connected directly with the feed hopper and a transport tube going into the riser. The pneumatic injector uses the current air supply traveling into the riser to move the particles as well. The solid mixture at the bottom of the feed hopper was directly connected with the particle injector.

Two air flow lines are connected to the injector. One line is a high pressure air line which flows directly into the back of the injector. The other air flow line is a low pressure air line connected to the neck of the injector, which connects onto the feed hopper. By connecting the second air line in this manner, the particles are able to be circulated in the bottom of the feed hopper by aerating the mix so that no clogs would form in the neck of the injector.

The air flows into the injector, then into a transport tube section which flows into the riser. This air flow creates a section of low pressure in the tube which holds the solid mixture, which then in turn entrains the solid mixture into the air flow and into the riser. A schematic of the pneumatic injector is show in Figure 3.1.2.a. 


\section{Pneumatic Particle Iniector}

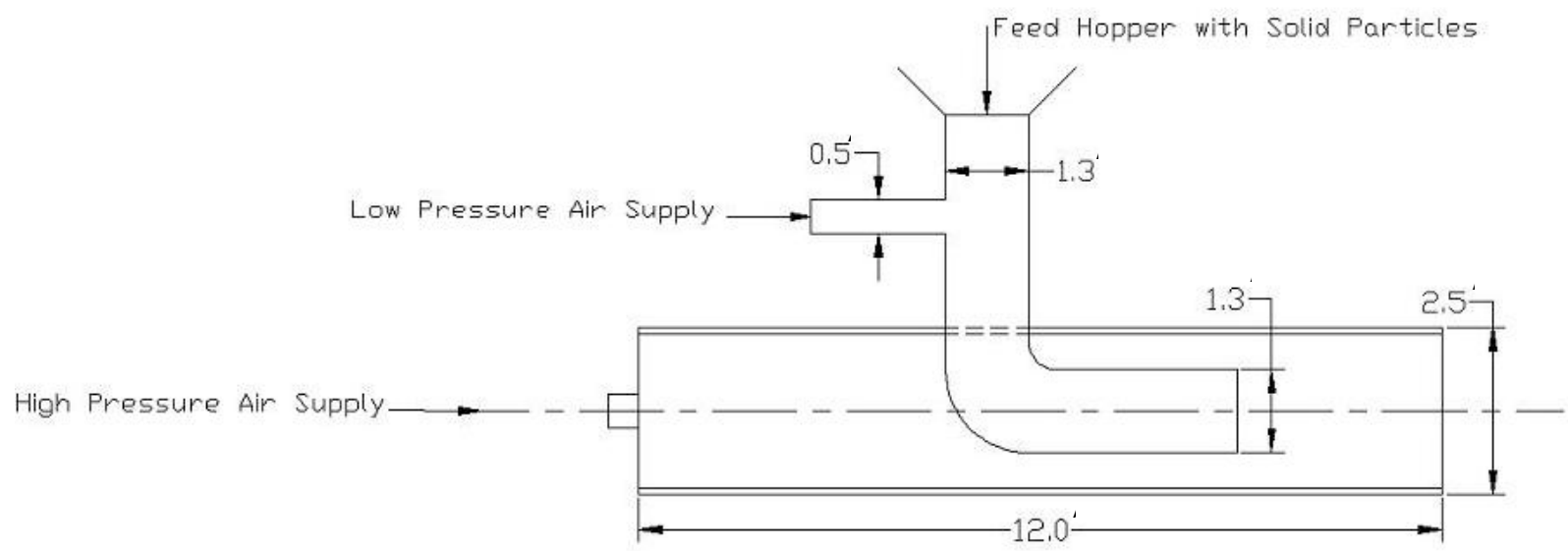

Figure 3.1.2.a. Diagram of the Pneumatic Particle Injector

\subsubsection{Riser Design}

The riser for the CFB is made of clear acrylic tubing with a height of 14 feet $(4.27$ meters) with an inner diameter of 5 inches $(12.7 \mathrm{~cm})$. The riser is built in several sections that are bolted together with acrylic flanges that have gaskets in between them to prevent gas from leaking out of the riser. The sections are made in sizes of: one section of 1 foot ( 0.305 meters), two sections of 2 feet ( 0.610 meters $)$, and three sections of three feet (0.914 meters). The wall thickness of each of these sections is $1 / 4$ inch $(0.635 \mathrm{~cm})$. The riser sections are bolted together, and then hooked onto a larger frame which holds the system in place.

The transport tube enters into the riser through the side wall of the bottom riser section. The particle inlet tube crosses the riser and is hooked to the other opposite wall. There is an outlet in the middle of the riser from the particle inlet tube which allows the solids to enter the system. This outlet is 3/4 inch T-shaped for reduced erosion. The riser assembly also contains a distributor plate and dense particle collection bin, which will also be discussed in later sections. The particles exit the top of the riser via a 90 degree 
swept outlet. Regester (2004) determined that this exit geometry allowed for the highest efficiency in the separation of particles. Along the outside of the riser assembly are 4 pressure gauges spaced evenly measuring the pressure at the inside of the riser wall. These gauges are hooked up to the DAPVIEW computer data acquisition system so that they may measure the pressure drop in the riser from gauge to gauge when the system is running. The riser is shown in Figure 3.1.3.a.

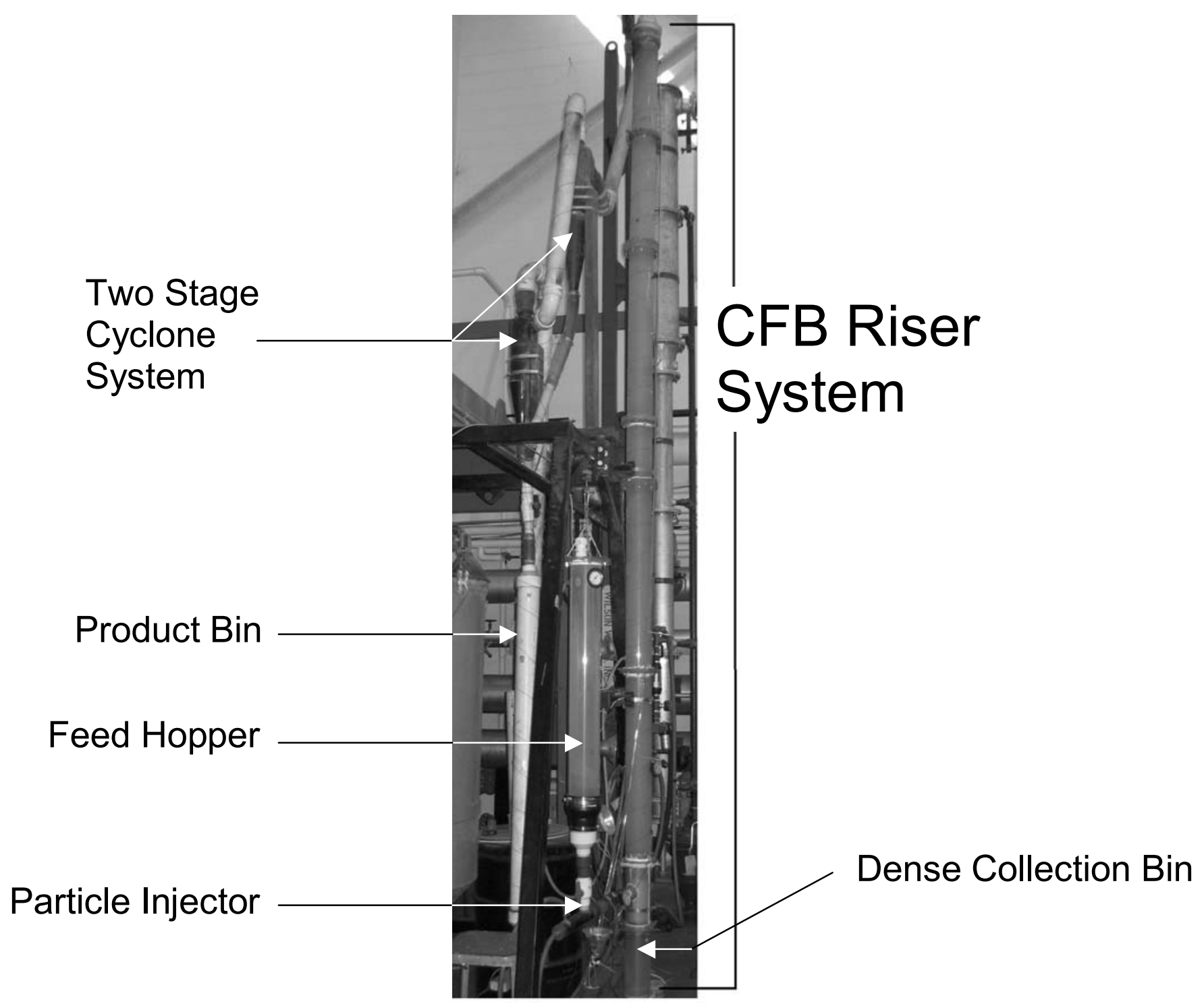

Figure 3.1.3.a. Picture of the Modified Riser System 


\subsubsection{Distributor Plate Design}

The particles moving into the riser system come in through a t-shaped inlet in the middle portion of the riser. Directly below this particle inlet is a distributor plate which allows the incoming air to be evenly distributed through the cross sectional area of the riser. This air will move upwards and be mixed with the air-solid mixture coming from the particle inlet: This mixture will then continue moving up the riser.

The distributor was conical in shape, and had a 60 degree slant to where the air flow enters. Several air jet holes were drilled horizontally into the bottom of this conical section, each pointing towards the center of the distributor, and had a small hood covering them, preventing particles from entering the air holes. At the bottom of the distributor plate was a small hole to collect any stray particles that made it past the air flow that would allow them to be emptied into the dense bin after a test was completed. The distributor had a small ring in which small bed wall extensions could be placed, also allowing the collection gap size to be changed. The original wall height of the distributor where the extensions could be placed was 4 inches $(10.16 \mathrm{~cm})$ in height. A picture of the distributor is show in Figure 3.1.4.a. Shown also in Figure 3.1.4.a. is the T-shaped particle inlet into the riser. 


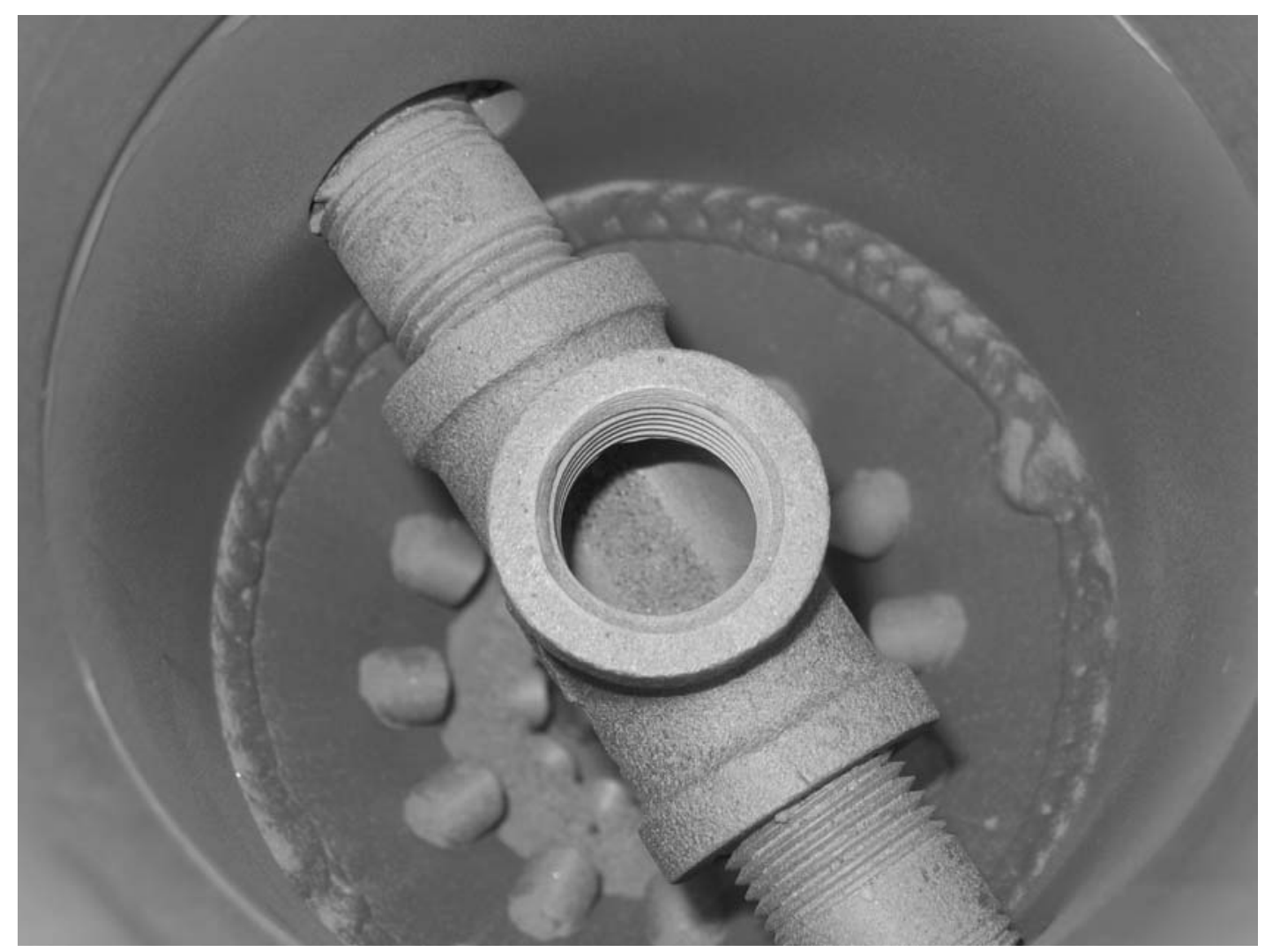

Figure 3.1.4.a Distributor Plate and T-Shaped Particle Entrance into Riser

\section{$\underline{\text { 3.1.5 Collection Ring/Bed Wall Design }}$}

The distributor plate has a small ring in which the fluidized bed wall can be attached. This forms the wall in which the particle bed will form. At the top of this section, a collection ring is placed that determines the size of the gap between the distributor cone and the riser wall. Regester (2004) determined that a gap size of $1 / 8$ inch (6.4 mm) was optimal. A gap size of this distance allows larger particles to pass through to the dense collection bin, while allowing the smaller particles to be re-entrained into the air flow coming from the distributor. With this experimental set up, it was observed that with the sand and steel shot mixture that some bubbling occurred in the dense bed and particles spilled over from the bed and directly into the dense collection bin when higher mass flux values were used. To correct this problem new wall extensions were created to 
allow for a greater height for the fluidized bed. These changes are discussed in Section

\subsection{3.}

\subsubsection{Dense Particle Collection Bin Design}

Large, heavy particles, pass the collection ring gap continue traveling downwards along the riser wall and into a dense collection bin. The collection bin is made of the same acrylic as the rest of the riser system and is connected by means of six wing-nuts and bolts so that it could be easily removed for emptying.

\subsubsection{Cyclone Separator System}

Smaller, light particles, leaving the top of the riser exit out via a 90 degree outlet and then travel into a two stage cyclone separator system. The system uses two, twostage cyclones to clean the air-solid mixture and separate the particles from the gas stream. The primary cyclone is slightly larger than the secondary cyclone as is commonly found in a dual cyclone system. The specifications for the design of the cyclones came from the Air Pollution Engineering Manual (Danielson 1967). These dimensions are shown, along with a diagram of the cyclones, in Figure 3.1.7.a. (Danielson 1967). 


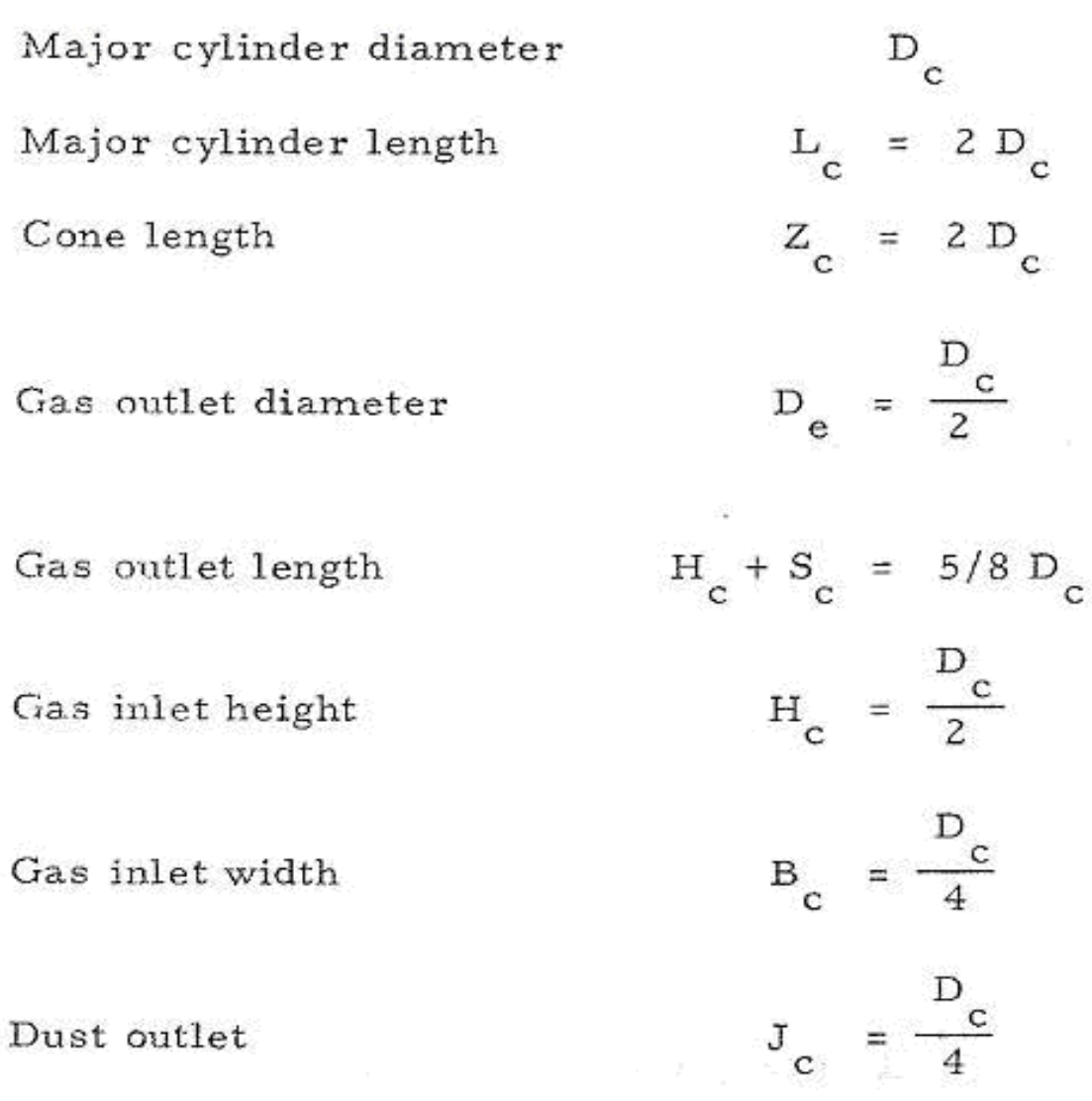
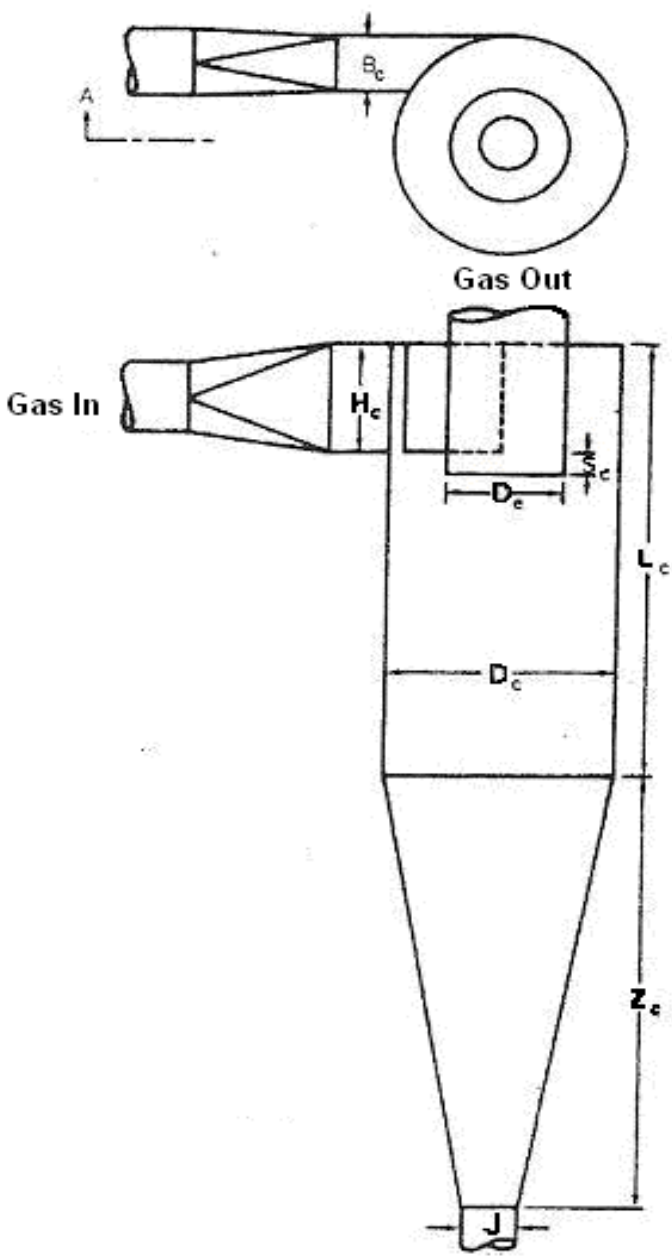

Dust Out

Figure 3.1.7.a. Cyclone Dimensions and Schematic

A major aspect of cyclone design is the collection efficiency and cut size. By predicting the cut size $d_{\text {cut }}$, or $d_{50}$, which is the particle size that would be collected with $50 \%$ efficiency by mass, allows the system to be properly designed. The following equation, shown in the Air Pollution Engineering Manual is generally used to determine this value (Danielson 1967).

$$
d_{p c}=\sqrt{\frac{9 \mu b}{2 \pi\left(\rho_{p}-\rho_{g}\right) V_{i} N_{e}}}
$$

Where $\mathrm{d}_{\mathrm{pc}}$ is the diameter of the cut size particle at $50 \%$ efficiency, $\mathrm{V}_{\mathrm{i}}$ is the inlet gas velocity in $\mathrm{ft} / \mathrm{sec}, \mu$ is the gas viscosity in $\mathrm{lb}$ mass/sec-ft, $\mathrm{b}$ is the cyclone inlet width in 
feet, $N_{e}$ is the effective number of turns within the cyclone, and $\rho_{p}$ and $\rho_{g}$ are the particle and gas density in $\mathrm{lb} / \mathrm{ft}^{3}$ respectively.

Shown below is a table from Almond (2005) which shows the dimensions and the cut sizes for the cyclones used in the system. Also noted are the different particle diameter cut sizes, one found by Leith (1982), and one found in the Air Pollution Engineering Manual (Danielson 1967).

\begin{tabular}{|c|c|c|c|c|}
\hline Cyclone Dimension & Symbol & Units & Primary & Secondary \\
\hline Inlet Width & $\mathrm{W}$ & $\mathrm{m}$ & 0.057 & 0.038 \\
\hline Inlet Height & $\mathrm{A}$ & $\mathrm{m}$ & 0.102 & 0.038 \\
\hline Dust Outlet Width & $\mathrm{B}$ & $\mathrm{m}$ & 0.051 & 0.032 \\
\hline Gas Outlet Diameter & $\mathrm{O}$ & $\mathrm{m}$ & 0.102 & 0.064 \\
\hline Cyclone Diameter & $\mathrm{D}$ & $\mathrm{m}$ & 0.203 & 0.127 \\
\hline Total Length & $\mathrm{H}$ & $\mathrm{m}$ & 0.711 & 0.483 \\
\hline Volume Flow Rate & $\mathrm{Q}$ & $\mathrm{m} / \mathrm{s}$ & 0.031 & 0.031 \\
\hline Inlet Velocity & $\mathrm{U}_{1}$ & $\mathrm{~m} / \mathrm{s}$ & 5.283 & 26.906 \\
\hline Number of Turns & $\mathrm{N}$ & & 5.000 & 5.000 \\
\hline Cut Diameter & $\mathrm{d}($ cut) Lapple & $\mathrm{m}$ & $4.6 \mathrm{E}-06$ & $1.7 \mathrm{E}-06$ \\
\hline Cut Diameter & $\begin{array}{c}\mathrm{d}(\text { cut) Pollution } \\
\text { Manual }\end{array}$ & $\mathrm{m}$ & $8.7 \mathrm{E}-06$ & $3.1 \mathrm{E}-06$ \\
\hline
\end{tabular}

Table 3.1.7.a Cyclone Dimensions and Cut Diameters for Cyclone System

The volumetric flow rate was considered to be the same in the cyclone system as it was in the riser, since the gas flow went directly from the riser to the cyclones. The number of turns $\mathrm{N}$, was determined by taking the overall height of the cyclone, and dividing it by the inlet length, as shown in Figure 3.1.7.a. As shown, the analytical values for the cut diameter from the Air Pollution Engineering Manual (Danielson 1967) are found to be 8.7 and 3.05 microns. Using the equations found in Leith (1982), the cut diameter is found to be 4.6 and 1.67 microns for the two-stage cyclones.

The initial system was set up such that the particle flow from the primary cyclone would be fed back into the riser from the opposing side of the of the T-shaped particle entrance to allow for re-circulation. Albeit this is commonly used practice, it was 
determined by Regester (2004) that the performance found by simply passing the particles through the riser one time was sufficient. This is known as what is a one-pass test. The particle feed from the primary cyclone was then plumbed into line with the secondary cyclone, which would allow for even further separation. One of the cyclones from the system is shown in Figure 3.1.7.b.

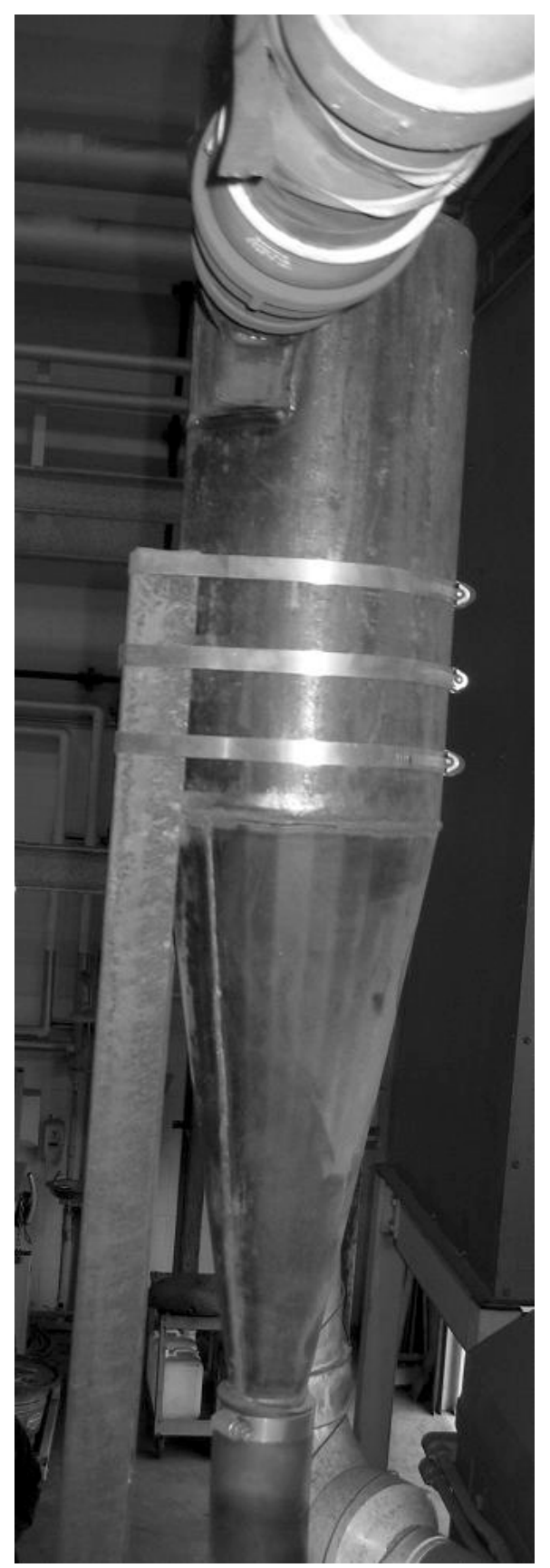

Figure 3.1.7.b. Experimental Set up - Two Stage Cyclone 


\subsubsection{Design of the Light Particle (Product) Collection Bin}

After the air-solid mixture exited the secondary cyclone, the particles traveled into a light particle collection bin. This bin was constructed of a 1.37 meter long, 4 inch diameter, piece of PVC tubing and had a plastic ball valve at the bottom so the particles could be emptied. This bin was sealed by using hose clamps and rubber tubing from the cyclone downward.

\subsubsection{Design of the Filtration System}

The finest particles that had passed through the riser during a run would exit the top of the secondary cyclone, and then be fed into a filtration system. This system would allow the particles to be captured, while allowing the gas in the system to escape. Regester (2004) and Almond (2005) designed two such filter systems that could be used with the CFB.

The water filter was mainly used for the sand and steel shot mixture, as the paper filtration system was not necessary. The water filtration system was comprised of a plastic 55 gallon barrel with a piece of PVC pipe. The PVC pipe had several holes drilled into it which would be towards the bottom section of the inside of the barrel. The barrel was then filled with water to a level that ensured all the holes in the PVC piping were covered. This allowed the gas to escape by bubbling, while the particles were trapped in the water and not released into the atmosphere.

For coal runs, a paper filtration was use. For the paper filter a steel 55 gallon drum was used with an air tight lid, and a solid PVC pipe connected to the top of the lid. This allowed for the piping to be connected directly to that exiting the secondary cyclone with an airtight seal. A set of two holes were drilled into the top of the lid to allow the 
excess air to escape from the system after passing by the filter. The pipe then led to the inside of the barrel where a paper vacuum cleaner bag was attached by means of a pipe clamp to the PVC pipe. This formed a filter in which the gas coming into the barrel could escape through the filter and out small holes in the barrel lid, while allowing fine particles to be trapped. It was determined by Almond (2005) that pressure build up occurred in the bag filter which caused some back pressure in the system. To alleviate this problem a second bag filter was added into the filter system.

\subsubsection{Design of the System Frame}

The entire CFB system was connected to a large frame for support. The frame was made of 4 inch $(10.2 \mathrm{~cm})$ tubular steel. The riser was mounted to the frame using hose clamps with rubber padding to allow for vibration free operation. The air supply system was also mounted directly to this framework. The filter system barrels are not connected directly to the frame, but were placed inside of the framework so that they could be easily moved. The entire frame has four industrial wheels so that it may be moved freely. 


\subsection{Modifications to the Initial System}

The initial riser system used by Regester (2004) and Almond (2005) needed to be modified to accommodate the set of tests being performed. Some of these modifications included the feed hopper, collection ring/distributor wall height, and the particle entrance into the riser. Other small modifications were also performed to increase the overall efficiency of the system.

\subsubsection{Feed Hopper Modification}

The original feed hopper drum was not an optimal design. The original drum was built to hold up to 2000 pounds $(907 \mathrm{~kg})$ of solids. The maximum amount of material being run during any one test was approximately 20 pounds $(9.07 \mathrm{~kg})$. There was also a long upward rise from the bottom of the feed hopper to where the particles entered into the riser. This created an area in which particles would lay in the transport tube and not be transported on several occasions. To correct this problem, the steel hopper was moved, and a small acrylic feed hopper was constructed.

The feed hopper was constructed of the same acrylic plastic the rest of the riser was constructed of. It was approximately 3.5 feet (1.0668 meters) tall, and had a 5 inch $(12.7 \mathrm{~cm})$ inner diameter. A small $11 / 2$ inch $(3.81 \mathrm{~cm})$ PVC fitting was attached to the top of the feed hopper that had a removable lid: This could be removed to put the solids mixture into the feed hopper. The lid to the feed hopper was an acrylic lid which was permanently sealed in place. Towards the top portion of the riser was a pressure gauge that measured the air pressure (psi) in the hopper. The feed hopper was connected onto the frame system with a small rope that was connected by a closed eyelet hook into a load cell that would measure the weight of the mixture in the hopper. 
The bottom end of the feed hopper was open ended, and connected to a rubber boot with 3 hose clamps. This funneled down into a ball valve which would allow the feed rate of the particles entering the system to be controlled more accurately. After passing through the ball valve the particles then entered into the top portion of the particle injector.

Another reason for re-designing the feed hopper was to allow the operator to view how much material was left to be run. The steel drums had no viewing area, so it was sometimes hard to tell if any material was stuck or was unable to be transported to the riser. The clear acrylic hopper visibly shows the amount of material remaining in the hopper. The pressure gauge also allows the user to see how much pressure is needed to start the solids flow into the injector. A picture of the feed hopper may be viewed in Figure 3.2.1.a. 


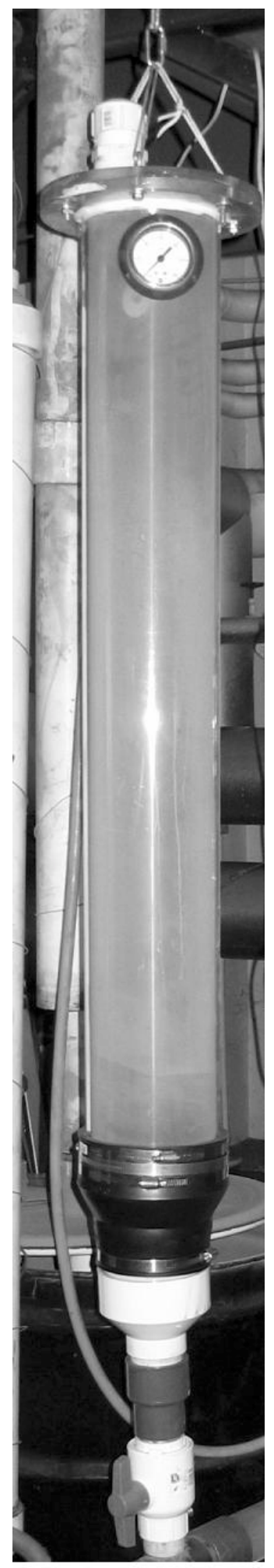

Figure 3.2.1.a Modified Feed Hopper 


\subsubsection{Transport Tube Modification}

The original transport tube used on the system was a long flexible piece of hosing that had to travel upwards and over several feet before letting the particles enter into the system. The transport tube was replaced by a small piece of acrylic tubing that allowed the particles to travel a shorter distance, and on a horizontal plane with the entrance into the riser. It had a pressure gauge installed in it so that pressure could be monitored throughout the tests. The transport tube was approximately 15 inches $(38.1 \mathrm{~cm})$ long, and had a 2.5 inch $(6.35 \mathrm{~cm})$ inner diameter. The transport tube is shown in Figure 3.2.2.a.

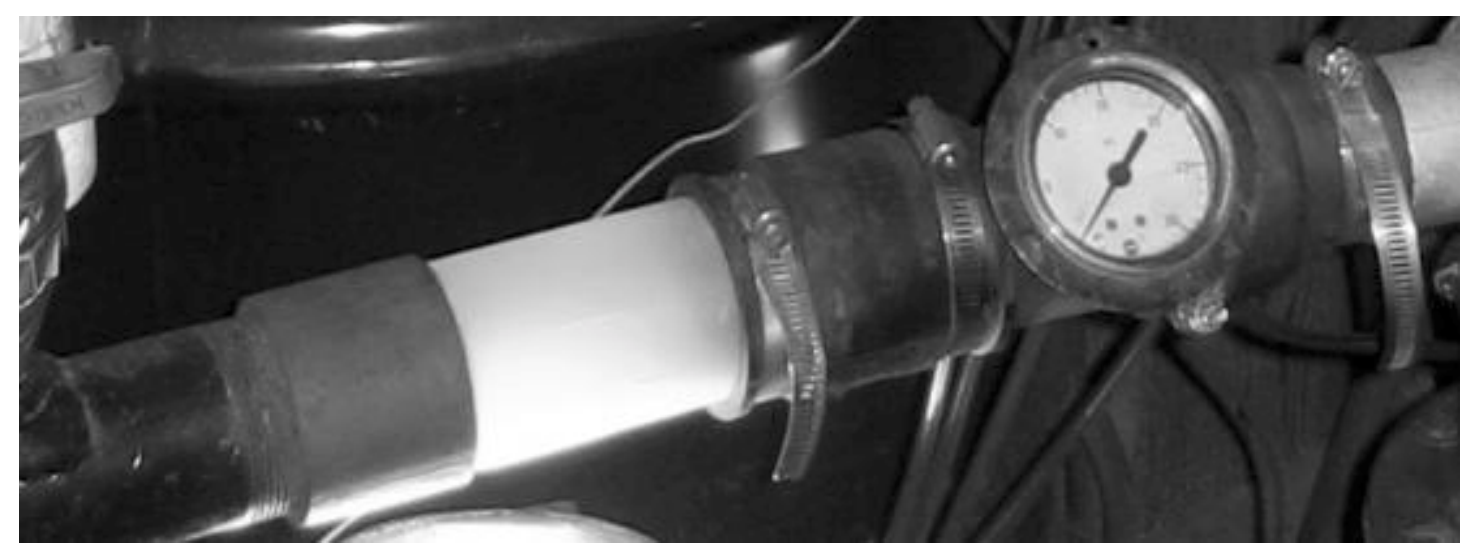

Figure 3.2.2.a. Modified Transport Tube

\subsubsection{Collection Ring/Bed Wall Height Modifications}

It was noted that when the original system ran at high mass flux values, that some bubbling was noted in the dense bed at the bottom of the riser, causing particles to spill over into the dense collection bin undesirably. To correct this problem two collection ring/distributor wall extensions were created that allowed for a higher mass flux of particles to be run through the system.

The distributor plate had a small ring which allowed for different sized sections to be placed on top of it. Two sections were made, each of aluminum tubing. One section was made 8 inches $(20.32 \mathrm{~cm})$ tall, and the other was made 11 inches $(27.94 \mathrm{~cm})$ tall. 
This brought the total heights of the distributor wall bed height/collection ring height to 12 inches $(30.48 \mathrm{~cm})$ and 15 inches $(38.1 \mathrm{~cm})$, respectively. A small ring of aluminum was added to the top of each section that formed the collection ring, which allowed for the $1 / 8$ inch gap between the riser wall and fluidized bed. On each small aluminum collection ring, three small wooden dowel rods were placed to ensure an even 1/8 gap all the way around the ring to allow the particles to pass through. The added extensions allowed for higher mass flux values to be run in the system. No bubbling of the bed was noted during preliminary test runs. The collection ring/distributor wall extensions are shown in Figure 3.2.3.a.

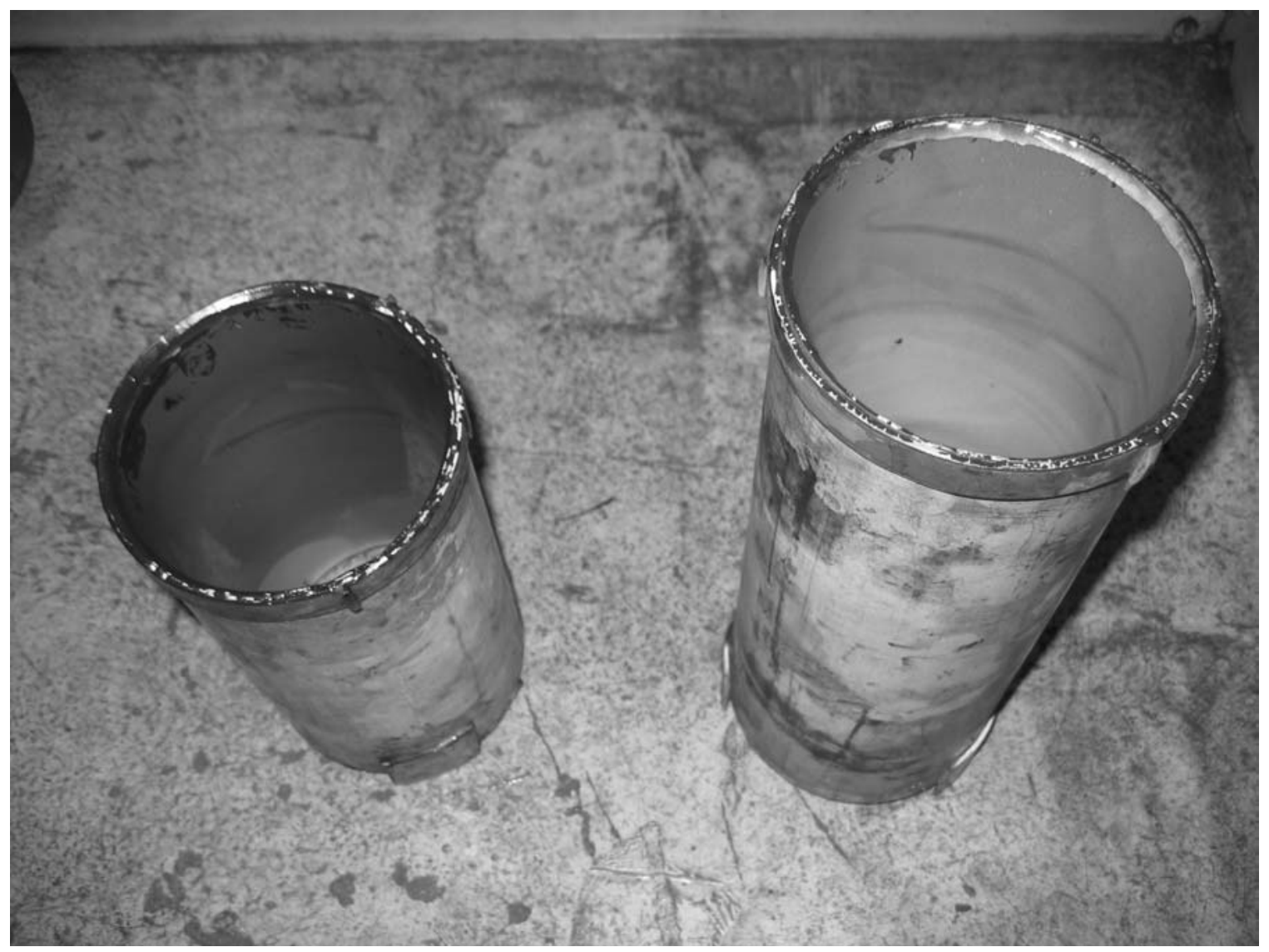

Figure 3.2.3.a Collection Ring/Distributor Wall Extensions 


\subsubsection{Design of the Particle Entrance into the Riser}

A main focus of this thesis is to determine the effect of particle entrance diameter into the riser on separation. It was desirable to form a concentric jet style flow in which the particles were concentrated as they entered the system instead of being dispersed. The initial system let the particles enter into the riser by means of a $3 / 4$ inch $(1.905 \mathrm{~cm}) \mathrm{t}$ shaped threaded pipe opening. The particle inlet into the riser was located approximately 3 inches $(7.62 \mathrm{~cm})$ above the bottom of the distributor plate. This opening is shown in

\section{Figure 3.1.4.a.}

To achieve a concentric jet of particles, nozzles were needed. For their cost efficiency and ease of use, several brass nozzles were purchased. Each nozzle had a threaded base of $3 / 4$ inch, which allowed them to be easily screwed into the original pipe fitting. The nozzles were extremely easy to use and produced the desired jet style flow. The nozzle sizes used for this experiment were of the following diameters: $1 / 2$ inch (1.27 $\mathrm{cm}), 14 / 32$ inch $(1.111 \mathrm{~cm}), 9 / 32$ inch $(0.714 \mathrm{~cm})$, and 7/32 inch $(0.556 \mathrm{~cm})$. Very minimal wearing occurred on the $14 / 32(1.111 \mathrm{~cm})$ nozzle size during the sand and steel shot mixture test runs. It was determined this wearing did not effect the overall design of the nozzle as the opening sizes remained the same. No wearing was noticed that would disrupt the flow pattern. No other wearing or problems were encountered using the nozzles. The nozzles are shown in Figure 3.2.4.a. 


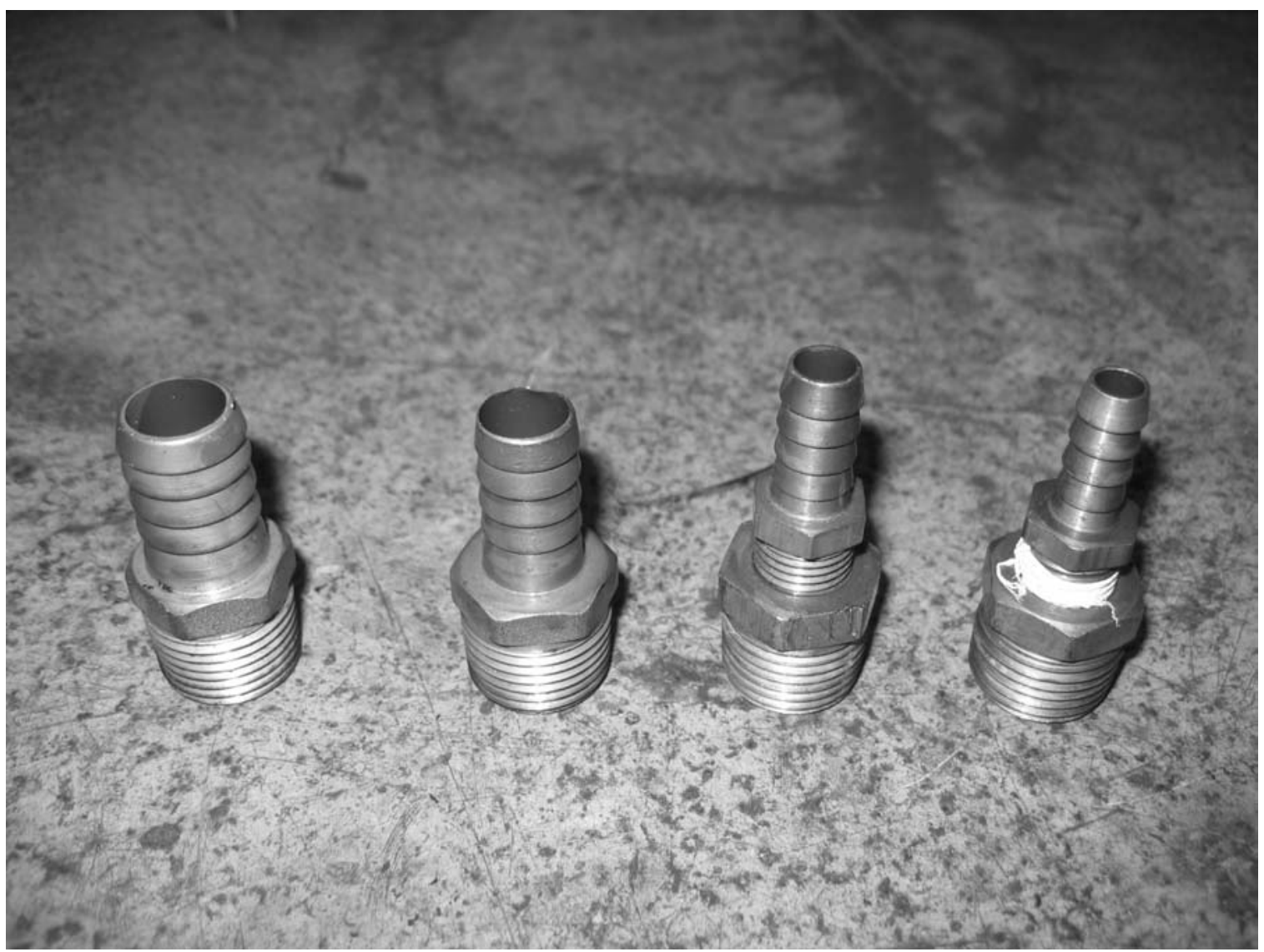

Figure 3.2.4.a Particle Entrance Nozzles

\section{$\underline{\text { 3.2.5 Modifications of the Paper Filtration System }}$}

Almond (2005) noted some problems with back pressure in the original system due to the paper filter. Almond then changed the system to the current paper filter set up with vacuum cleaner bags that can attach to the end of a PVC pipe inside of the barrel. During some of the first high velocity test runs, the paper filter bags had sizeable tears in them, which allowed some of the particles to escape. To further curb this problem a T-shaped section of 3 inch PVC pipe was created for the inside portion of the barrel. This allowed for a second paper filter to be placed in the barrel, which gives twice the surface area for the gas coming from the riser to escape. It was noted that this did indeed solve some of the bag tearing, but was later decided that not enough of the solid particles 
were entering in the filters, which led to reverting to the water filter. The re-designed filter system is shown as a schematic in Figure 3.2.5.a.

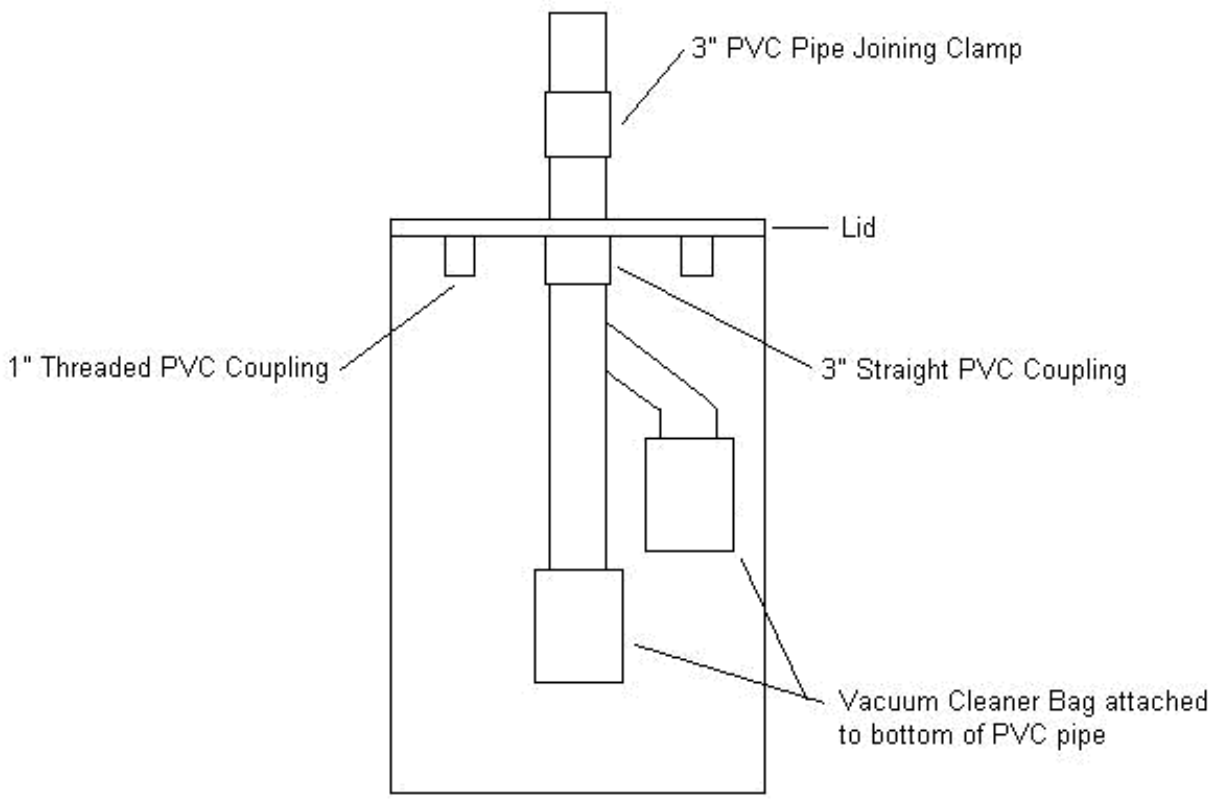

Figure 3.2.5.a. Modified Paper Filtration System 


\section{$\underline{3.3 \text { Instrumentation }}$}

The Circulating Fluidized Bed (CFB) system required several data acquisition components to properly measure values throughout the experiments. There were two air flow meters, three pressure transducers, one load cell, and three pressure gauges to measure the air flow pressure in the system. Although data was taken using these devices, the analyzing of the final product was completed by weighing the masses of the product and dense bins, and also by having analysis completed by the NRCCE Chemical Analysis Laboratory. Instrumentation is shown in Figure 3.3.b. Shown in Figure 3.3.a is the air supply and flow meter system.

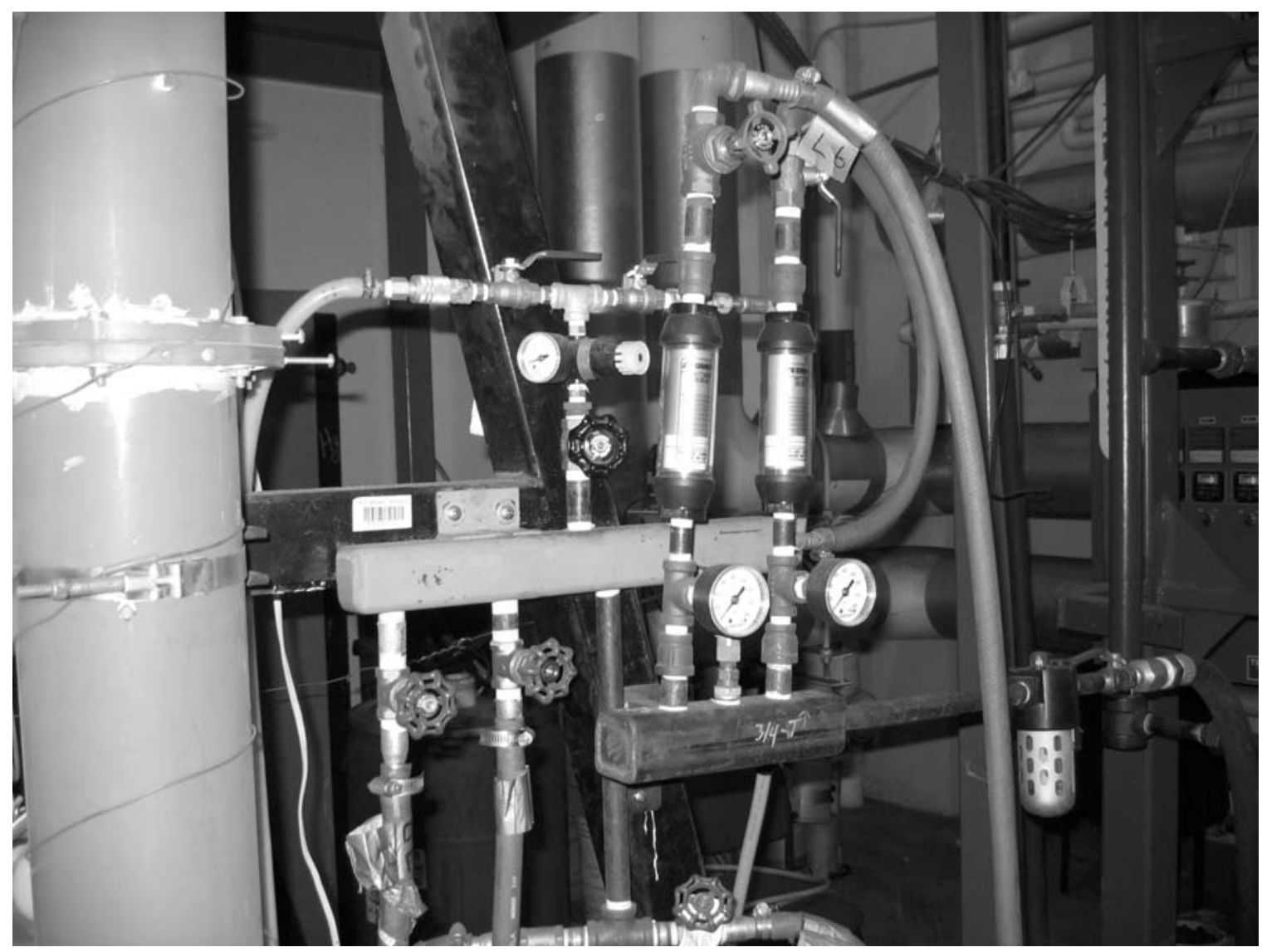

Figure 3.3.a Air Supply and Flow Meter System 


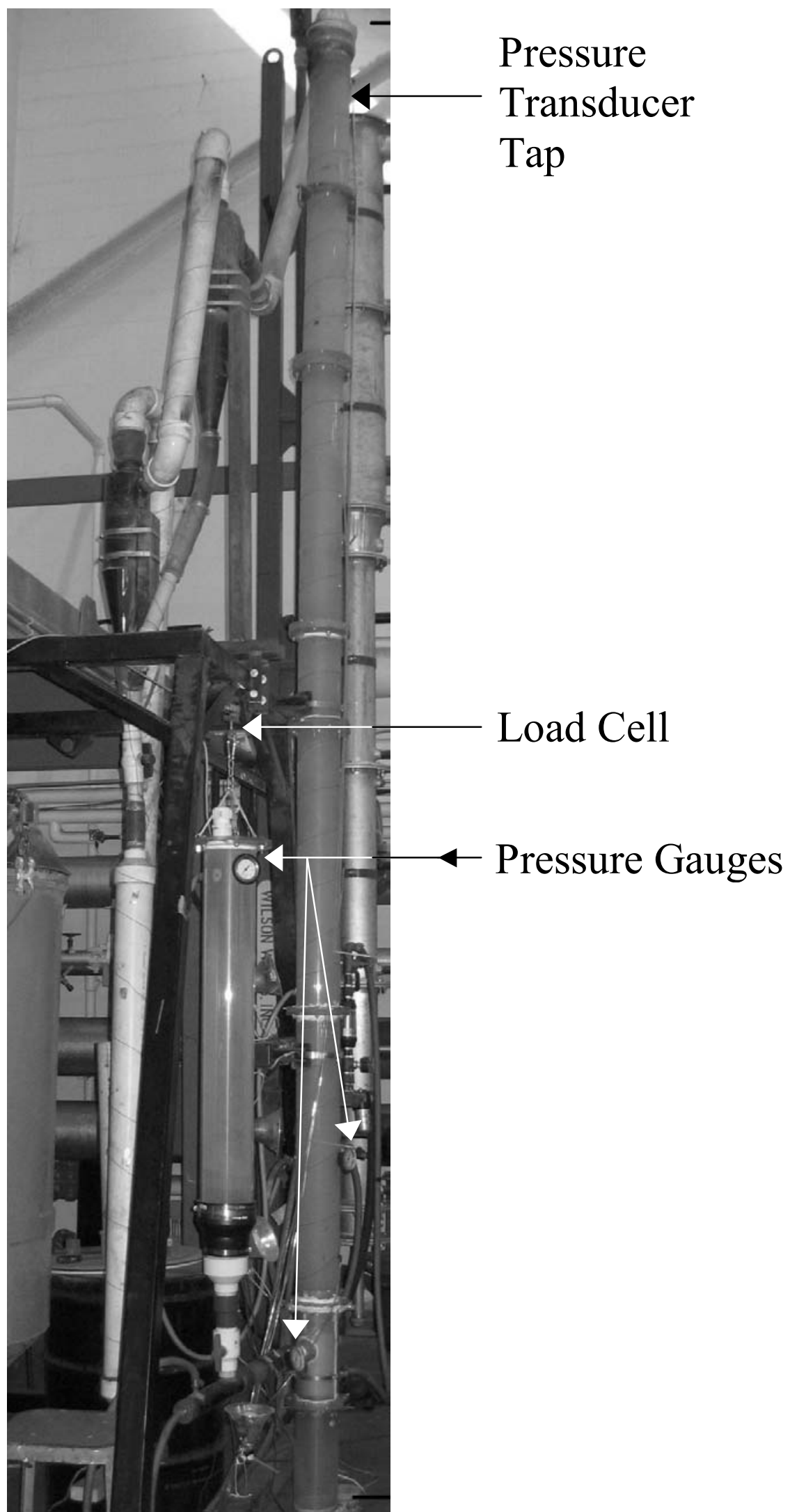

Figure 3.3.b Instrumentation Location 


\subsubsection{Data Acquisition System}

A PC computer system was loaded with DAPView data acquisition system. DAPView was used to read the signals coming from the load cell and the pressure transducers found in the CFB riser. The signal coming into the DAPView program was read after it had been conditioned and converted to the proper units. According to Regester (2004), the load cell and pressure transducer data was sent by analog method and into the Analog Devices 5B40-03 signal conditioner to allow amplification of the signal. The signal was then sent to an analog termination board MSTB 009-09, and finally to a Microstar Laboratories DAP 5200a/526 data acquisition board before being sent to the DAPView program.

\subsubsection{Flow Meters}

Two flow meters were used to measure the air flow coming into the distributor plate and the pneumatic transport system. The flow meters used were Omega FLMG series meters, which measure flow rate from values of 10 , to 100 , standard cubic feet per minute (SCFM). The flow meters were placed directly in line with the air flow lines coming into the system. Each of the flow values had to be read manually off the front of the flow meters. The actual flow rate of air for the flow meters had been checked previously by Almond (2005) and accounted for. The corrected flow rate values were accounted for in the data acquisition spread sheet.

\subsubsection{Load Cell}

A load cell was bolted to the main frame supporting the system so that feed hopper weights could be measured. The load cell was an Omega S-Beam load cell series LC101 rated up to 3000 pounds. The load cell was bolted to the frame at one end, while 
the other end had an eye hook that allowed the feed hopper to be connected to it which

allowed for easy disassembly. The load cell data was sent into the DAPView program as described earlier and measured in lb/min. The load cell was calibrated and checked by taking appropriate readings for corresponding weights that was added to the system.

\subsubsection{Pressure Gauges}

Three pressure gauges were placed in the system to monitor the air pressure at various points. The gauges were USG brand, and measured up to 35 psi. One pressure gauge was mounted in the Feed Hopper, one in the transport tube from the feed hopper to the riser, and one was located just above the particle bed level at the base of the riser wall. These pressure gauges were screwed in to $1 / 8$ inch holes that had been drilled and tapped into the acrylic surfaces. These threads were wrapped in thread tape and then lined with silicone to ensure that no air could escape from the system.

\subsubsection{Inductively Coupled Plasma - Optical Emission Spectroscopy Machine}

Once test runs were completed in the CFB system with coal, samples were taken from the dense and light particle collection bins and sent to the NRCCE chemical analysis lab. The samples were then checked on an ICP (Inductively Coupled Plasma) machine to check for overall sulfur percentage. Coal samples of 0.5 grams have water, hydrochloric, and nitric acid added to them to allow them to be in liquid form $(50 \mathrm{ml}$ total), as the ICP requires. The ICP reads the spectroscopy of the elements found within the sample by reading light energy from them. The machine excites the electrons and raises the energy level by spraying them into a flame. When the element electron levels relax they give off specific wavelengths which are then recorded by the ICP by a 
spectrometer. These recorded wavelengths are then reported in $\mathrm{mg} / \mathrm{L}$, which are manually changed into the percentage of overall sulfur.

\subsubsection{Scanning Electron Microscope (SEM)}

Coal samples from the third test run on 8-30-06 were taken to the Chemical Engineering Department's Scanning Electron Microscope (SEM). In an SEM electrons are emitted from a cathode and accelerated towards an anode. An electron beam is emitted and then focused on the specimen. Electrons are then emitted from the subject, thus producing an image. The SEM was used to look at the particles from the dense and product bin at a magnification of $250 \mathrm{X}$. The particle mixture was then carbon coated which allowed a spectrum to be taken to perform an elemental analysis to look for sulfur.

\subsubsection{Riser Start-Up/Shut-Down Procedure}

The riser start-up and shut-down procedure may be viewed in Appendix D. 


\section{Chapter 4: Selection of Test Conditions}

\subsection{Test Matrix Selection}

\subsubsection{Basic Riser Geometry/Variable Selection}

The basic geometry of the riser was kept the same for all the experiments completed as used by Almond (2005). There were three main modifications that were to be made to the system. The collection ring wall height, the nozzle sizes, and the percent delivery of air flow between the nozzle/distributor were to be changed to see how they affected the efficiency of the separation process. The basic geometry and changes to the system are shown in Table 4.1.a.

\begin{tabular}{|c|c|}
\hline \multicolumn{2}{|c|}{ Experimental Setup } \\
\hline Riser Height & $4.3 \mathrm{~m}$ \\
\hline Outlet Geometry & Swept Bend \\
\hline Collection Gap Width & $3.2 \mathrm{~mm}$ \\
\hline Number of Passes & 1 \\
\hline Filtration & Water Filter \\
\hline Modifications & $\begin{array}{c}\text { Collection Ring Wall Height } \\
\text { Nozzle Size } \\
\text { Nozzle/Distributor Flow }\end{array}$ \\
\hline
\end{tabular}

Table 4.1.a. Experimental System Setup/Modifications

Along with the modifications to the system, the mass flux values were also changed for the coal tests, as they would greatly affect the separation process. The mass flux value changes are described further in Section 4.4.

\subsubsection{Selection of Sand and Steel Shot Test Matrix}

Data from the test runs for the sand and steel shot were used to determine the test conditions for the coal tests. The variables used - nozzle size, nozzle/distributor flow, and ring wall height, are shown in the sand and steel shot experimental test matrix. It is noted that when more air is run through the distributor plate, it is referred to as Regular Style Flow, and when more air is run through the transport tube, it is known as Concentric Jet 
Style Flow. Regester (2004) completed tests with a split of $75 \%$ of the gas going to the distributor, and $25 \%$ of the gas going to the transport of particles. Reaching satisfactory results, this was used as a baseline to begin the sand and steel shot tests.

Three different nozzle sizes and two different ring wall heights were used. The mass flow rates for the solids entering the riser, which were arbitrarily determined by setting the system to a steady state condition, are also shown. The experimental test matrix for the sand and steel shot may be viewed in Table 4.1.b.

\begin{tabular}{|c|c|c|c|c|c|c|c|}
\hline \multicolumn{6}{|c|}{ Sand and Steel Shot Separation Test Runs - 250-500 Micron Size Range } \\
\hline $\begin{array}{c}\text { Run } \\
\text { Number }\end{array}$ & $\begin{array}{c}\text { Total } \\
(\text { SCMH) }\end{array}$ & $\begin{array}{c}\text { Distributor } \\
\text { Flow } \\
(\text { SCMH) }\end{array}$ & $\begin{array}{c}\text { Transport } \\
\text { Flow } \\
(\text { SCMH) }\end{array}$ & $\begin{array}{c}\% \\
\text { Nozzle } \\
\text { Flow }\end{array}$ & $\begin{array}{c}\text { Particle } \\
\text { Inlet Size } \\
(\mathrm{cm})\end{array}$ & $\begin{array}{c}\text { Mass } \\
\text { Fux } \\
\left(\mathrm{kg} / \mathrm{m}^{\wedge} 2 \mathrm{~s}\right)\end{array}$ & $\begin{array}{c}\text { Ring Wall } \\
\text { Height }(\mathrm{m})\end{array}$ \\
\hline 1 & 169.0 & 108.2 & 60.8 & 36.0 & 1.905 & 0.725 & 0.3048 \\
\hline 2 & 172.9 & 51.2 & 121.7 & 70.4 & 1.905 & 0.81 & 0.3048 \\
\hline 3 & 170.0 & 109.3 & 60.8 & 35.7 & 1.270 & 0.893 & 0.3048 \\
\hline 4 & 167.6 & 68.4 & 99.2 & 56.2 & 1.270 & 1.49 & 0.3048 \\
\hline 5 & 168.2 & 113.2 & 60.7 & 36.1 & 1.111 & 0.746 & 0.3048 \\
\hline 6 & 169.0 & 94.0 & 76.9 & 45.5 & 1.111 & 0.893 & 0.3048 \\
\hline 7 & 169.0 & 108.2 & 60.8 & 36.0 & 1.905 & 1.05 & 0.381 \\
\hline 8 & 170.0 & 47.5 & 122.5 & 72.1 & 1.905 & 1.27 & 0.381 \\
\hline 9 & 170.0 & 109.3 & 60.8 & 35.7 & 1.270 & 0.81 & 0.381 \\
\hline 10 & 167.6 & 68.4 & 99.2 & 59.2 & 1.270 & 1.19 & 0.381 \\
\hline 11 & 170.5 & 111.4 & 59.2 & 34.7 & 1.111 & 1.05 & 0.381 \\
\hline 12 & 168.2 & 93.5 & 74.9 & 44.5 & 1.111 & 1.79 & 0.381 \\
\hline
\end{tabular}

Table 4.1.b Sand and Steel Shot Test Matrix

Satisfactory results were found from completing the initial sand and steel shot tests. The results will be discussed in Chapter 5. It was, however, determined the percent of nozzle/distributor flow did not have a significant impact on the dense particle mass fraction or collection efficiency. It was concluded the other variables were more of an influence and would be studied for the coal tests, while the percentage of nozzle flow would remain constant. Another reason the percent flow through the nozzle was left constant for the coal tests was due to very high pressures in the feed hopper and transport 
tube for the sand and steel shot tests, when most of the flow was passed through the nozzle.

\subsubsection{Selection of Pyritic Coal/Clean Coal Test Matrix}

Several test variables were used for the dry separation test runs to see if pyritic laden coal could be separated from clean coal. The variables investigated were the mass flux of particles into the system, the collection ring wall height, and the nozzle size for the particle entrance into the riser. It was determined from the sand and steel shot experiments that the percentage of air flow coming from the nozzle/distributor plate did not influence the results as anticipated. It was therefore decided to leave an even $50 \%$ split of the gas through both the nozzle and distributor. This would allow the coal to be properly carried into the riser, while still leaving enough pressure to properly lift particles by the distributor plate gases as well. The experimental test matrix for the coal test runs is shown in Table 4.1.c. The run number, percent nozzle/distributor, variables used, and test comparison descriptions are shown in the table. The results of trying to separate pyritic coal from clean coal will be discussed in Chapter 6. 


\begin{tabular}{|c|c|c|c|c|c|c|}
\hline \multicolumn{7}{|c|}{ Coal (Kingwood Coal) Separation Test Runs - 105-210 Micron Size Range } \\
\hline $\begin{array}{c}\text { Run } \\
\text { Number }\end{array}$ & $\begin{array}{l}\text { Nozzle - } \\
\text { Distributor } \\
\text { Flow }\end{array}$ & $\begin{array}{l}\text { Air Flow } \\
\text { Rate } \\
\text { (SCMH) }\end{array}$ & $\begin{array}{c}\text { Particle Mass } \\
\text { Flux } \\
\left(\mathrm{kg} / \mathrm{m}^{\wedge} 2 \mathrm{~s}\right)\end{array}$ & $\begin{array}{l}\text { Riser Wall } \\
\text { Height (m) }\end{array}$ & $\begin{array}{l}\text { Particle } \\
\text { Inlet Size } \\
\text { (cm) }\end{array}$ & Comments \\
\hline 1 & $50 / 50$ & 42.25 & 0.399 & 0.3048 & 1.905 & \multirow{5}{*}{$\begin{array}{l}\text { Initial test runs to } \\
\text { check velocity value } \\
\text { and how it } \\
\text { corresponds with } \\
\text { particle inlet size. }\end{array}$} \\
\hline 2 & $50 / 50$ & 42.25 & 0.352 & 0.3048 & 1.27 & \\
\hline 3 & $50 / 50$ & 42.25 & 0.346 & 0.3048 & 1.11 & \\
\hline 4 & $50 / 50$ & 42.25 & 0.388 & 0.3048 & 0.714 & \\
\hline 5 & $50 / 50$ & 42.25 & 0.334 & 0.3048 & 0.556 & \\
\hline
\end{tabular}

\begin{tabular}{|c|c|c|c|c|c|c|}
\hline 6 & $50 / 50$ & 50.7 & 0.298 & 0.3048 & 1.905 & \multirow{5}{*}{$\begin{array}{l}\text { Test runs to check } \\
\text { higher velocity value } \\
\text { and how it } \\
\text { corresponds with } \\
\text { particle inlet size. }\end{array}$} \\
\hline 7 & $50 / 50$ & 50.7 & 0.328 & 0.3048 & 1.27 & \\
\hline 8 & $50 / 50$ & 50.7 & 0.298 & 0.3048 & 1.11 & \\
\hline 9 & $50 / 50$ & 50.7 & 0.280 & 0.3048 & 0.714 & \\
\hline 10 & $50 / 50$ & 50.7 & 0.334 & 0.3048 & 0.556 & \\
\hline
\end{tabular}

\begin{tabular}{|c|c|c|c|c|c|c|}
\hline 11 & $50 / 50$ & 50.7 & 1.192 & 0.3048 & 1.905 & \multirow{4}{*}{\begin{tabular}{|c|} 
High mass flux \\
values with .3048 \\
meter ring wall \\
height. Aimed for 1.2 \\
$\mathrm{~kg} / \mathrm{m}^{\wedge} 2 \mathrm{~s}$. \\
\end{tabular}} \\
\hline 13 & $50 / 50$ & 50.7 & 1.157 & 0.3048 & 1.27 & \\
\hline 15 & $50 / 50$ & 50.7 & 1.246 & 0.3048 & 1.11 & \\
\hline 17 & $50 / 50$ & 50.7 & 1.127 & 0.3048 & 0.714 & \\
\hline & & & & & & \multirow{5}{*}{$\begin{array}{l}\text { Low mass flux values } \\
\text { with .3048 meter ring } \\
\text { wall height. Aimed for } \\
.60 \mathrm{~kg} / \mathrm{m}^{\wedge} 2 \mathrm{~s} \text {. }\end{array}$} \\
\hline 12 & $50 / 50$ & 50.7 & 0.608 & 0.3048 & 1.905 & \\
\hline 14 & $50 / 50$ & 50.7 & 0.608 & 0.3048 & 1.27 & \\
\hline 16 & $50 / 50$ & 50.7 & 0.614 & 0.3048 & 1.11 & \\
\hline 18 & $50 / 50$ & 50.7 & 0.572 & 0.3048 & 0.714 & \\
\hline
\end{tabular}

\begin{tabular}{|c|c|c|c|c|c|c|}
\hline 19 & $50 / 50$ & 50.7 & 1.318 & 0.381 & 1.905 & High mass flux \\
\hline 21 & $50 / 50$ & 50.7 & 1.282 & 0.381 & 1.27 & values with .381 \\
\hline 23 & $50 / 50$ & 50.7 & 1.127 & 0.381 & 1.11 & meter ring wall \\
\hline 25 & $50 / 50$ & 50.7 & 1.133 & 0.381 & 0.714 & $\mathrm{~kg} / \mathrm{m}^{\wedge} 2 \mathrm{~s}$ \\
\hline
\end{tabular}

\begin{tabular}{|c|c|c|c|c|c|c|}
\hline 20 & $50 / 50$ & 50.7 & 0.638 & 0.381 & 1.905 & \multirow{4}{*}{$\begin{array}{c}\text { Low mass flux values } \\
\text { with } .381 \text { meter ring } \\
\text { wall height. Aimed for } \\
.60 \mathrm{~kg} / \mathrm{m}^{\wedge} 2 \mathrm{~s} \text {. }\end{array}$} \\
\hline 22 & $50 / 50$ & 50.7 & 0.620 & 0.381 & 1.27 & \\
\hline 24 & $50 / 50$ & 50.7 & 0.614 & 0.381 & 1.11 & \\
\hline 26 & $50 / 50$ & 50.7 & 0.608 & 0.381 & 0.714 & \\
\hline
\end{tabular}

\begin{tabular}{|c|c|c|c|c|c|c|}
\hline 27 & $50 / 50$ & 50.7 & 0.306 & 0.3048 & 1.905 & \multirow{6}{*}{$\begin{array}{c}\text { Re-runs of test } \\
\text { numbers } 6,7, \& 8 \text { to } \\
\text { check for } \\
\text { repeatability of } \\
\text { results }\end{array}$} \\
\hline 28 & $50 / 50$ & 50.7 & 0.280 & 0.3048 & 1.905 & \\
\hline 29 & $50 / 50$ & 50.7 & 0.310 & 0.3048 & 1.27 & \\
\hline 30 & $50 / 50$ & 50.7 & 0.317 & 0.3048 & 1.27 & \\
\hline 31 & $50 / 50$ & 50.7 & 0.311 & 0.3048 & 1.11 & \\
\hline 32 & $50 / 50$ & 50.7 & 0.317 & 0.3048 & 1.11 & \\
\hline
\end{tabular}

Table 4.1.c Clean Coal/Pyritic Coal Test Matrix 


\subsubsection{Selection of Pure Crushed Pyrite/Clean Coal Test Conditions}

Results from separating pyritic coal and clean coal were not as favorable as

desired. For this reason, another test was completed in which pure pyrite was ground and added to clean coal to be separated in the riser. Only two tests were completed, both with no nozzles installed, a 0.3048 meter high collection ring height, and an air flow of 50.7

SCMH. The mass flux of solids for both tests was aimed to be 0.5 pounds per minute.

The results of the tests are discussed further in Chapter 7. The test matrix may be viewed in Table 4.1.d.

\begin{tabular}{|c|c|}
\hline \multicolumn{2}{|c|}{ Experimental Setup } \\
\hline Riser Height & $4.3 \mathrm{~m}$ \\
\hline Outlet Geometry & Swept Bend \\
\hline Collection Gap Width & $3.2 \mathrm{~mm}$ \\
\hline Number of Passes & 1 \\
\hline Filtration & Water Filter \\
\hline Modifications & None \\
\hline Particle Inlet Size & $1.905 \mathrm{~cm}$ \\
\hline Air Flow Rate & $50.7 \mathrm{SCMH}$ \\
\hline Collection Ring Wall Height & $.3048 \mathrm{~m}$ \\
\hline Nozzle/Distributor Flow \% & $50 / 50$ \\
\hline Particle Mass Flow & $.5 \mathrm{lbs} / \mathrm{min}$ \\
\hline
\end{tabular}

Table 4.1.d Clean Coal/Pure Pyrite Test Matrix

\subsection{Experimental Gas Velocities}

One of the main principles that a circulating fluidized bed operates on is terminal velocity. By determining the terminal velocity of the particles being used in the riser empirically, it is possible to determine at what point segregation will occur. For such separation of the particles to occur, the superficial gas velocity in the riser must be set according to the corresponding terminal velocity of the particles used. The superficial gas velocity should be set greater than large dense particles, and less than the smaller light particles, thus allowing the separation to occur. 


\subsubsection{Terminal Velocity Equation}

The terminal velocity of a particle can be determined empirically by the Terminal Velocity Equation found in Fan and Zhu (1998), which is dependent on the particle size and density, fluid density and viscosity, and the Reynolds and Archimedes Numbers. All of the following equations are based on several assumptions. The first of these is that the particle considered is spherical in shape. Another assumption is that the equations are used for a single particle, not a cluster of particles. The last assumption is that all equations are only valid for turbulent Reynolds numbers between the ranges of $2<\mathrm{Re}_{\mathrm{t}}<500$ where $\mathrm{Re}_{\mathrm{t}}$ is identified as:

$\operatorname{Re}_{t}=\frac{\rho_{g} U_{p t} d_{p}}{\mu}$

The first variable to be calculated is the Archimedes Number, which is found by using the following equation:

$$
A r=\frac{\rho_{g}\left(\rho_{p}-\rho_{g}\right) g d_{p}^{3}}{\mu^{2}}
$$

The second variable to be calculated is the Reynolds number of the particle, which is dependent on the Archimedes number. It is found by using the equation:

$$
\operatorname{Re}_{t r}=2.28 A r^{0.419}
$$

The terminal velocity of a single particle may then be found with the terminal velocity equation, which is defined in Fan and Zhu (1998) as:

$$
V_{p t}=\left\{0.072 \frac{d_{p}^{1.6}\left(\rho_{p}-\rho_{g}\right) g}{\rho_{g}^{0.4} \mu^{0.6}}\right\}^{\frac{1}{1.4}}
$$


By using this equation, the terminal velocity of a single, spherical particle may be calculated.

\subsubsection{Superficial Gas Velocities}

To determine the superficial gas velocities moving up the riser, a terminal velocity analysis was completed on the solid particles being used. The first sets of tests were completed with white play sand and steel shot. White Quickcrete play sand and steel shot were screened and run through American Standard Mesh sieves. All material found between the 35 and 65 mesh screens were kept, making the particle size range between 250 and 500 micron.

The second material run was coal fines from Kingwood Coal Company. The coal was crushed down to a micronized size by use of a jaw crusher. Once completed, the batch of coal was run through American Standard Mesh sieves. All coal material found between the 70 mesh, and 140 mesh screen sizes was kept. This kept the particles size range from 105 micron to 210 micron. The fine particle size was picked so that a greater amount of pyrite could be released from the larger pieces. This is described further in

\section{Section 2.2.}

For the sand, steel shot, and coal terminal velocity analysis, the density of the materials was needed. For the sand and steel shot density, a small bench experiment was performed in which the data was found. The sand and steel shot was sieved down to the desired size of 250 to 500 microns. A known mass of $1 \mathrm{~kg}$ of steel shot, and $0.5 \mathrm{~kg}$ of play sand, was weighed out and then placed into a graduated beaker marked out with 200 $\mathrm{ml}$ of water. After the material was placed into the beaker, the new water level was recorded. The values were found to be $330 \mathrm{ml}$ of water for the steel shot, and $391 \mathrm{ml}$ of 
water in the beaker with the play sand. By taking the known mass of material and dividing by the displaced amount of water, the following densities were found:

\section{Steel Shot Density: $7692 \mathrm{~kg} / \mathrm{m}^{3}$ \\ Play Sand Density: $2617 \mathrm{~kg} / \mathrm{m}^{3}$}

For the coal fines, two values were needed. As described earlier, for the run-ofmine coal test runs, coal with large amounts of pyrite were trying to be separated from those with small amounts. It was therefore assumed that to find a separation point that the density of coal and pure pyrite would be used. Commonly accepted values of both were used and assumed to be:

\section{Clean Coal: $1350 \mathrm{~kg} / \mathrm{m}^{3}$ \\ Pyrite: $4800 \mathrm{~kg} / \mathrm{m}^{3}$}

The other values used in the terminal velocity equation needed were the density of air, viscosity of air, and gravitational constant. The values used were at 20 degrees Celsius and were as follows:

$$
\begin{gathered}
\text { Density of Air }=1.204 \mathrm{~kg} / \mathrm{m}^{3} \\
\text { Dynamic Viscosity of Air }=1.82 \mathrm{e}-5 \mathrm{~kg} \mathrm{~m} / \mathrm{s} \\
\text { Gravitational Constant }=9.81 \mathrm{~m} / \mathrm{s}^{2}
\end{gathered}
$$

A Matlab program was created so that the terminal velocity of each different material could be plotted as a function of particle size. The program was then used to create plots of the velocity vs. particle size so that a separation velocity could be found. On each figure two distinct lines for the terminal velocity are created. A horizontal line, representing the mass average velocity of the gas, can be drawn between these two lines at a desired separation point corresponding to the superficial gas velocity. The line 
should be drawn between the two particles starting with the largest particle size of the lower density material, and then drawn to the left, to the y-axis and the corresponding terminal velocity. The Matlab program code can be found in Appendix A. Figure

4.2.2.a and Figure 4.2.2.b show the Matlab plots used to determine the superficial gas velocities for sand and steel shot, and for coal and pyrite, respectively.

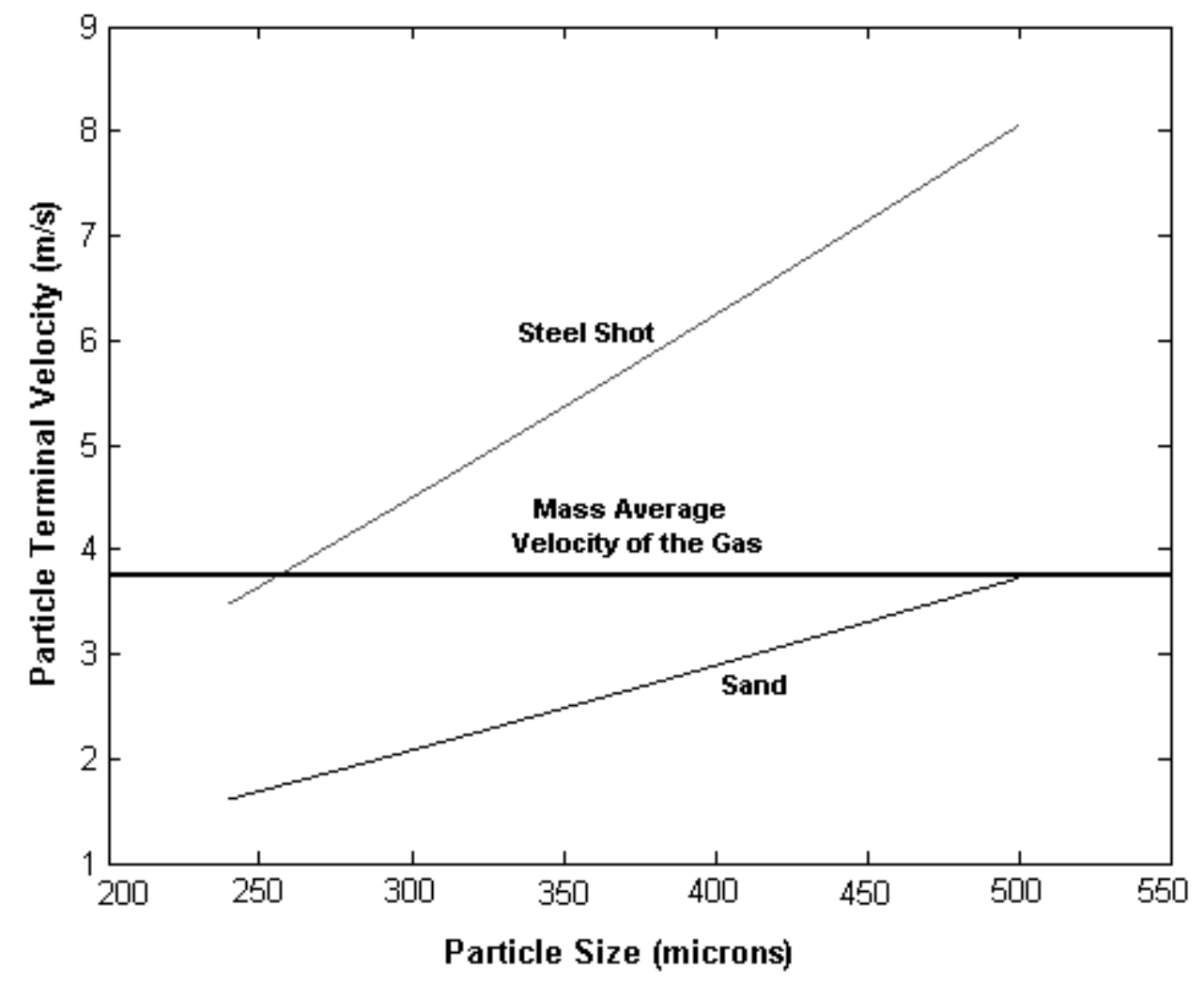

Figure 4.2.2.a Terminal Velocity vs. Particle Size of Sand and Steel Shot 


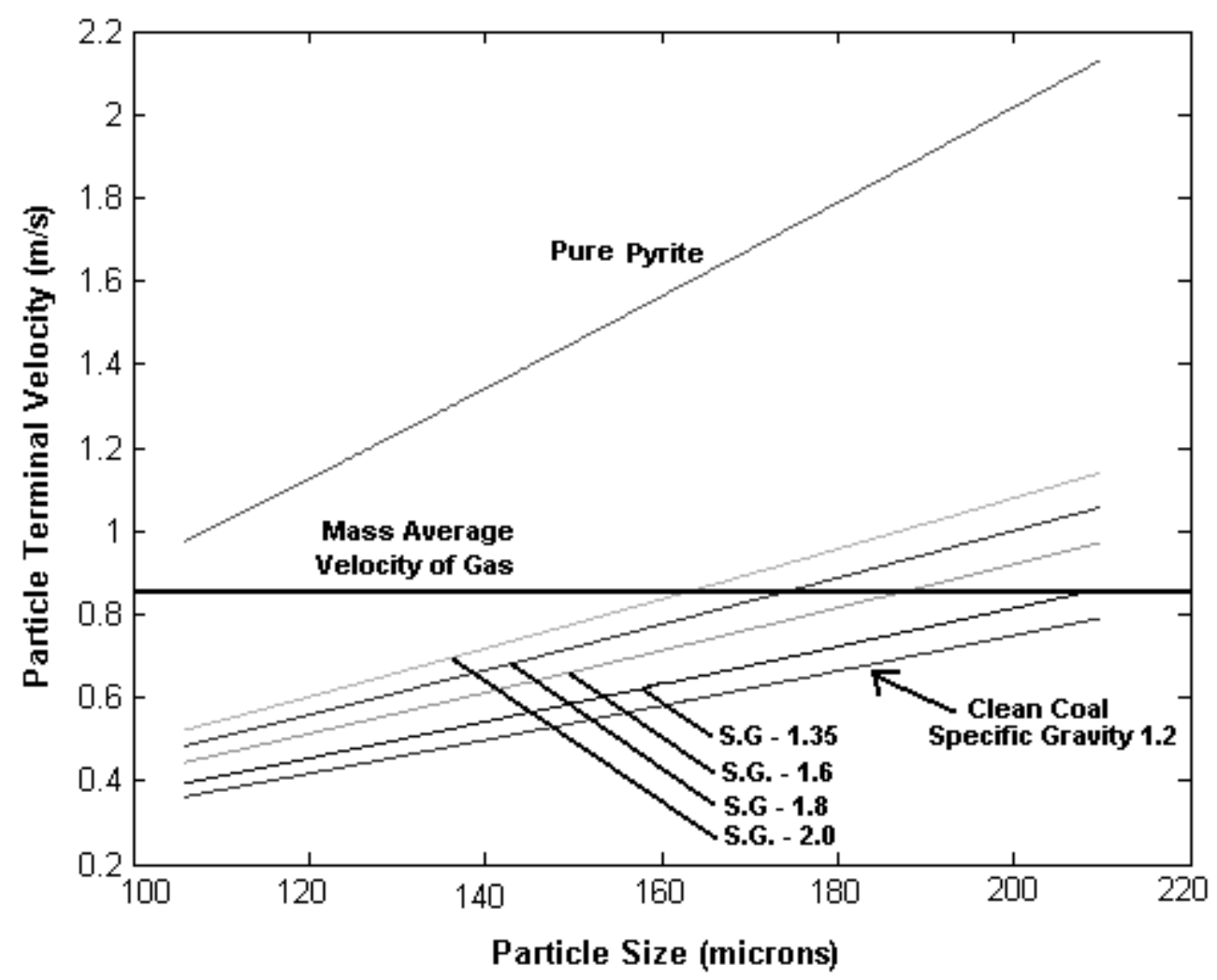

Figure 4.2.2.b Terminal Velocity vs. Particle Size of Coal and Pyrite

For the figures, the lines intersect on the left hand side of the y-axis of the graph to show the velocity of the particles, thus giving the superficial velocity at which the riser should be operated. The following gas velocities were used in the main riser to achieve separation:

\section{Sand and Steel Shot: $3.774 \mathrm{~m} / \mathrm{s}$}

\section{Coal and Pyrite: $0.8726 \mathrm{~m} / \mathrm{s}$}

The corresponding volumetric flow rates used for these, with a 5 inch $(12.7 \mathrm{~cm})$ diameter riser, are:

Sand and Steel Shot: 100 standard cubic feet per minute (SCFM) Coal and Pyrite: 25 standard cubic feet per minute (SCFM) 
Several preliminary test runs were completed with both sets of air-solid mixtures to see how they would perform in the riser system at the given velocities. Although the coal mixture transported into the riser as desired, the dense particle collection bin would fill to a point near levels where it would begin backing up into the distributor area and collect most of the 10 pounds of material. This did not affect any of the test runs completed at $25 \mathrm{SCFM}$, but to achieve a better distribution of collection between the dense and light particle collection bins, a higher superficial gas velocity was picked. The corrected gas velocity decided upon for separation was:

\section{Corrected Coal and Pyrite Gas Velocity: 30 SCFM $=(1.117 \mathrm{~m} / \mathrm{s})$}

Figure 4.2.2.c shows the corresponding terminal velocity plot with a corrected separation line on it.

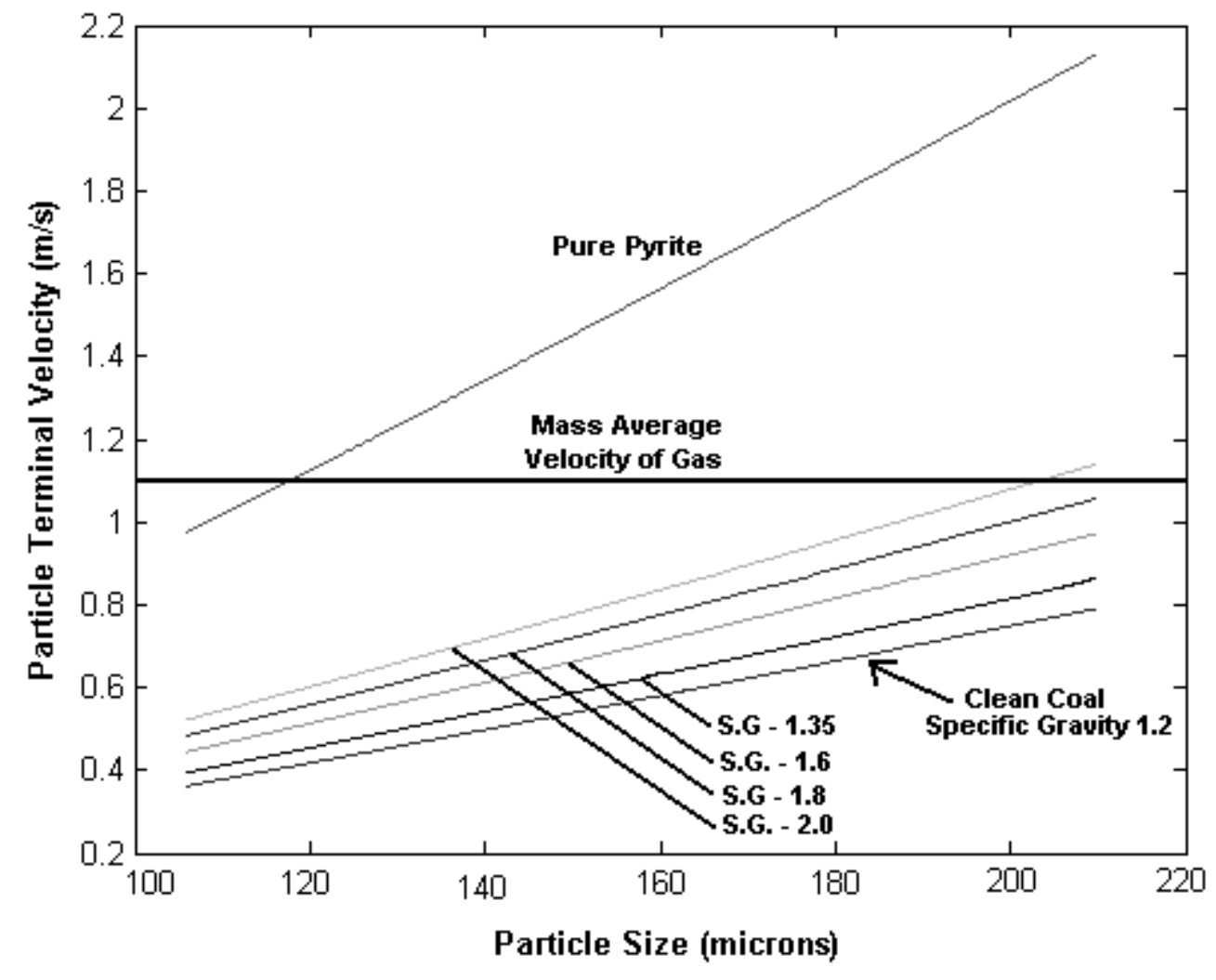

Figure 4.2.2.c Corrected Terminal Velocity vs. Particle Size of Coal and Pyrite 
The figure shows the newly selected line is well above clean coal. Despite this fact, a fairly even split of coal was found in both the dense particle collection bin, and the light particle collection bin, during preliminary testing. It has been determined that most of the coal would have most likely been at the higher end of the $150-210$ micron size range, thus causing a larger amount of material to gather in the dense collection bin at the lower gas velocity. This however was not the case for the actual test runs as most of the coal was at the smaller end of the 105 to 210 micron size range. A short discussion of this will follow in Chapter 6.

\subsection{Solids Mixture Composition}

For the sand and steel shot tests, a solids mixture of 15 pounds $(6.80 \mathrm{~kg})$ was used. For each mixture, 3 pounds (1.36 kg) of steel shot was added to 12 pounds (5.44) of sand, making for a $20 \%$ mixture of steel shot by weight. This allowed for an adequate mixture to see if the system could effectively separate the steel shot from the sand. For the coal test mixtures, a mixture of 10 pounds $(4.54 \mathrm{~kg})$ of crushed coal was used. Each batch of solids was stirred to ensure a homogenous mixture before they were added to the feed hopper. For the third project separating of pure pyrite from clean coal, pure pyrite chunks were ground to a size range of 105 to 210 micron. Approximately 0.3 pounds was added to the clean coal mixture to bring the percent of sulfur to a desired level.

\section{$\underline{4.4 \text { Selection of Mass Flux Values }}$}

One of the main variables in this study is the mass flow rate of the particles into the riser system. The amount of solids entering the system plays a great role in factors such as the regime the CFB operates in, and the separation efficiency. Regester (2004) noted some problems when operating the CFB system at high mass flux values. The 
particles entering into the system would sometimes form a bubbling bed in which the particles would bubble over the riser collection gap, thus disrupting proper flow. To correct this problem, riser bed wall extensions were created, which are discussed in Section 3.2.3. These extensions were created to allow a higher flow rate of air/solid mixture to enter the riser without the particles bubbling over and falling past the collection gap ring. The results found from changing the extensions to raise the collection ring wall height will be discussed in Chapter 5.

Regester (2004) completed sand and steel shot tests at varying mass flux ranges from $0.24 \mathrm{lb} / \mathrm{ft}^{2} \mathrm{~s}$ to $0.98 \mathrm{lb} / \mathrm{ft}^{2} \mathrm{~s}\left(1.17 \mathrm{~kg} / \mathrm{m}^{2} \mathrm{~s}\right.$ to $\left.4.78 \mathrm{~kg} / \mathrm{m}^{2} \mathrm{~s}\right)$. For this research project the sand and steel shot tests had mass flow rates from $1.2 \mathrm{lb} / \mathrm{min}$ to $3.0 \mathrm{lb} / \mathrm{min}$. All sand and steel shot runs completed for this study were completed between mass flux values of $0.149 \mathrm{lb} / \mathrm{ft}^{2} \mathrm{~s}$ to $0.367 \mathrm{lb} / \mathrm{ft}^{2} \mathrm{~s}\left(0.728 \mathrm{~kg} / \mathrm{m}^{2} \mathrm{~s}\right.$ to $\left.1.79 \mathrm{~kg} / \mathrm{m}^{2} \mathrm{~s}\right)$. Two various methods were used for selecting the mass flow rate of solids into the riser. One experimental variable for the sand and steel shot tests was to see the effect of having a higher velocity through either the transport tube, or the distributor, on the separation efficiency. The data from the test runs are shown in Table 5.3.a. Once the maximum velocity for each test was set through the transport tube (without exceeding the pressure limit of the system) the ball valve above the injector was opened so the solids mixture could enter the riser. Instead of aiming for a specific mass flow rate, the ball valve was opened until a steady state flow was started to ensure the test data would be valid. If the solids mixture did not enter the riser in a steady state flow, the test was re-run so that suitable data could be taken.

It was desired for the coal tests, to see how mass flow of solids into the system affected the separation efficiency. Three separate mass flow rates were run $-0.5 \mathrm{lb} / \mathrm{min}$, 
$1 \mathrm{lb} / \mathrm{min}$, and $2 \mathrm{lb} / \mathrm{min}(0.23 \mathrm{~kg} / \mathrm{min}, 0.45 \mathrm{~kg} / \mathrm{min}$, and $0.91 \mathrm{~kg} / \mathrm{min})$. The $0.5 \mathrm{lb} / \mathrm{min}$ value was decided upon because it allowed the solids mixture to enter into the riser at a low velocity. This ensured few particles would enter the dense collection bin due to bubbling. When the solids mixture entered the riser section faster or slower than desired, the test was stopped and re-run. Exact flow rates for both the sand and steel shot and coal test may be viewed in the experimental test matrices in Table 4.1.b and Table 4.1.c.

\subsection{Selection of Transport and Fluidization Air Flows}

In circulating fluidized beds, an injector such as the one described in Section

3.1.2 is commonly used. This design uses pneumatic flow to entrain the solids mixture in the transport tube, which is described in Section 3.2.3. According to Fan and Zhu (1998), no definitive theory has been proposed in devices such as this to accurately predict the air velocity needed to induce transportation. Some proposed equations, such as the Reynolds Transport number equation found in Fan and Zhu (1998), can be used to estimate this value, but the transportation velocity still relies more on the gas and particle properties. Another factor needing to be considered is the saltation velocity, which is the air velocity needed to keep particles mixed with the air flow in the transport tube. This keeps the particles from falling from the air flow and becoming stagnant in the transportation tube. For this research project, various velocities were used to find the best possible combination of air flow through the distributor and transport tube to allow for the best separation efficiency and operation of the system.

For the sand and steel shot tests, an overall volumetric flow rate of 170 Standard Cubic Meters per Hour (100 SCFM) was used, while the coal separation tests used a flow rate of 50.7 SCMH (30 SCFM). To arrive at the proper transportation velocities, several 
experimental test runs were completed to see what percentage of the air flow needed to be sent through the injector. The limiting factor in deciding this is the maximum pressure in which the feed hopper or transport tube could hold. The particle inlet into the riser is approximately $3 / 4$ inches in diameter with no nozzle installed. When a great amount of gas is used in the particle injector and transport tube back pressure would build up and be released into the feed hopper. This would create a dense-fluidized bed in which the solids mixture in the hopper would begin to bubble, thus aiding in the transportation process by aerating the mix.

The feed hopper was only designed to hold up to 12 psi before failure, thus being the deciding factor in pneumatic flow. In the experimental runs, with both the sand and steel shot and the coal mixtures, the pneumatic flow through the injector was increased until the feed hopper reached the maximum value of 12 psi. This value varied with the different nozzle sizes used for the different test runs.

One variable for the sand and steel shot mixture test runs was to investigate the effect of lowering or raising the transport velocity to produce more or less of a "jet" style flow into the riser. With a combination of different nozzles, two sets of test conditions were used. One set used a lower air velocity through the transport tube, thus leaving the remaining gas entering the riser through the distributor. The other set of conditions allowed most of the air to be passed through the transport tube, with the remaining gas being passed through the distributor plate. The air velocities used for the test conditions may be viewed in the Sand and Steel Shot Experimental Test Matrix Table 4.1.b.

For the coal test runs, a total pneumatic flow of 50.7 SCMH (30 SCFM) was used. The sand and steel shot test runs were used to determine how the nozzle/distributor flow 
would affect the separation process. It was found the other variables played a greater role in determining the efficiency of separation. It was therefore determined that using a $50 \%$ split of the gas velocities between the distributor plate and transport tube would provide adequate fluidization of the particles, while providing efficient operation of the riser. This meant the velocity profile in the riser could only be manipulated with the nozzles that were installed in the particle inlet into the riser. The Coal Test Run Experimental Test Matrix may be viewed in Table 4.1.c.

\subsection{Experimental Uncertainty}

There were a few experimental uncertainties during testing. The particle injector is pneumatically operated. This made a steady flow rate into the system very hard to obtain during some test conditions. If the data acquisition system showed any signs of the mass flux being irregular, the test was stopped and re-run.

All scales used in measuring fine amounts of material measured to the thousandths place (.001) grams. All scales used to measure larger amounts of material read to the tenths place (.1) grams. This allowed minute room for error in the measurements. All measurements were taken after the weight of the containers holding the samples were tarried, allowing even less room for error.

The ICP machine used by the NRCCE Chemical Analysis Lab is very accurate in measurements. However, only a small amount of material (less than one gram) was used to achieve the results. Coal is very inhomogeneous by nature. The small amount of material used could have produced skewed results. Three samples, per collection bin, were therefore used to obtain an overall percentage of sulfur for each desired value. 


\section{Chapter 5: Sand and Steel Shot Separation Projects}

\subsection{Initial CFB Tests}

Initial test runs were completed in the CFB riser to observe what flow rates of solids and air would be needed to be completed for proper separation to occur. It was also noted during this time the general effects of the nozzles and the higher collection ring wall height on the air-solid mixture to see if particles bubbled over the collection ring. Preliminary calculations were completed to find the terminal velocities of the sand and steel shot mixture being used, which in turn determined the superficial gas velocity in the riser. A 15 pound $(6.80 \mathrm{~kg})$ mixture of sand and steel shot was arbitrarily selected to be 3 pounds of steel shot, and 12 pounds of sand, as with characteristics described in Section 4.3. This mixture was run through the system so that observations could be made as to the effect different test conditions created.

\subsubsection{Clusters Along the Wall}

Regester (2004) states clusters of the solids mixture will form along the wall of the riser as particles come down to be re-entrained in the flow or enter the dense collection bin. During initial testing, it was noted a dense region of particles were indeed distinguishable, and clusters of particles did form as they traveled down along the riser wall. The clusters forming along the wall were sometimes clumped together, but usually took the form of a "stream" of particles coming down the wall. Two pictures were taken during the initial runs which show the cluster and stream formations falling along the wall. They can be viewed in Figure 5.1.1.a. 


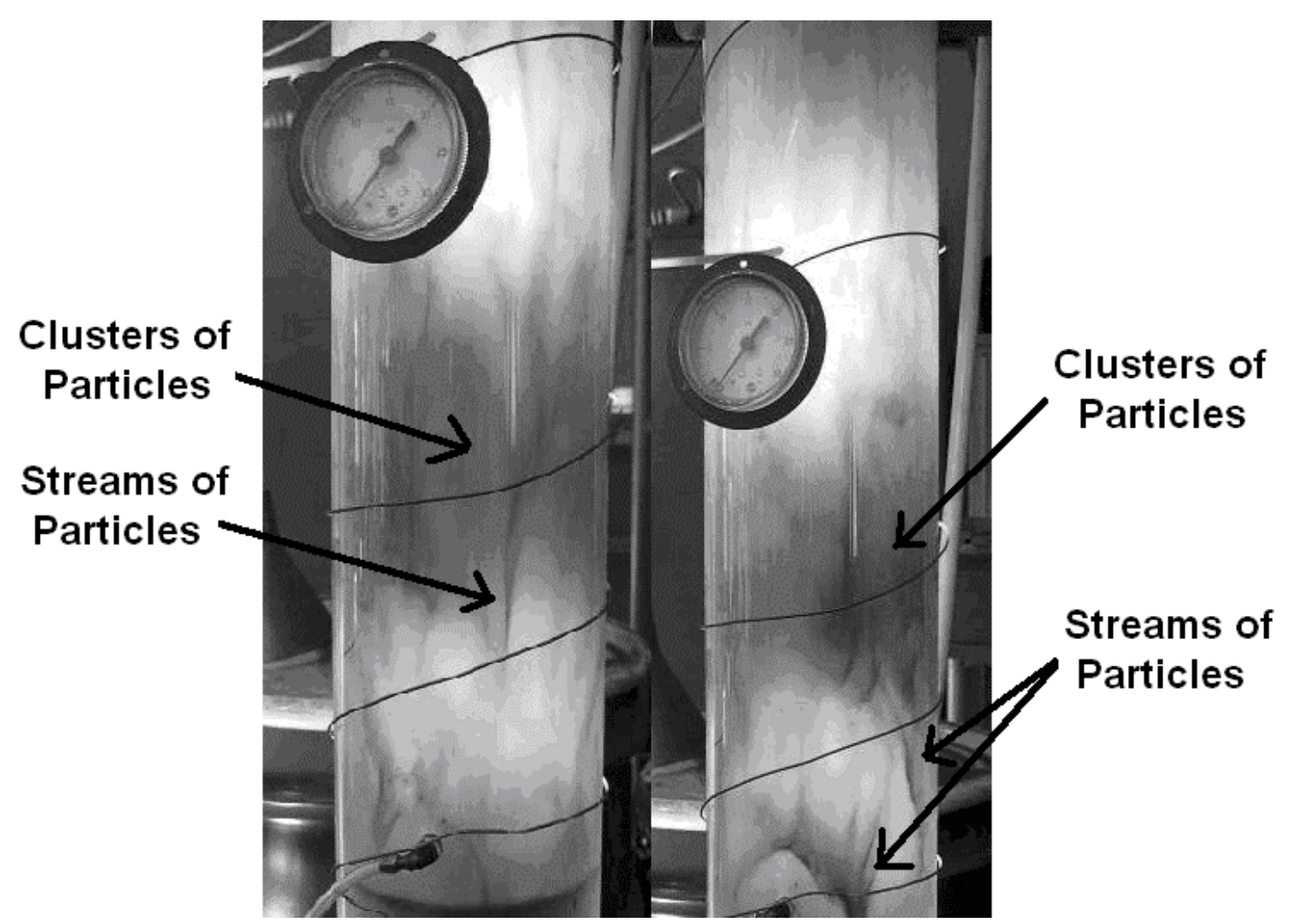

Figure 5.1.1.a Cluster and Stream formations of sand and steel shot mixture traveling down along the riser wall

\subsubsection{Nozzle Effect on Particle Flow}

When running the initial sand and steel shot mixture, different nozzle sizes were installed to see the effect they would have on the flow. The 14/32-inch $(1.111 \mathrm{~cm})$ nozzle was the smallest size that could be used with the sand and steel shot due to back pressure in the feed hopper. With the $9 / 32$-inch $(0.714 \mathrm{~cm})$ nozzle installed in the riser, the back pressure in the feed hopper reached 12 psi at different points of the test. It was at this point that the feed hopper would then fail, or the joints would come apart, thus disrupting the test.

It was observed with no nozzle in place, the particles would form clusters along the wall as they traveled downwards towards the dense particle collection bin. As the nozzles were installed, however, it was observed that an area of turbulence would form 
towards the bottom of the riser near the wall. As the nozzle diameter decreased, a larger region of turbulence along the wall of the riser was viewed. The effects were noted on both the sand and steel shot, and coal separation tests. Figure 5.1.2.a shows a picture taken during a coal separation test in which the 7/32-inch $(0.556 \mathrm{~cm})$ nozzle was installed. The area where the cluster/stream formations end and the turbulence begins is marked.

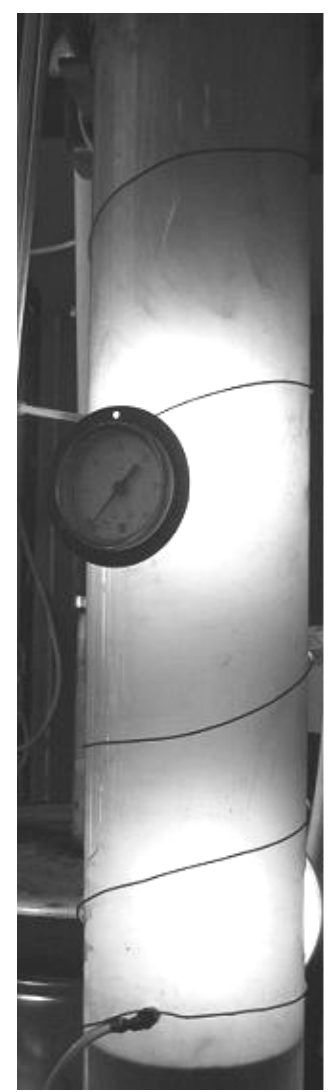

End of Cluster/Stream

Formation Area -

Beginning of Turbulent

Flow Area

Figure 5.1.2.a Beginning of Turbulent Particle Flow/End of Cluster Flow 


\subsubsection{Effect of the Collection Ring Wall Height}

It was noted by Regester (2004) that some bubbling of the solids mixture occurred in which particles in the bed would bubble over and immediately pass the collection ring. For this research project, two different sections were made that would extend this collection ring wall height, thus extending the area of the particle bed. It was hoped if the particles could be kept from bubbling over the collection ring, that a higher mass flux of solids could be run through the riser without affecting the separation efficiency. Both of the rings were higher than that previously used by Regester (2004) and Almond (2005). It was observed with the raised collection ring wall height the particles did not bubble over and spill past the collection ring. It was therefore determined that the sections made to raise this ring height worked effectively. The results of raising this collection ring height are discussed in Section 5.3.4.

\subsection{Introduction to the Sand and Steel Shot Separation Project}

The first separation project consisted of taking a mixture of play sand and steel shot to separate and selecting a specific size range of material. The mixture, described in Section 4.3, was run through the circulating fluidized bed to see how well the system could separate the steel shot from the sand. Several variables were investigated during the test runs of the mixture. The material was then collected from the dense particle and light particle collection bins. The steel shot was then separated by magnet from the sand to check the efficiency of the system. 


\subsection{Separation by Density of Steel Shot from Sand}

\subsubsection{Introduction}

The Circulating Fluidized Bed riser system in the NRCCE high bay at West Virginia University has shown potential in past research as a suitable method of dry particle separation. This separation process was based upon either the size or the density of the material being separated in previous research. To further show the prospective uses of the riser system, a series of experiments have been developed based on separation by density, which will help to show improved efficiency of the CFB.

\subsubsection{Material Preparation}

The material used for this portion of the research project was Quickcrete play sand and steel shot. The sand and steel shot were run through US Standard mesh sieves as described in Section 4.2.2 to reach a size range of $250-500$ micron. A mixture of 12 pounds $(5.44 \mathrm{~kg})$ of sand and 3 pounds $(1.36 \mathrm{~kg})$ of steel shot was used to give a $20 \%$ ratio of steel shot to sand by mass. The mixture was then loaded into the feed hopper after being mixed thoroughly to provide a homogeneous mixture.

The CFB riser system was set up with the original geometry used by (Almond 2005) with the noted changes from Chapter 3. The configuration of the riser system is discussed in Section 4.1. To determine the superficial gas velocities, an analysis was completed on the sand and steel shot particles being used. A description of this is found in Section 4.2.2. Different size collection ring wall height and different nozzle sizes were also used. All of these variables played a role into the mass flux, gas velocity, and geometries used in the riser and are shown in the Sand and Steel Shot Experimental Test Matrix in Table 4.1.b. 


\subsubsection{Analysis of Sand and Steel Shot Test Results}

To determine how well the CFB separated the steel shot from the sand, the dense particle mass fraction and dense particle collection efficiency were calculated. To determine the values, the sand and steel shot were taken from the dense particle collection bin. The total weight of all material in the dense collection bin was then recorded. A magnet was then passed through the mixture extensively in which all of the steel shot was collected. The sand and steel shot were then completely separated, and the weights of each were recorded. To determine the dense particle mass fraction the following equation was used:

Dense Particle Collection Efficiency $=\frac{\text { Mass of Steel Shot in Dense Bin }}{\text { Initial Steel Shot Mass }} * 100$

To determine the dense particle collection efficiency, the following equation was used:

Dense Particle Mass Fraction $=\frac{\text { Mass of Steel Shot in Dense Bin }}{\text { Total Mass in Dense Collection Bin }} * 100$

\subsubsection{Discussion of Sand and Steel Shot Results}

The circulating fluidized bed previously discussed was investigated as a viable means of dry particle separation. For the sand and steel shot test runs, all dense particle mass fraction values were found to be above $90 \%$. The dense particle collection efficiency for all twelve runs was found to be above $70 \%$, while most of the values fell between $80-90 \%$. Figure 5.3.4.a shows the dense particle mass fraction for all runs, while Figure 5.3.4.b shows the dense particle collection efficiency for all runs. Table 5.3.a shows the collection efficiency and mass fraction values, along with the test conditions for the sand and steel shot runs. One of the main variables examined during these tests was the nozzle/distributor air flow. It was determined from the data that the 
amount of air flowing to either the nozzle or the distributor did not affect he separation as much as the other variables involved. It is therefore determined that there is no trend for these values, and will not be evaluated for the coal test runs.

\begin{tabular}{|c|c|c|c|c|c|c|c|c|c|}
\hline \multicolumn{8}{|c|}{ Sand and Steel Shot Separation Test Runs - 250-500 Micron Size Range } \\
\hline $\begin{array}{c}\text { Run } \\
\text { Number }\end{array}$ & $\begin{array}{c}\text { Total } \\
(\text { SCMH) }\end{array}$ & $\begin{array}{c}\text { Distributor } \\
\text { Flow } \\
(\text { SCMH) }\end{array}$ & $\begin{array}{c}\text { Transport } \\
\text { Flow } \\
(\text { SCMH })\end{array}$ & $\begin{array}{c}\text { Particle } \\
\text { Inlet Size } \\
(\mathrm{cm})\end{array}$ & $\begin{array}{c}\text { Mass Flux } \\
\left(\mathrm{kg} / \mathrm{m}^{\wedge} 2 \mathrm{~s}\right)\end{array}$ & $\begin{array}{c}\text { Ring } \\
\text { Wall } \\
\text { Height } \\
(\mathrm{m})\end{array}$ & $\begin{array}{c}\text { Dense } \\
\text { Mass } \\
\text { Fraction }\end{array}$ & $\begin{array}{c}\text { Dense } \\
\text { Collection } \\
\text { Efficiency }\end{array}$ & $\begin{array}{c}\text { Nozzle } \\
\text { Flow }\end{array}$ \\
\hline 1 & 169.0 & 108.2 & 60.8 & 1.905 & 0.725 & 0.3048 & $99.40 \%$ & $78.00 \%$ & 36.0 \\
\hline 2 & 172.9 & 51.2 & 121.7 & 1.905 & 0.81 & 0.3048 & $99.30 \%$ & $84.80 \%$ & 70.4 \\
\hline 3 & 170.0 & 109.3 & 60.8 & 1.270 & 0.893 & 0.3048 & $97.90 \%$ & $84.40 \%$ & 35.7 \\
\hline 4 & 167.6 & 68.4 & 99.2 & 1.270 & 1.49 & 0.3048 & $93.40 \%$ & $81.50 \%$ & 56.2 \\
\hline 5 & 168.2 & 113.2 & 60.7 & 1.111 & 0.746 & 0.3048 & $92.20 \%$ & $91.60 \%$ & 36.1 \\
\hline 6 & 169.0 & 94.0 & 76.9 & 1.111 & 0.893 & 0.3048 & $96.50 \%$ & $93.30 \%$ & 45.5 \\
\hline 7 & 169.0 & 108.2 & 60.8 & 1.905 & 1.05 & 0.381 & $99.40 \%$ & $89.10 \%$ & 36.0 \\
\hline 8 & 170.0 & 47.5 & 122.5 & 1.905 & 1.27 & 0.381 & $90.30 \%$ & $70.80 \%$ & 72.1 \\
\hline 9 & 170.0 & 109.3 & 60.8 & 1.270 & 0.81 & 0.381 & $97.00 \%$ & $81.70 \%$ & 35.7 \\
\hline 10 & 167.6 & 68.4 & 99.2 & 1.270 & 1.19 & 0.381 & $97.40 \%$ & $85.20 \%$ & 59.2 \\
\hline 11 & 170.5 & 111.4 & 59.2 & 1.111 & 1.05 & 0.381 & $99.70 \%$ & $86.50 \%$ & 34.7 \\
\hline 12 & 168.2 & 93.5 & 74.9 & 1.111 & 1.79 & 0.381 & $98.80 \%$ & $84.70 \%$ & 44.5 \\
\hline
\end{tabular}

Table 5.3.a Results of Sand and Steel Shot Separation Tests

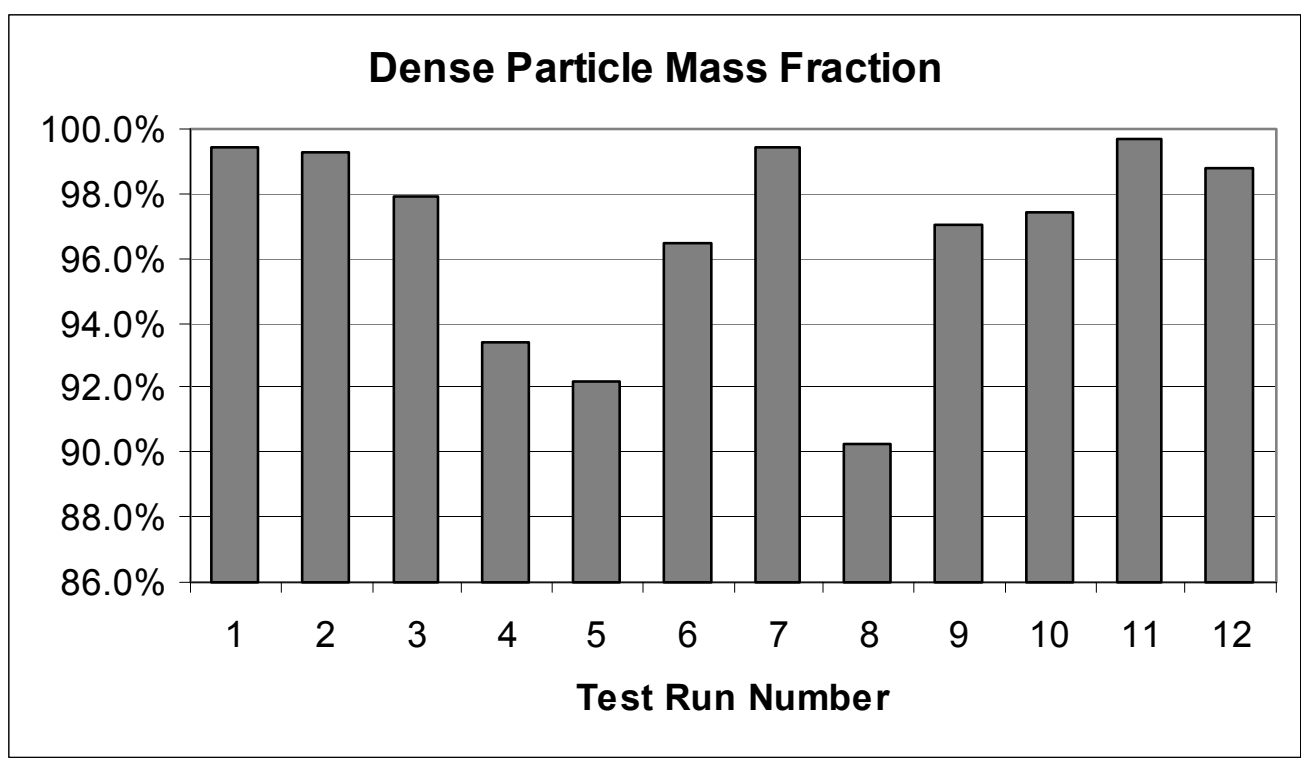

Figure 5.3 4.a Dense Particle Mass Fraction for Sand and Steel Shot Runs 


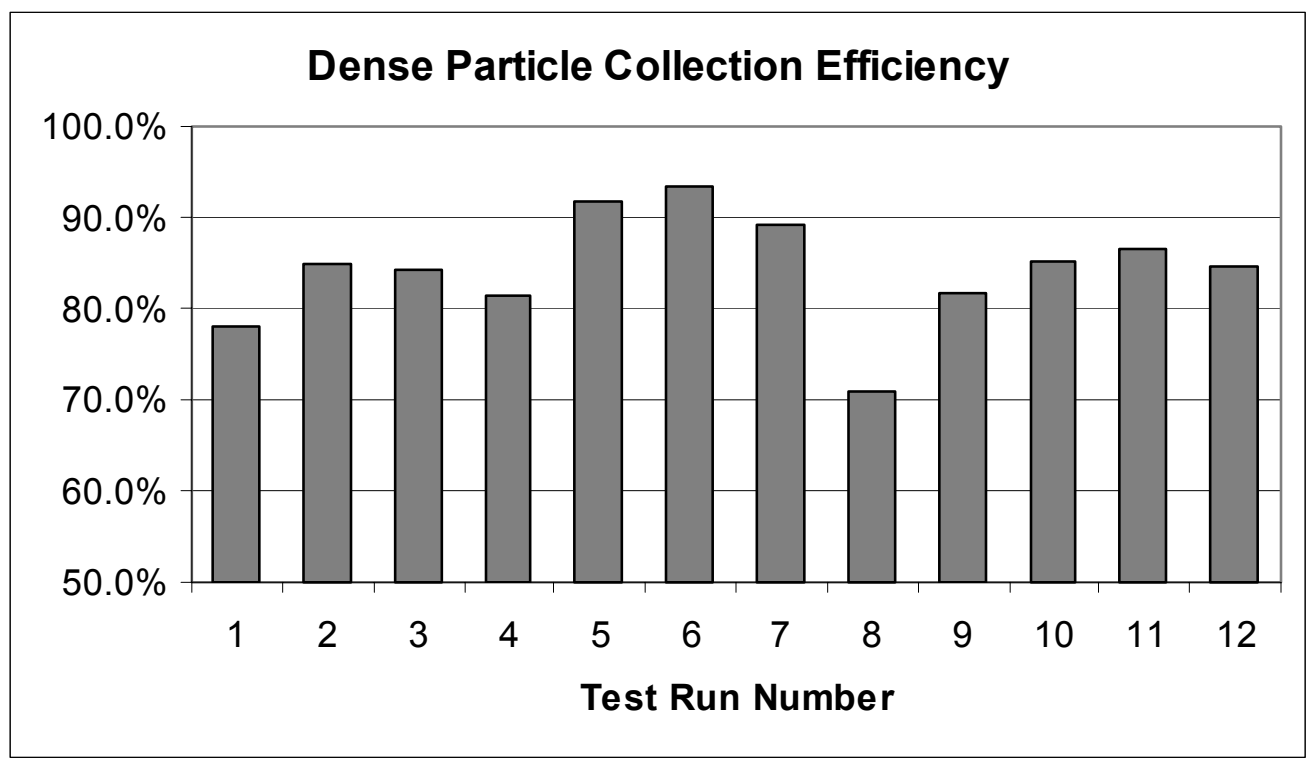

Figure 5.3.4.b Dense Particle Collection Efficiency for Sand and Steel Shot Runs

As shown in Figure 5.3.4.a the highest mass fraction values occurred for runs 1,

2, 7, and 11 - all which have mass fraction values above 99\%. Figure 5.3.4.b shows that some of the higher collection efficiency values occurred for runs 5 and 6 , which have some of the lower mass fraction values. The collection efficiencies for runs 5 and 6 were both above $91 \%$.

On average, the 0.3048 meter high collection ring wall height showed the greatest collection efficiencies. It is believed the reason behind this is the dissipation of the jet effects downstream. As described in Chapter 2, in jet flows, the modification of the gas and particle velocity profiles, due to the jet, will dissolve as the flow moves downstream. Figure 2.5.e shows that at 10 nozzle diameters downstream, the velocity profile has changed dramatically. In this experiment, the effect of the nozzle has potentially dissipated by the time it reaches the top of the bed wall. The nozzle effect will not have worn off as the particles reach the top of the bed wall. This has likely allowed better separation efficiencies when using the nozzles for the lower collection ring wall height. 
Shown in Figure 5.3.4.c and Figure 5.3.4.d are the dense particle mass fraction and dense particle collection efficiency versus the mass flux values. As shown in Figure 5.3.4.c, for the dense mass fraction values vs. the mass flux values, a trend exists for the $1.905 \mathrm{~cm}$ and $1.111 \mathrm{~cm}$ nozzle sizes in which the highest mass fraction values occur near a mass flux value of $1 \mathrm{~kg} / \mathrm{m}^{2} \mathrm{~s}$. The $1.270 \mathrm{~cm}$ nozzle has a lower value near this mass flux. Due to the fact all mass fraction values are above $90 \%$, it would only take a slight change in values to skew the data. The particular values for the $1.270 \mathrm{~cm}$ nozzle test could have been affected by other factors, such as pressure fluctuations, in the system. As seen in Figure 5.3.4.d a similar trend exists for the dense collection efficiency vs. mass flux values for the $1.905 \mathrm{~cm}$ and $1.270 \mathrm{~cm}$ nozzle size in which the highest collection efficiency values occur near $1 \mathrm{~kg} / \mathrm{m}^{2} \mathrm{~s}$.

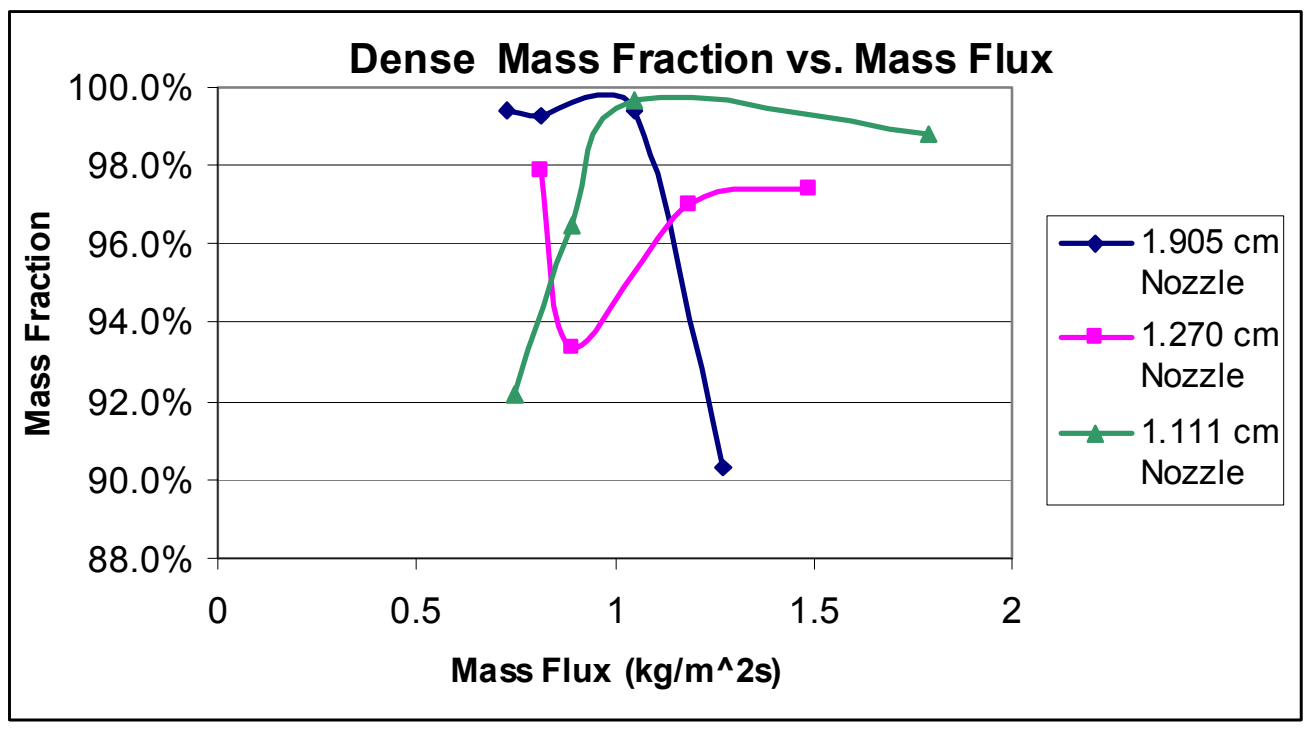

Figure 5.3.4.c Dense Mass Fraction vs. Mass Flux for Sand and Steel Shot Tests 


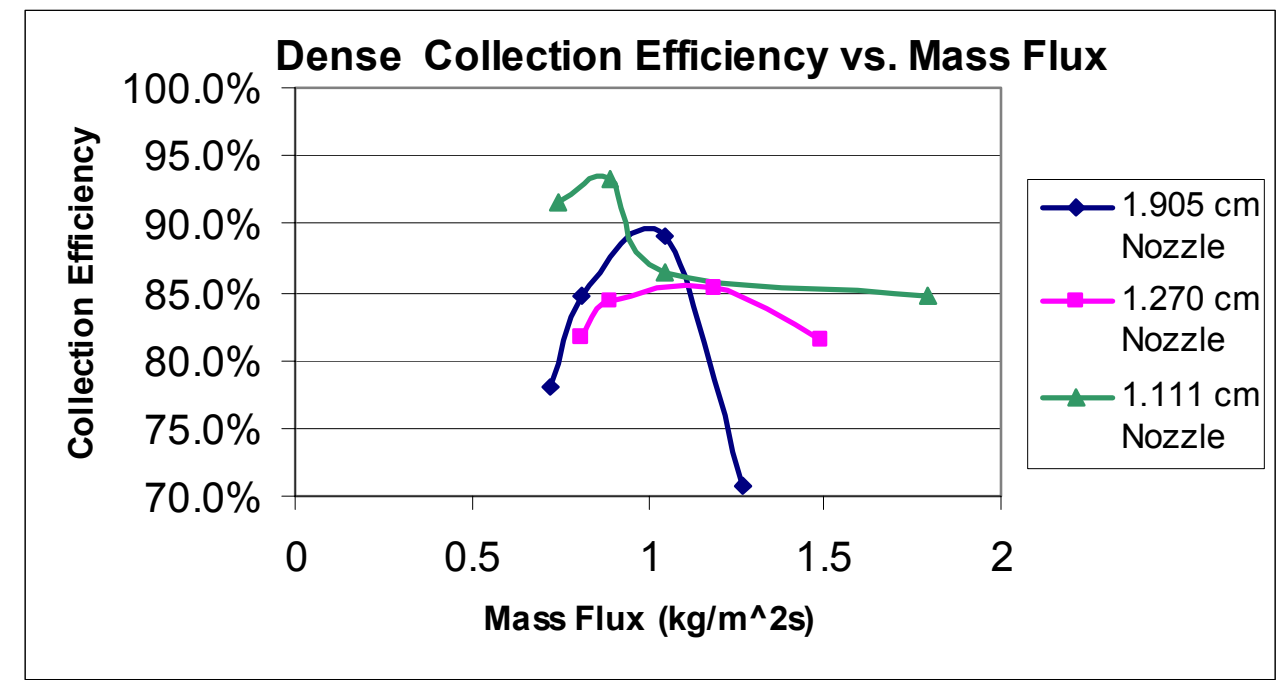

Figure 5.3.4.d Dense Collection Efficiency vs. Mass Flux for Sand and Steel Shot Tests

One of the main variables in dealing with this separation project was to see the effect of limiting the size of the particle entrance into the riser. This was accomplished by installing nozzles of different sizes that would force the particles into more of a concentric jet style flow. Another variable was to either force more of the volumetric flow rate of air either through the distributor plate or the transport tube, thus also forcing more of a concentric jet style flow. The main trend that was noticed is that with a 0.3048-meter high ring collection wall that the dense particle mass fraction decreased, as the nozzle sizes decreased (for regular style flow). Contradictorily the dense particle collection efficiency increases as the nozzle size decreases. It was also noted that when more of the air was forced through the transport tube the dense particle mass fraction values increased as the nozzle size decreased, when using the .381-meter high collection ring wall height. These trends are shown in graph form in Figure 5.3.4.e, Figure 5.3.4.f and Figure 5.3.4.g. 


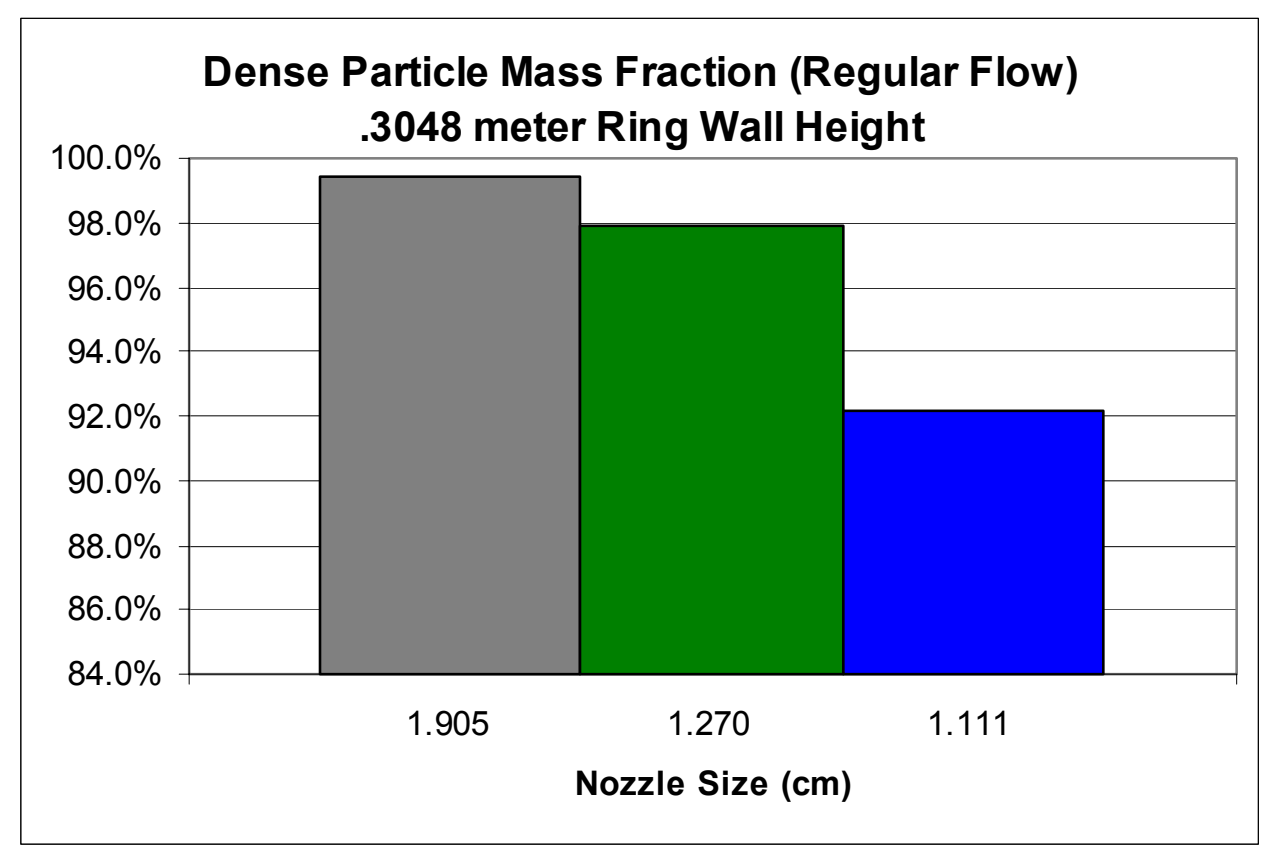

Figure 5.3.4.e Dense Particle Mass Fraction as a Function of Nozzle Size (Regular Flow)

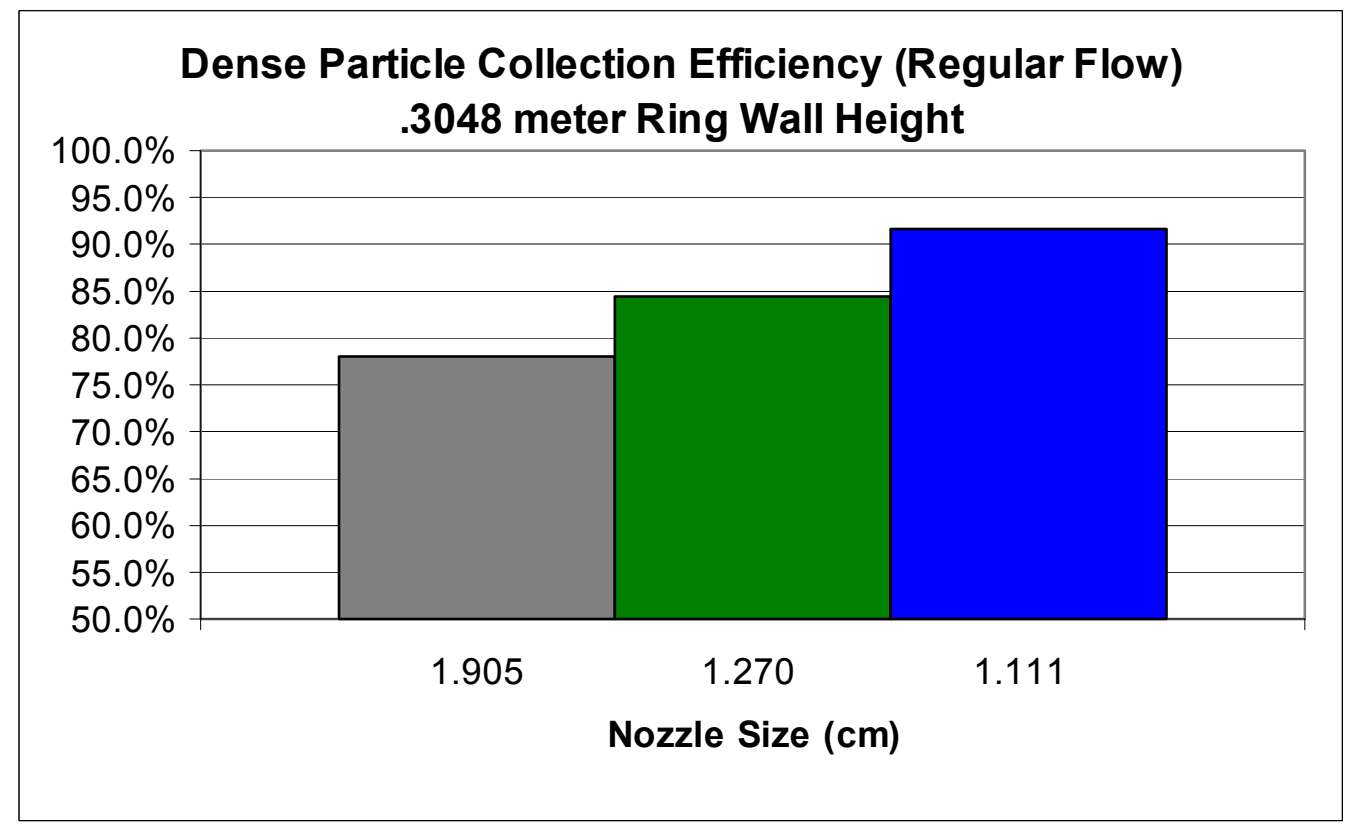

Figure 5.3.4.f Dense Particle Collection Efficiency as a Function of Nozzle Size (Regular Flow) 


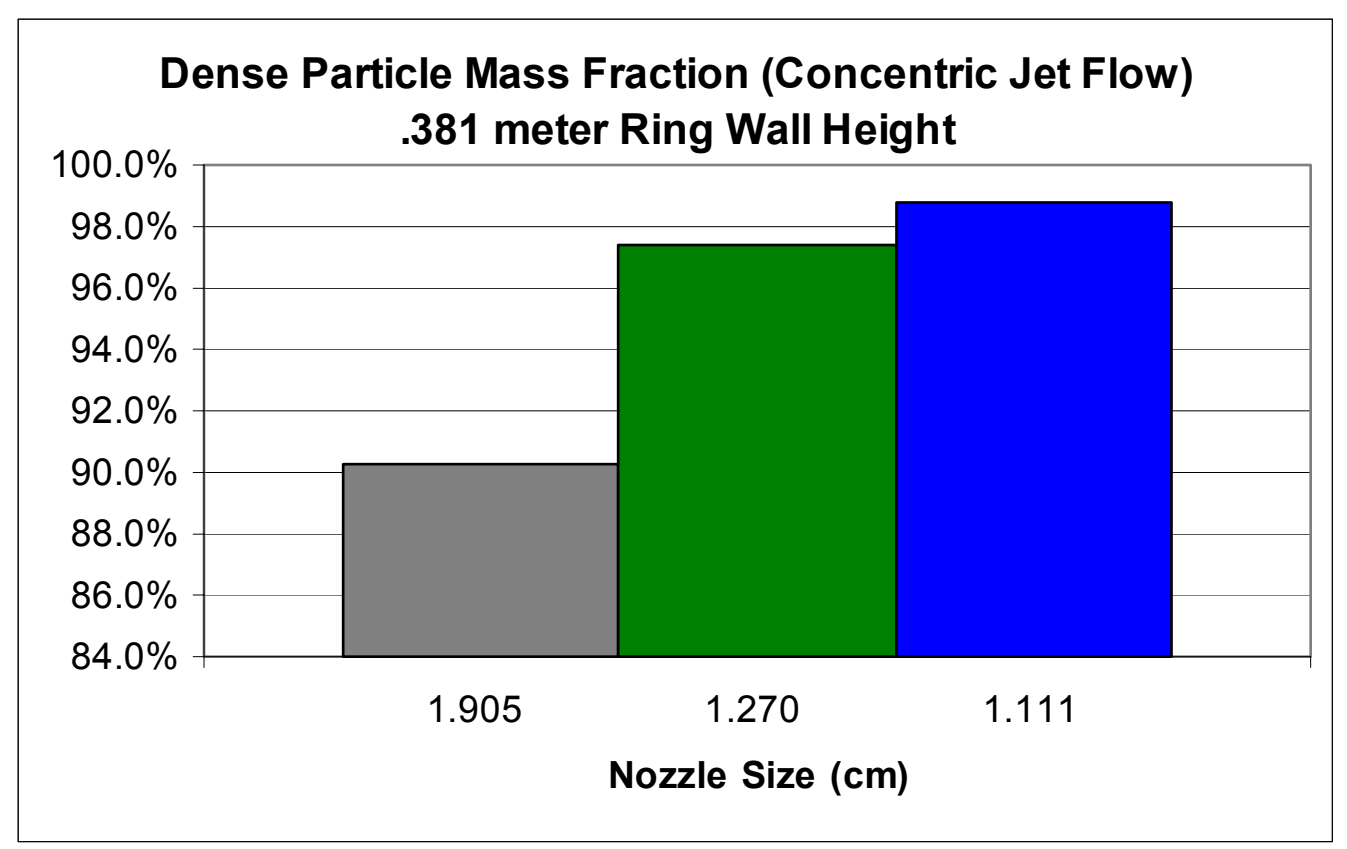

Figure 5.3.4.g Dense Particle Mass Fraction as a Function of Nozzle Size (Concentric Jet Flow)

It is believed that the reasoning behind the mass fraction being higher for the raised collection ring wall height, for smaller nozzle sizes, is the area of turbulence as described earlier in Section 5.1.2. As the turbulent area of particle flow is found to be higher up in the riser, more of the particles would be collected as the collection ring wall height is raised to reduce the amount of turbulent flow the mixture must travel through.

No other notable trends were found during the sand and steel shot test runs. All other graphs and comparisons for this study are found in Appendix B. Also shown are pictures of the sand and steel shot mixture taken previous to and after separation. It is decided for the best possible mass fraction rates that a medium sized nozzle of $1.27 \mathrm{~cm}$ should be used with either size collection ring wall height. To achieve the best possible collection efficiency, in most cases, the smallest nozzle size possible, with the highest collection ring wall height should be used. It is inconclusive whether it is better to use more air through the distributor plate or the transport tube. 


\section{Chapter 6: Separation of Pyrite Laden Coal from Clean Coal}

\section{$\underline{6.1 \text { Introduction }}$}

The CFB riser system has shown potential in past research as a viable means of dry separation for mineral matter from coal. This separation process was based upon the density difference of the mineral matter being separated from the clean coal. To further demonstrate this type of dry separation potential of the riser, a series of experiments has been developed that will aim to achieve better separation efficiency. The second separation project involved running the same circulating fluidized bed with a mixture of coal to see if pyrite laden coal could be extracted.

\subsubsection{Preparation of Materials and Test Conditions}

Coal was taken from the Kingwood Coal Company, and crushed down to a size range of 105 - 210 microns. Approximately $4.536 \mathrm{~kg}$ (10 pounds) of the coal mixture, described in Section 4.3, was placed in the feed hopper of the CFB riser system to be run during the experiments. The riser system was configured with the geometry shown in Table 4.1.a.

To determine the superficial gas velocities needed, an analysis was completed on the coal particles being used. To do this, the two particles considered were a clean coal particle, and a coal particle laden with pyrite. This analysis is discussed further in

Section 4.2.2. The other test conditions were determined through the initial test runs completed and by selecting the variables that would be used for the tests. The variables are discussed further in Section 4.1.3. It should also be noted that all test runs used a $50 \%$ split of the air flow between the distributor plate and the transport tube as discussed previously. All other test variables are shown in the coal test matrix in Table 4.1.c 


\subsection{Analysis of Coal Test Runs}

To analyze the data for the coal separation test runs, the dense and light (product) particle collection bins were emptied and the material was weighed accordingly. From each of these bins, three small samples of coal, approximately 3-5 grams in mass, were taken from the dense and product collection bins and then placed in Ziploc bags. The samples were then taken to the NRCEE Chemical Analysis lab to be checked for the content of overall sulfur, as described in Section 3.3.6. The water filter was put into place for the tests as it was determined that there was not enough coal in the filters to effect the separation process. The paper filtration system was put into place for the initial tests, but it was found that several tests had to be completed in order to retrieve a uniform sample. One such sample was taken and is listed in Table 6.3.a. It was also deemed inefficient to replace both of the filter bags used for every test run completed.

The results from the chemical analysis lab were reported in total percentage of sulfur found in the coal. The total weight of material from the dense particle and light (product) particle collection bins were listed, as well as the initial weight of the coal. The values were then used to determine how much weight should have been found in the filter bags. Using the total percentage of sulfur reported from the chemical analytical lab, the overall mass of sulfur found in each of the bins was then calculated. To determine the initial mass of sulfur in the sample, the masses of the dense and product collection bins were added together. This initial mass of sulfur was then taken and divided by the initial mass of coal to find what the initial percentage of sulfur in the sample should be. Initial samples were taken throughout testing, and it was found that the coal mixture was heterogeneous with sulfur content. This is the reasoning behind the initial sulfur 
percentages being found from the total masses of the sulfur in the dense and product collection bins.

To check the separation efficiency of the riser system for the coal, a percent change in sulfur was found for the dense and product bins. To find this value, a percent change was found by using the following equation:

Percent Change in Sulfur $=\frac{\text { Percent Sulfur in Dense } / \text { Product }- \text { Initial Percent Sulfur }}{\text { Initial Percent Sulfur }} * 100$

The percent change in sulfur was the value used to measure the overall efficiency of the system.

To further analyze the coal material, an initial sample, and a sample from the dense and product collection bins from 8-30-06 run 3 were taken and looked at under a Scanning Electron Microscope (SEM). A spectrum was taken to analyze the sulfur content found in each of the samples. Pictures were also taken at a magnification of $x 250$ to make a comparison of particle size.

\subsection{Discussion of Coal Test Results}

The coal mixture was run through the circulating fluidized bed to separate the clean coal from the pyritic coal. Table 6.3.a contains the test data results for the coal tests. The test run numbers are shown, along with the individual percent of sulfur in each of the samples taken, and the average percent of sulfur found in each of the bins. The calculated initial percent sulfur, the weights of coal found in each of the bins, the initial mass of sulfur and sulfur found in each of the bins, and the percentage change in sulfur are also shown in the table.

The percentage of mass found in each bin should also be noted. Mass recovery for the dense particle collection bin was lower for the lower gas velocity. Once the gas 
velocity was raised, a recovery rate of approximately $60 \%$ was found for the dense collection bin. Approximately $40 \%$ of the mass was recovered for the product collection bin. Since the dense particle collection bin contained less sulfur, it would be the coal that would be passed on to the combustion boilers. The $60 \%$ recovery rate was viewed as being satisfactory. 


\begin{tabular}{|c|c|c|c|c|c|c|c|c|c|c|c|c|c|c|c|}
\hline \multicolumn{16}{|c|}{ Coal Test Data - 105-210 micron size range } \\
\hline $\begin{array}{c}\text { Run } \\
\text { Number }\end{array}$ & Test Number & 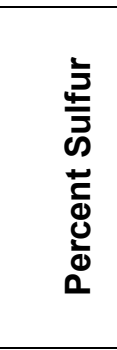 & 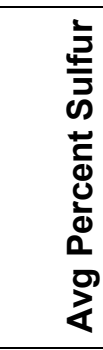 & 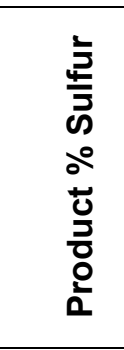 & 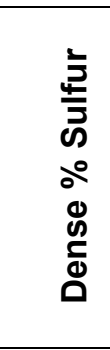 & 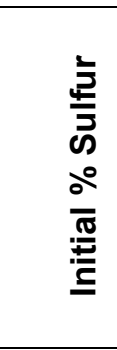 & 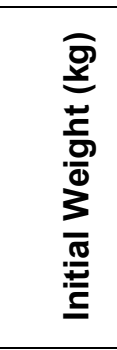 & 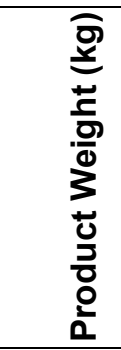 & 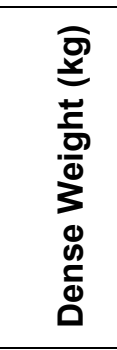 & 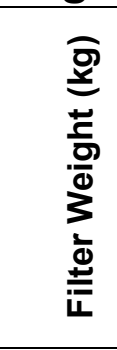 & 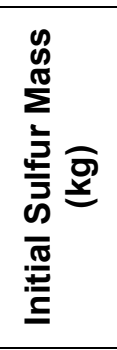 & 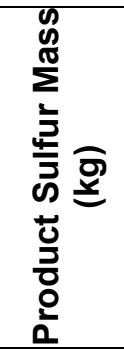 & 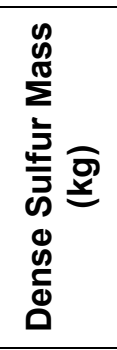 & 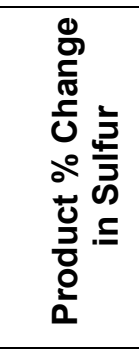 & 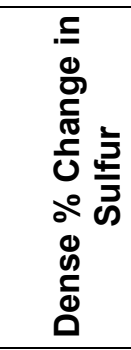 \\
\hline 1 & $\begin{array}{l}\text { 8-16-06-01 Dense } 1 \\
\text { 8-16-06-01 Dense } 2 \\
\text { 8-16-06-01 Dense } 3 \\
\text { 8-16-06-01 Product } 1 \\
\text { 8-16-06-01 Product } 2 \\
\text { 8-16-06-01 Product } 3\end{array}$ & $\begin{array}{l}0.770 \\
0.750 \\
0.710 \\
0.870 \\
0.820 \\
0.760\end{array}$ & $\begin{array}{l}0.743 \\
0.817\end{array}$ & 0.817 & 0.743 & 0.754 & $\begin{array}{l}4.536 \\
4.536\end{array}$ & 1.583 & 2.862 & 0.091 & 0.034 & 0.013 & 0.021 & 8.303 & -1.423 \\
\hline 2 & $\begin{array}{l}\text { 8-16-06-02 Dense } 1 \\
\text { 8-16-06-02 Dense } 2 \\
\text { 8-16-06-02 Dense } 3 \\
\text { 8-16-06-02 Product } 1 \\
\text { 8-16-06-02 Product } 2 \\
\text { 8-16-06-02 Product } 3\end{array}$ & $\begin{array}{l}0.740 \\
0.750 \\
0.740 \\
0.850 \\
0.850 \\
0.950\end{array}$ & 0.743 & 0.883 & 0.743 & 0.786 & $\begin{array}{l}4.536 \\
4.536\end{array}$ & 1.960 & 2.468 & 0.109 & 0.036 & 0.017 & 0.018 & 12.387 & -5.425 \\
\hline 3 & $\begin{array}{l}\text { 8-17-06-01 Dense } 1 \\
\text { 8-17-06-01 Dense } 2 \\
\text { 8-17-06-01 Dense } 3 \\
\text { 8-17-06-01 Product } 1 \\
\text { 8-17-06-01 Product } 2 \\
\text { 8-17-06-01 Product } 3\end{array}$ & $\begin{array}{l}0.790 \\
0.880 \\
0.860 \\
1.000 \\
1.020 \\
0.990\end{array}$ & $\begin{array}{l}0.843 \\
1.003\end{array}$ & 1.003 & 0.843 & 0.906 & $\begin{array}{l}4.536 \\
4.536\end{array}$ & 2.136 & 2.332 & 0.068 & 0.041 & 0.021 & 0.020 & 10.738 & -6.921 \\
\hline 4 & $\begin{array}{l}\text { 8-17-06-02 Dense } 1 \\
\text { 8-17-06-02 Dense } 2 \\
\text { 8-17-06-02 Dense } 3 \\
\text { 8-17-06-02 Product } 1 \\
\text { 8-17-06-02 Product } 2\end{array}$ & $\begin{array}{l}0.900 \\
0.880 \\
0.910 \\
1.170 \\
1.020\end{array}$ & 1.073 & 1.073 & 0.897 & 0.970 & 4.536 & 2.146 & 2.341 & 0.050 & 0.044 & 0.023 & 0.021 & 10.611 & -7.595 \\
\hline
\end{tabular}




\begin{tabular}{|c|c|c|c|c|c|c|c|c|c|c|c|c|c|c|c|}
\hline & 8-17-06-02 Product 3 & 1.030 & & & & & & & & & & & & & \\
\hline 5 & $\begin{array}{l}\text { 8-17-06-03 Dense } 1 \\
\text { 8-17-06-03 Dense } 2 \\
\text { 8-17-06-03 Dense } 3 \\
\text { 8-17-06-03 Product } 1 \\
\text { 8-17-06-03 Product } 2 \\
\text { 8-17-06-03 Product } 3\end{array}$ & $\begin{array}{l}1.030 \\
0.970 \\
0.840 \\
1.140 \\
1.150 \\
1.110\end{array}$ & $\begin{array}{l}0.947 \\
1.133\end{array}$ & 1.133 & 0.947 & 1.025 & $\begin{array}{l}4.536 \\
4.536\end{array}$ & 1.524 & 3.084 & -0.073 & 0.046 & 0.017 & 0.029 & 10.619 & -7.600 \\
\hline 6 & $\begin{array}{l}\text { 8-18-06-01 Dense } 1 \\
\text { 8-18-06-01 Dense } 2 \\
\text { 8-18-06-01 Dense } 3 \\
\text { 8-18-06-01 Product } 1 \\
\text { 8-18-06-01 Product } 2 \\
\text { 8-18-06-01 Product } 3\end{array}$ & $\begin{array}{l}0.930 \\
0.940 \\
0.920 \\
1.150 \\
1.240 \\
1.140\end{array}$ & $\begin{array}{l}0.930 \\
1.177\end{array}$ & 1.177 & 0.930 & 1.036 & $\begin{array}{l}4.536 \\
4.536\end{array}$ & 1.814 & 2.758 & -0.036 & 0.047 & 0.021 & 0.026 & 13.566 & -10.241 \\
\hline 7 & $\begin{array}{l}\text { 8-18-06-02 Dense } 1 \\
\text { 8-18-06-02 Dense } 2 \\
\text { 8-18-06-02 Dense } 3 \\
\text { 8-18-06-02 Product } 1 \\
\text { 8-18-06-02 Product } 2 \\
\text { 8-18-06-02 Product } 3\end{array}$ & $\begin{array}{l}1.050 \\
0.970 \\
1.080 \\
1.110 \\
1.050 \\
1.010 \\
\end{array}$ & $\begin{array}{l}1.033 \\
1.057\end{array}$ & 1.057 & 1.033 & 1.036 & $\begin{array}{l}4.536 \\
4.536\end{array}$ & 1.833 & 2.672 & 0.032 & 0.047 & 0.019 & 0.028 & 2.041 & -0.212 \\
\hline 8 & $\begin{array}{l}\text { 8-21-06-01 Dense } 1 \\
\text { 8-21-06-01 Dense } 2 \\
\text { 8-21-06-01 Dense } 3 \\
\text { 8-21-06-01 Product } 1 \\
\text { 8-21-06-01 Product } 2 \\
\text { 8-21-06-01 Product } 3\end{array}$ & $\begin{array}{l}0.900 \\
0.950 \\
1.080 \\
0.970 \\
1.010 \\
1.090\end{array}$ & $\begin{array}{l}0.977 \\
1.023\end{array}$ & 1.023 & 0.977 & 0.998 & $\begin{array}{l}4.536 \\
4.536\end{array}$ & 1.370 & 3.198 & -0.032 & 0.045 & 0.014 & 0.031 & 2.580 & -2.098 \\
\hline 9 & $\begin{array}{l}\text { 8-21-06-02 Dense } 1 \\
\text { 8-21-06-02 Dense } 2 \\
\text { 8-21-06-02 Dense } 3 \\
\text { 8-21-06-02 Product } 1 \\
\text { 8-21-06-02 Product } 2 \\
\text { 8-21-06-02 Product } 3\end{array}$ & $\begin{array}{l}1.130 \\
1.230 \\
1.120 \\
1.190 \\
1.210 \\
1.110\end{array}$ & $\begin{array}{l}1.160 \\
1.170\end{array}$ & 1.170 & 1.160 & 1.156 & $\begin{array}{l}4.536 \\
4.536\end{array}$ & 1.170 & 3.338 & 0.027 & 0.052 & 0.014 & 0.039 & 1.244 & 0.379 \\
\hline 10 & $\begin{array}{l}\text { 8-21-06-03 Dense } 1 \\
\text { 8-21-06-03 Dense } 2\end{array}$ & $\begin{array}{l}1.070 \\
1.110\end{array}$ & 1.090 & & 1.090 & 1.102 & 4.536 & & 2.649 & & 0.050 & & 0.029 & & -1.109 \\
\hline
\end{tabular}




\begin{tabular}{|c|c|c|c|c|c|c|c|c|c|c|c|c|c|c|c|}
\hline & $\begin{array}{l}\text { 8-21-06-03 Dense } 3 \\
\text { 8-21-06-03 Product } 1 \\
\text { 8-21-06-03 Product } 2 \\
\text { 8-21-06-03 Product } 3\end{array}$ & $\begin{array}{l}1.090 \\
1.230 \\
1.150 \\
1.130\end{array}$ & 1.170 & 1.170 & & & 4.536 & 1.805 & & 0.082 & & \multicolumn{2}{|l|}{0.021} & \multicolumn{2}{|l|}{6.149} \\
\hline 11 & $\begin{array}{l}\text { 8-28-06-01 Dense } 1 \\
\text { 8-28-06-01 Dense } 2 \\
\text { 8-28-06-01 Dense } 3 \\
\text { 8-28-06-01 Product } 1 \\
\text { 8-28-06-01 Product } 2 \\
\text { 8-28-06-01 Product } 3\end{array}$ & $\begin{array}{l}0.830 \\
0.950 \\
0.940 \\
0.920 \\
0.970 \\
1.110\end{array}$ & $\begin{array}{l}0.907 \\
1.000\end{array}$ & 1.000 & 0.907 & 0.964 & $\begin{array}{l}4.536 \\
4.536\end{array}$ & 1.985 & 2.635 & -0.084 & 0.044 & 0.020 & 0.024 & 3.705 & -5.974 \\
\hline 12 & $\begin{array}{l}\text { 8-28-06-02 Dense } 1 \\
\text { 8-28-06-02 Dense } 2 \\
\text { 8-28-06-02 Dense } 3 \\
\text { 8-28-06-02 Product } 1 \\
\text { 8-28-06-02 Product } 2 \\
\text { 8-28-06-02 Product } 3\end{array}$ & $\begin{array}{l}0.990 \\
1.010 \\
1.000 \\
0.980 \\
1.160 \\
0.700\end{array}$ & $\begin{array}{l}1.000 \\
0.947\end{array}$ & 0.947 & 1.000 & 0.973 & $\begin{array}{l}4.536 \\
4.536\end{array}$ & 2.273 & 2.263 & 0.000 & 0.044 & 0.022 & 0.023 & -2.734 & 2.745 \\
\hline 13 & $\begin{array}{l}\text { 8-30-03-01 Dense } 1 \\
\text { 8-30-03-01 Dense } 2 \\
\text { 8-30-03-01 Dense } 3 \\
\text { 8-30-03-01 Product } 1 \\
\text { 8-30-03-01 Product } 2 \\
\text { 8-30-03-01 Product } 3\end{array}$ & $\begin{array}{l}0.620 \\
0.630 \\
0.610 \\
0.650 \\
0.720 \\
0.690\end{array}$ & $\begin{array}{l}0.620 \\
0.687\end{array}$ & 0.687 & 0.620 & 0.637 & $\begin{array}{l}4.536 \\
4.536\end{array}$ & 1.819 & 2.649 & 0.068 & 0.029 & 0.012 & 0.016 & 7.724 & -2.735 \\
\hline 14 & $\begin{array}{l}\text { 8-30-06-02 Dense } 1 \\
\text { 8-30-06-02 Dense } 2 \\
\text { 8-30-06-02 Dense } 3 \\
\text { 8-30-06-02 Product } 1 \\
\text { 8-30-06-02 Product } 2 \\
\text { 8-30-06-02 Product } 3\end{array}$ & $\begin{array}{l}0.790 \\
0.740 \\
0.760 \\
0.780 \\
0.790 \\
0.870 \\
\end{array}$ & $\begin{array}{l}0.763 \\
0.813\end{array}$ & 0.813 & 0.763 & 0.784 & $\begin{array}{l}4.536 \\
4.536\end{array}$ & 2.227 & 2.286 & 0.023 & 0.036 & 0.018 & 0.017 & 3.733 & -2.644 \\
\hline 15 & $\begin{array}{l}\text { 8-30-06-03 Dense } 1 \\
\text { 8-30-06-03 Dense } 2 \\
\text { 8-30-06-03 Dense } 3 \\
\text { 8-30-06-03 Product } 1 \\
\text { 8-30-06-03 Product } 2\end{array}$ & $\begin{array}{l}0.770 \\
0.750 \\
0.780 \\
1.020 \\
0.950\end{array}$ & $\begin{array}{l}0.767 \\
0.973\end{array}$ & 0.973 & 0.767 & 0.838 & $\begin{array}{l}4.536 \\
4.536\end{array}$ & 1.665 & 2.844 & 0.027 & 0.038 & 0.016 & 0.022 & 16.162 & -8.503 \\
\hline
\end{tabular}




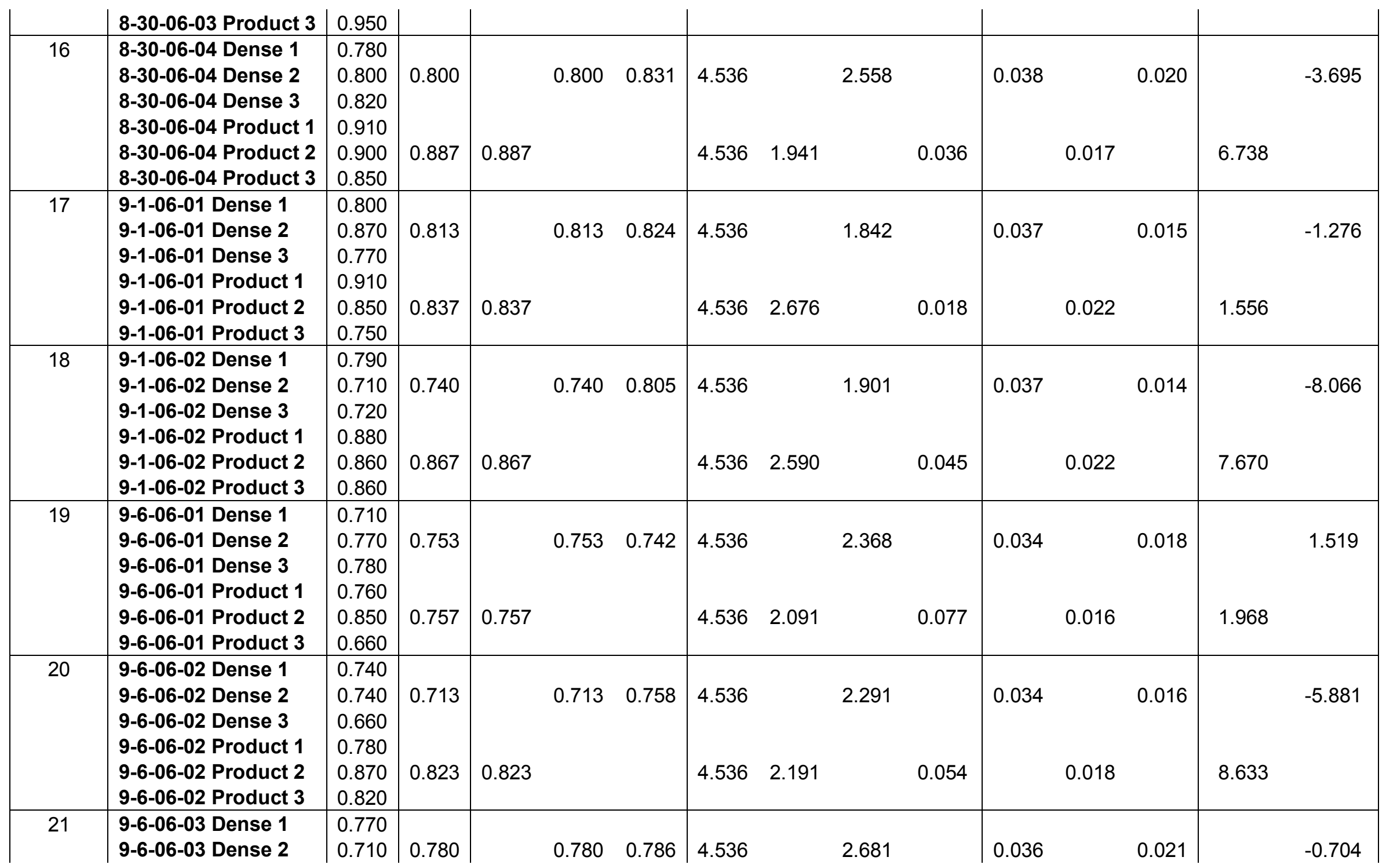




\begin{tabular}{|c|c|c|c|c|c|c|c|c|c|c|c|c|c|c|c|}
\hline & $\begin{array}{l}\text { 9-6-06-03 Dense } 3 \\
\text { 9-6-06-03 Product } 1 \\
\text { 9-6-06-03 Product } 2 \\
\text { 9-6-06-03 Product } 3\end{array}$ & $\begin{array}{l}0.860 \\
0.750 \\
0.890 \\
0.770\end{array}$ & 0.803 & 0.803 & & & 4.536 & 1.833 & & 0.023 & & \multicolumn{2}{|l|}{0.015} & \multicolumn{2}{|l|}{2.267} \\
\hline 22 & $\begin{array}{l}\text { 9-6-06-04 Dense } 1 \\
\text { 9-6-06-04 Dense } 2 \\
\text { 9-6-06-04 Dense } 3 \\
\text { 9-6-06-04 Product } 1 \\
\text { 9-6-06-04 Product } 2 \\
\text { 9-6-06-04 Product } 3\end{array}$ & $\begin{array}{l}0.740 \\
0.670 \\
0.770 \\
0.660 \\
0.830 \\
0.860\end{array}$ & $\begin{array}{l}0.727 \\
0.783\end{array}$ & 0.783 & 0.727 & 0.759 & $\begin{array}{l}4.536 \\
4.536\end{array}$ & 2.204 & 2.359 & -0.027 & 0.034 & 0.017 & 0.017 & 3.265 & -4.205 \\
\hline 23 & $\begin{array}{l}\text { 9-13-06-01 Dense } 1 \\
\text { 9-13-06-01 Dense } 2 \\
\text { 9-13-06-01 Dense } 3 \\
\text { 9-13-06-01 Product } 1 \\
\text { 9-13-06-01 Product } 2 \\
\text { 9-13-06-01 Product } 3\end{array}$ & $\begin{array}{l}0.740 \\
0.710 \\
0.750 \\
0.820 \\
0.770 \\
0.760\end{array}$ & $\begin{array}{l}0.733 \\
0.783\end{array}$ & 0.783 & 0.733 & 0.750 & $\begin{array}{l}4.536 \\
4.536\end{array}$ & 2.082 & 2.418 & 0.036 & 0.034 & 0.016 & 0.018 & 4.386 & -2.277 \\
\hline 24 & $\begin{array}{l}\text { 9-13-06-02 Dense } 1 \\
\text { 9-13-06-02 Dense } 2 \\
\text { 9-13-06-02 Dense } 3 \\
\text { 9-13-06-02 Product } 1 \\
\text { 9-13-06-02 Product } 2 \\
\text { 9-13-06-02 Product } 3\end{array}$ & $\begin{array}{l}0.690 \\
0.680 \\
0.700 \\
0.620 \\
0.690 \\
0.670\end{array}$ & $\begin{array}{l}0.690 \\
0.660\end{array}$ & 0.660 & 0.690 & 0.676 & $\begin{array}{l}4.536 \\
4.536\end{array}$ & 1.932 & 2.595 & 0.009 & 0.031 & 0.013 & 0.018 & -2.344 & 2.095 \\
\hline 25 & $\begin{array}{l}\text { 9-13-06-03 Dense } 1 \\
\text { 9-13-06-03 Dense } 2 \\
\text { 9-13-06-03 Dense } 3 \\
\text { 9-13-06-03 Product } 1 \\
\text { 9-13-06-03 Product } 2 \\
\text { 9-13-06-03 Product } 3\end{array}$ & $\begin{array}{l}0.620 \\
0.650 \\
0.620 \\
0.640 \\
0.640 \\
0.590\end{array}$ & $\begin{array}{l}0.630 \\
0.623\end{array}$ & 0.623 & 0.630 & 0.622 & $\begin{array}{l}4.536 \\
4.536\end{array}$ & 3.089 & 1.420 & 0.027 & 0.028 & 0.019 & 0.009 & 0.266 & 1.338 \\
\hline 26 & $\begin{array}{l}\text { 9-13-06-04 Dense } 1 \\
\text { 9-13-06-04 Dense } 2 \\
\text { 9-13-06-04 Dense } 3 \\
\text { 9-13-06-04 Product } 1 \\
\text { 9-13-06-04 Product } 2\end{array}$ & $\begin{array}{l}0.630 \\
0.590 \\
0.550 \\
0.530 \\
0.670\end{array}$ & $\begin{array}{l}0.590 \\
0.587\end{array}$ & 0.587 & 0.590 & 0.581 & $\begin{array}{l}4.536 \\
4.536\end{array}$ & 2.295 & 2.182 & 0.059 & 0.026 & 0.013 & 0.013 & 1.037 & 1.611 \\
\hline
\end{tabular}




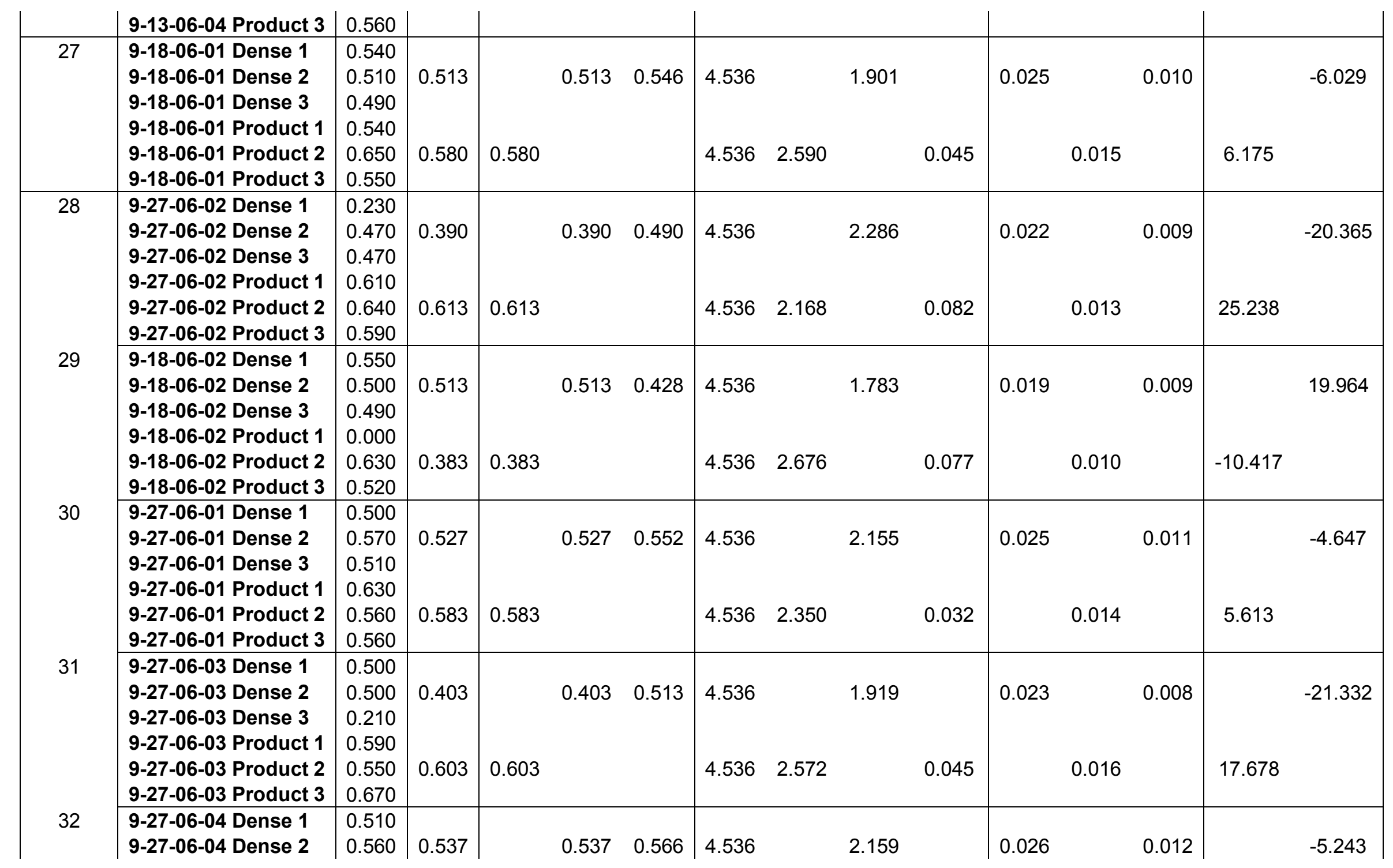




\begin{tabular}{|c|c|c|c|c|c|c|c|c|}
\hline $\begin{array}{l}\text { 9-27-06-04 Dense } 3 \\
\text { 9-27-06-04 Product } 1 \\
\text { 9-27-06-04 Product } 2 \\
\text { 9-27-06-04 Product } 3\end{array}$ & $\begin{array}{l}0.540 \\
0.650 \\
0.550 \\
0.580\end{array}$ & 0.593 & 0.593 & 4.536 & 2.377 & 0.000 & 0.014 & 4.763 \\
\hline 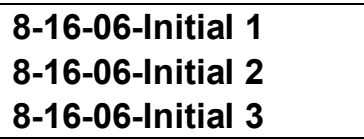 & $\begin{array}{l}0.770 \\
0.830 \\
0.790\end{array}$ & 0.797 & & 4.536 & & & & \\
\hline $\begin{array}{l}\text { 8-28-06-01 Initial } 1 \\
\text { 8-28-06-01 Initial } 2 \\
\text { 8-28-06-01 Initial } 3\end{array}$ & $\begin{array}{l}0.750 \\
0.710 \\
0.640\end{array}$ & 0.700 & & 4.536 & & & & \\
\hline $\begin{array}{l}\text { 9-6-06-01 Initial } 1 \\
9-6-06-01 \text { Initial } 2 \\
9-6-06-01 \text { Initial } 3 \\
\end{array}$ & $\begin{array}{l}0.770 \\
0.790 \\
0.760 \\
\end{array}$ & 0.773 & & 4.536 & & & & \\
\hline $\begin{array}{l}\text { 9-18-06-01 Initial } 1 \\
9-18-06-01 \text { Initial } 2 \\
\text { 9-18-06-01 Initial } 3\end{array}$ & $\begin{array}{l}0.590 \\
0.580 \\
0.550\end{array}$ & 0.573 & & 4.536 & & & & \\
\hline $\begin{array}{l}\text { 10-2-06-01 Initial } 1 \\
\text { 10-2-06-01 Initial } 2 \\
\text { 10-2-06-01 Initial } 3\end{array}$ & $\begin{array}{l}0.580 \\
0.560 \\
0.490\end{array}$ & 0.543 & & 4.536 & & & & \\
\hline 8-17-06-01 Filter & 1.500 & 1.153 & & & & & & \\
\hline
\end{tabular}

Table 6.3.a Experimental Results for Coal Test Runs 
As shown on Table6.3.a, the greatest percent changes occurred for the second test run on Sept 27, 2006. The percent change in sulfur for the dense collection bin is reported at $\mathbf{- 2 0 . 3 6 5 \%}$, while the product bin percent change in sulfur is found to be $\mathbf{2 5 . 2 3 8 \%}$. The conditions for this test were a $1.905 \mathrm{~cm}$ particle entrance (no nozzle), with the 0.3048 meter high collection ring wall height, and a mass flux rate $0.280 \mathrm{~kg} / \mathrm{m}^{2} \mathrm{~s}$.

This test, as well as the majority of the other tests, have percent sulfur changes with positive values for the product bin percent change, and negative values for the dense bin percent sulfur change. This means that the coal in the dense collection bin contains less sulfur than the product collection bin. The principle behind the CFB system is that particles with a higher terminal velocity will end up in the dense collection bin, while those with a smaller terminal velocity will exit out of the top of the riser to the product collection bin. In this research project, the opposite occurred. This is due to the fact the particles containing both the sulfur and the clean coal were micronized together, and it is unknown where the respective particles lie in the size range. In this case, the system separated particles based more on size, than density. This indicates the particles containing the majority of the sulfur were of smaller size, since they ended up in the product collection bin. Contrary to that, the clean coal particles must have been of larger size, as they ended up in the dense collection bin. Images taken from the SEM can be confirmed in Appendix C. Due to the complex nature of determining the effect of separation efficiency based on particle shape, all particles were assumed to be spherical in nature. However, it is noted from the figures that some of the particles are not spherical in nature. Shown also in Appendix C, in Figure C.7, is a spectrum overlay graph from the SEM microscope. The samples show that a higher percentage of sulfur is 
found in the dense particle collection bin. This can be explained due to the nature of the very small region being looked at by the SEM, meaning the coal sample taken is non homogeneous.

A series of percent sulfur change figures were created to display comparisons between the main variables investigated in this project.

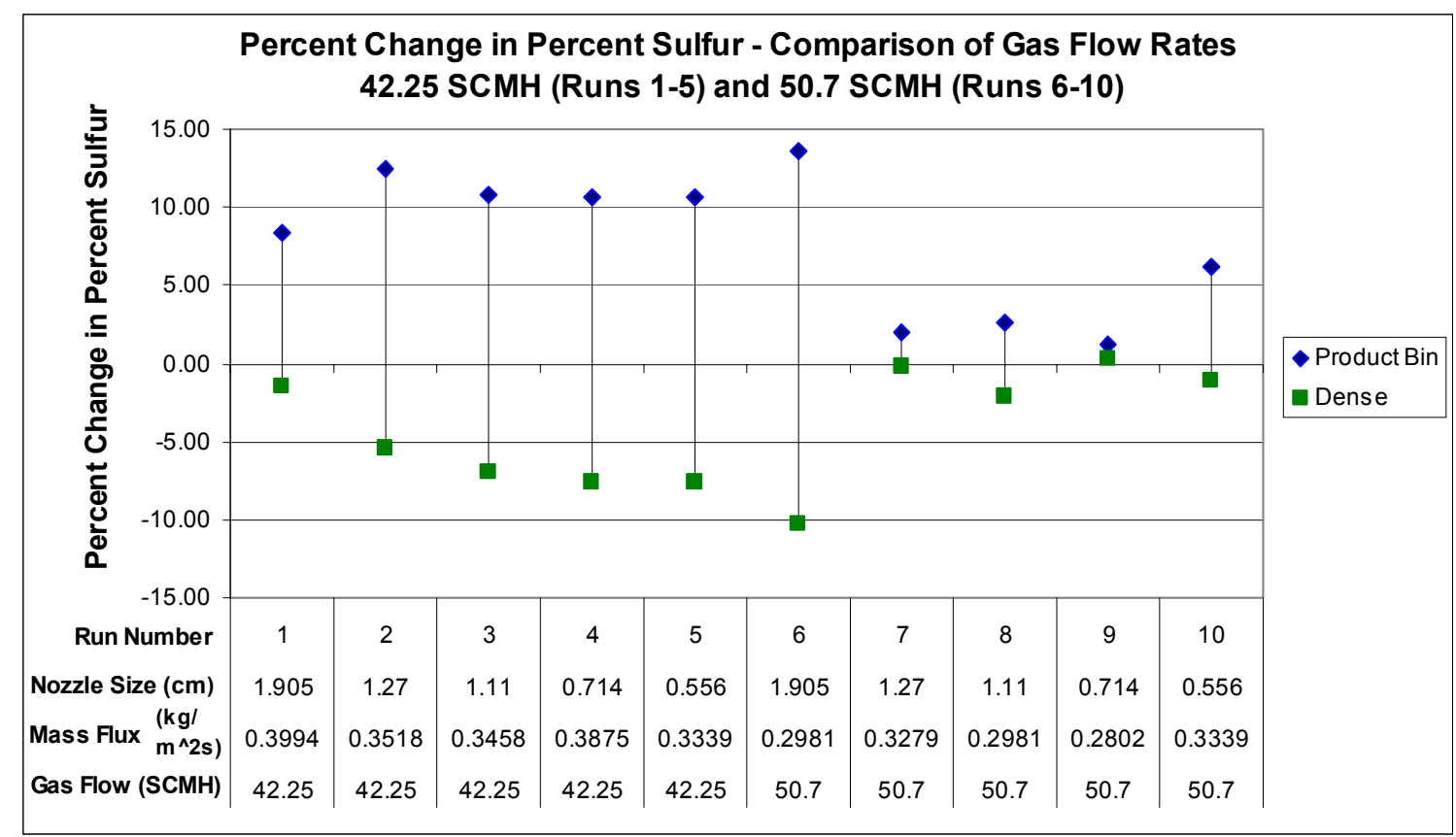

Figure 6.3.a Percent Sulfur Change Comparison for Gas Flow Rates

As shown in Figure 6.3.a, runs 1-5 provided much better separation of the clean coal from the pyritic coal. The test runs showed much higher separation values than those ran at higher gas velocities. The dense particle collection bin became filled before these tests were fully completed, thus leading to the gas velocity being raised so that more particles would exit the top of the riser. When the dense particle collection bin became filled the test had to be stopped and re-started, leading to inconsistency in the delivery of particles. It would have been desired to run less material at the lower gas velocity, in which the best results were achieved; however the results from the chemical analysis lab were not 
known until all coal tests were completed. It was therefore unknown the higher gas velocity produced less separation than did that of the low velocity.

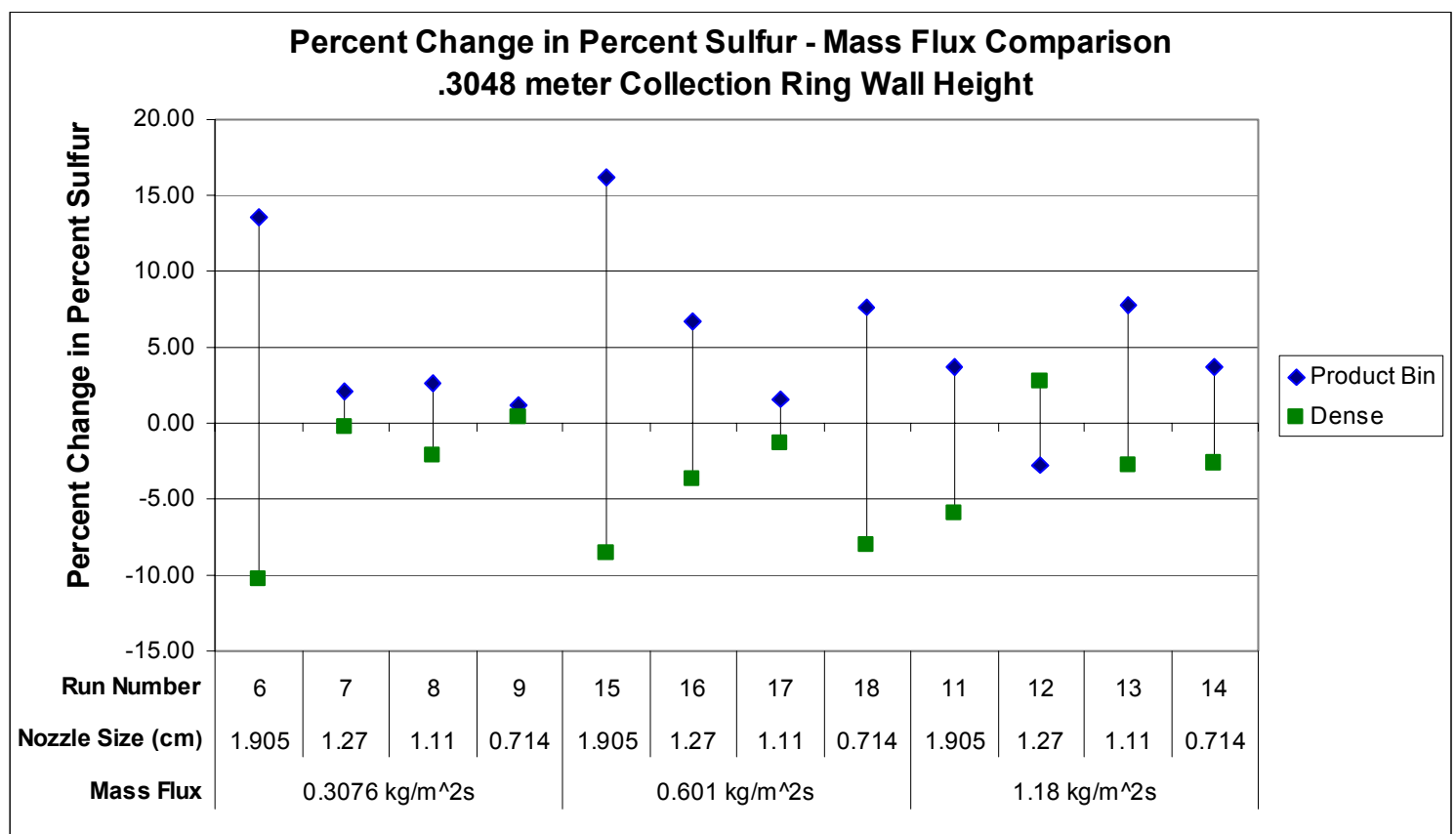

Figure 6.3.b Product Percent Change in Sulfur vs. Mass Flux (0.3048 meter Collection Ring Wall Height)

Figure 6.3.b shows the percent change in percent sulfur for the $0.3076 \mathrm{~kg} / \mathrm{m}^{2} \mathrm{~s}$, $0.601 \mathrm{~kg} / \mathrm{m}^{2} \mathrm{~s}$, and $1.180 \mathrm{~kg} / \mathrm{m}^{2} \mathrm{~s}$ mass flux values for the 0.3048 meter high collection ring wall height. The $1.905 \mathrm{~cm}$ nozzle showed the best separation efficiency for both of the lower mass flux rates. Collectively the $1.18 \mathrm{~kg} / \mathrm{m}^{2} \mathrm{~s}$ mass flux rate showed the best separation efficiency, although the $1.27 \mathrm{~cm}$ nozzle had a percent change in sulfur different than the normal trend. There is a slight decrease in separation efficiency as the nozzle size decreases. 


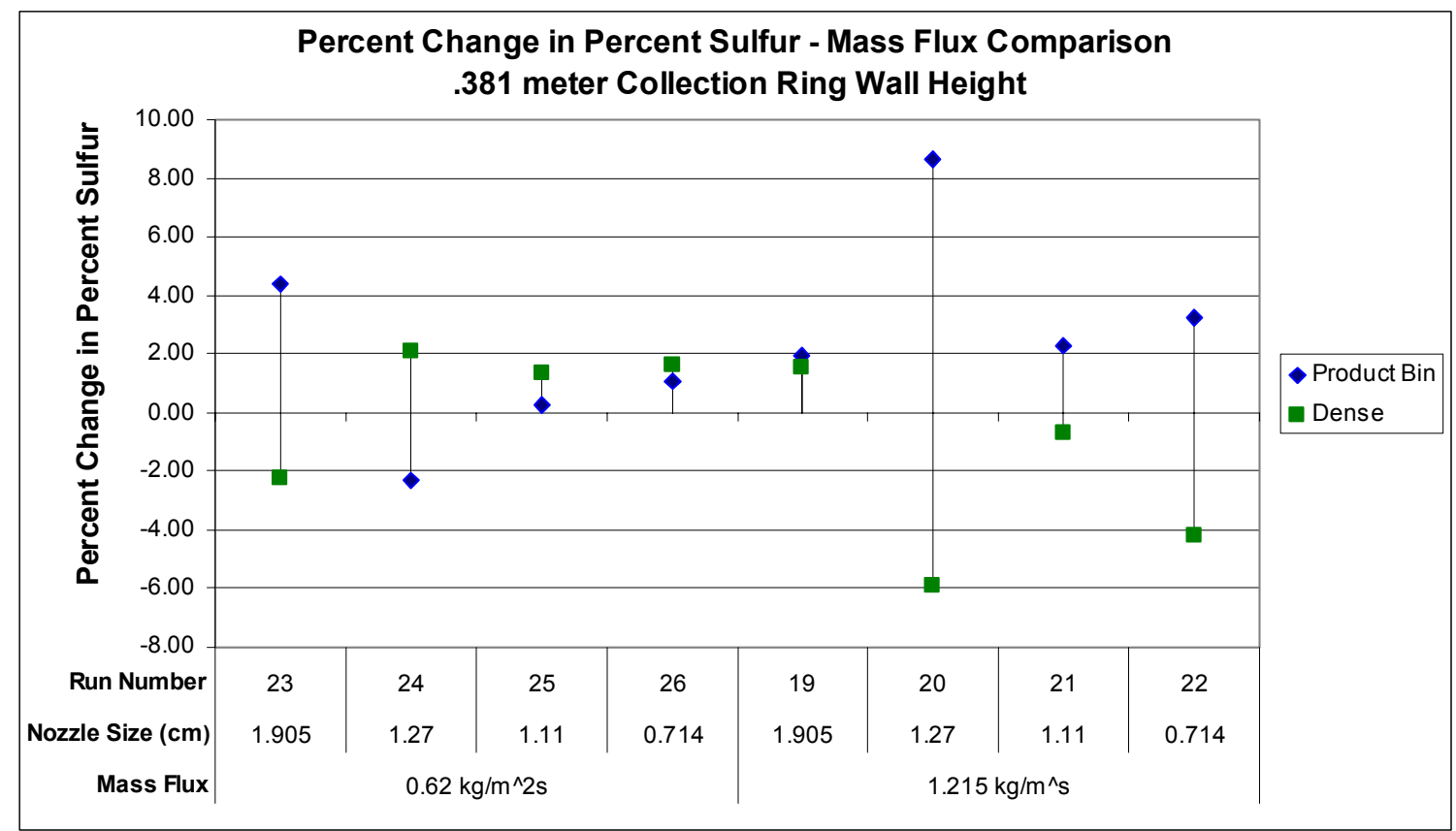

Figure 6.3.c Product Percent Change in Sulfur vs. Mass Flux (0.381 meter Collection Ring Wall Height)

Figure 6.3.c shows the percent change in percent sulfur of the 0.62

$\mathrm{kg} / \mathrm{m} 2 \mathrm{~s}$ and $1.215 \mathrm{~kg} / \mathrm{m} 2 \mathrm{~s}$ tests runs for the 0.381 meter high collection ring wall height.

As a whole, the separation efficiency is better for the $1.215 \mathrm{~kg} / \mathrm{m}^{2} \mathrm{~s}$ mass flux rate. 


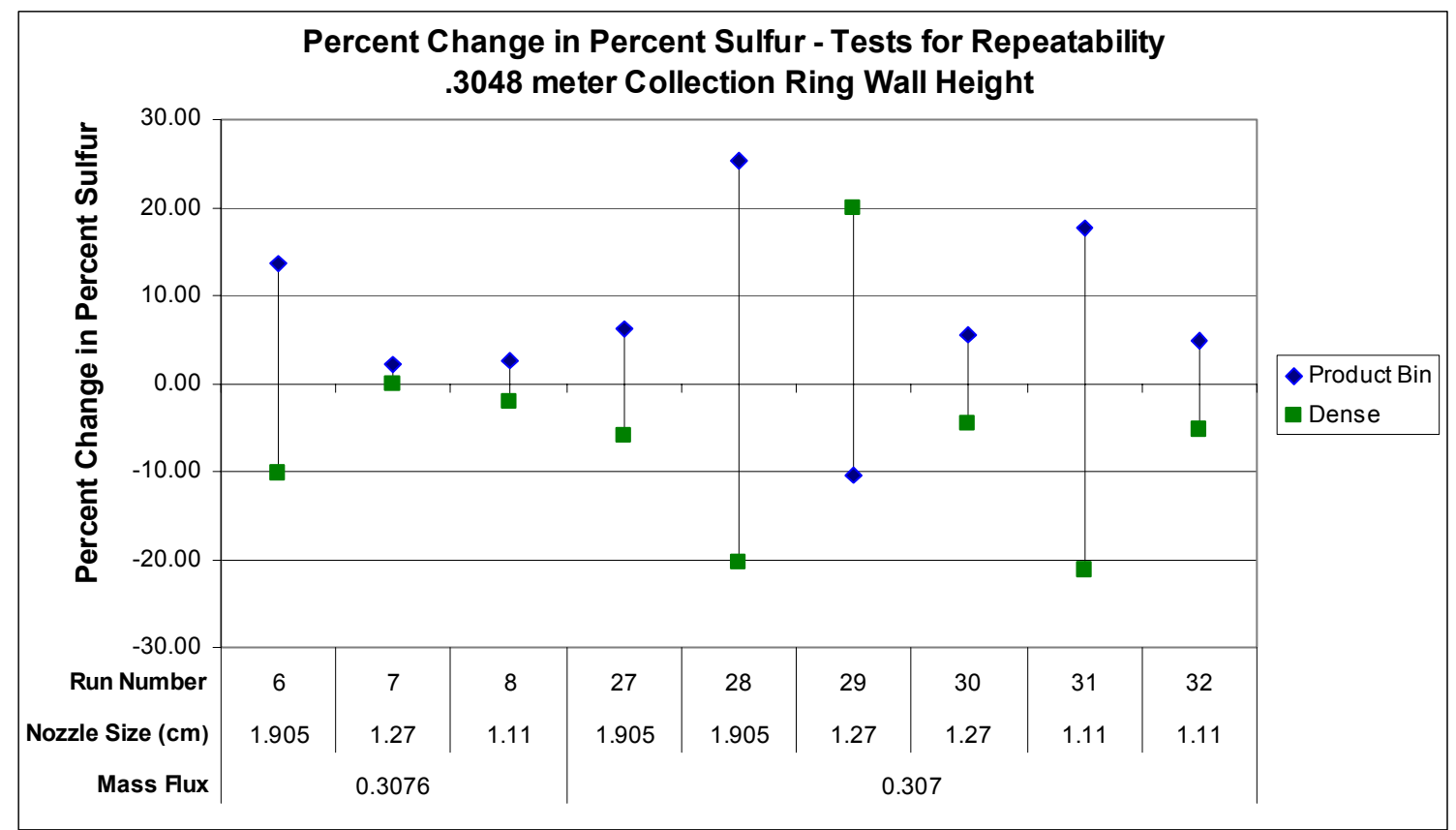

Figure 6.3.d Percent Sulfur Change Comparison for Repeatability Tests

Tests run numbers 6,7 , and 8 , were duplicated to check to see if the results could be accurately repeated. As shown in Figure 6.3.d the results of the tests vary from each other by a significant amount and seem to have no pattern. The mass flux rate for each of the tests was aimed to be $0.30 \mathrm{~kg} / \mathrm{m}^{2} \mathrm{~s}$. Due to the similarity of the test conditions used, other factors must play a role in the separation process. One such explanation is the fact the sample of coal run in each of the tests was non-uniform. Although the separation process could have occurred similarly in each test, the amount of sulfur used in each run could have varied since test runs 27 - 32 used a different portion of coal, although it was taken from the same batch. 


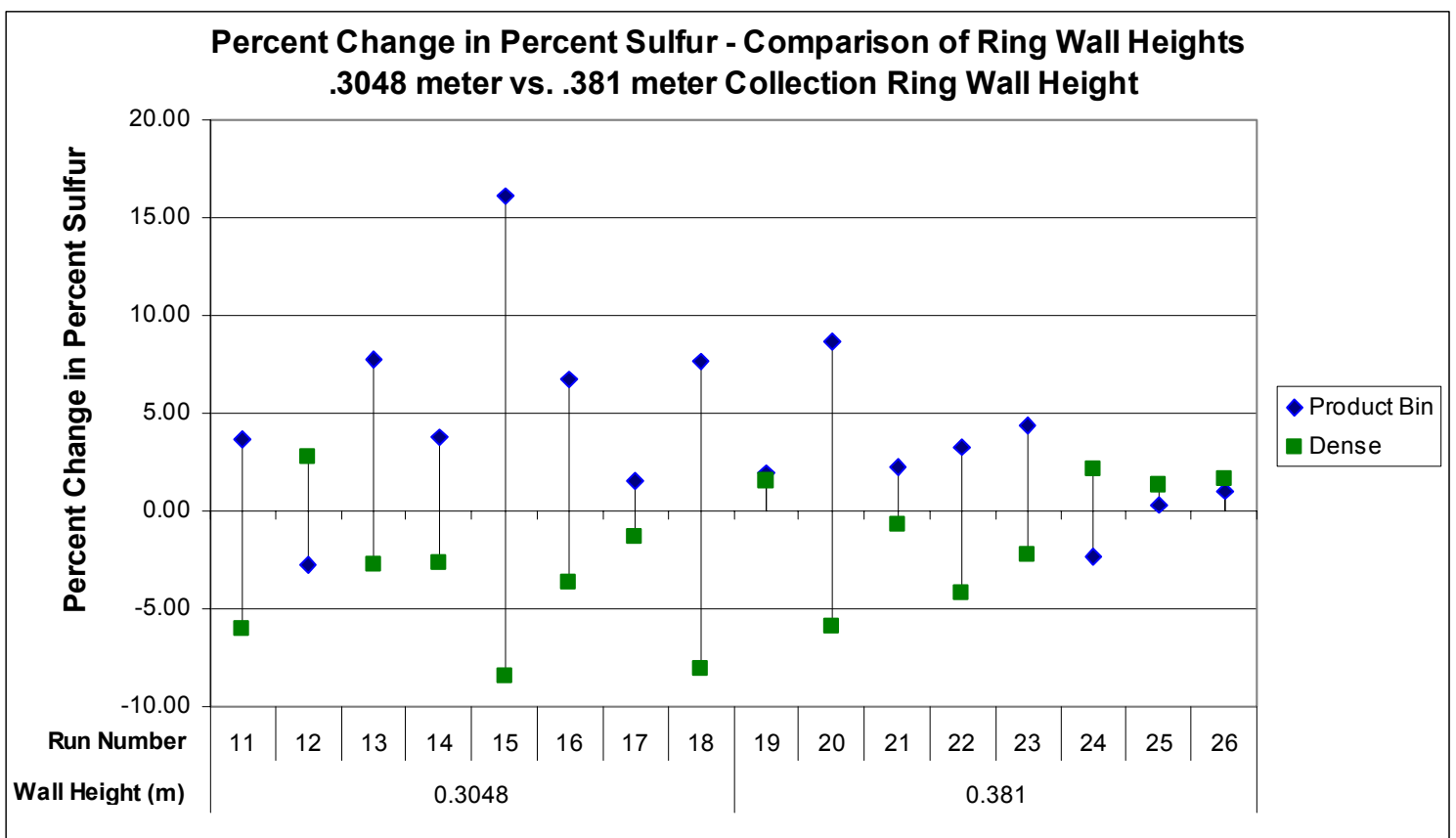

Figure 6.3.e Percent Change in Sulfur Comparison for Ring Wall Heights

Figure 6.3.e shows the percent change in percent sulfur for a number of runs using the 0.3048 meter and 0.381 meter collection ring wall heights. Run 15 shows much higher values of separation for the 0.3048 collection ring wall height than the other values. Collectively the 0.3048 meter collection ring wall height provides better separation efficiency when trying to separate pyritic coal from clean coal. The effect of having a concentric jet flow of particles into the riser will dissipate as the flow moves downstream. The flow from the nozzle, in this case, has dissipated by the time the flow reaches the higher collection ring wall height. This leads to better separation efficiency for the lower ring wall height. 


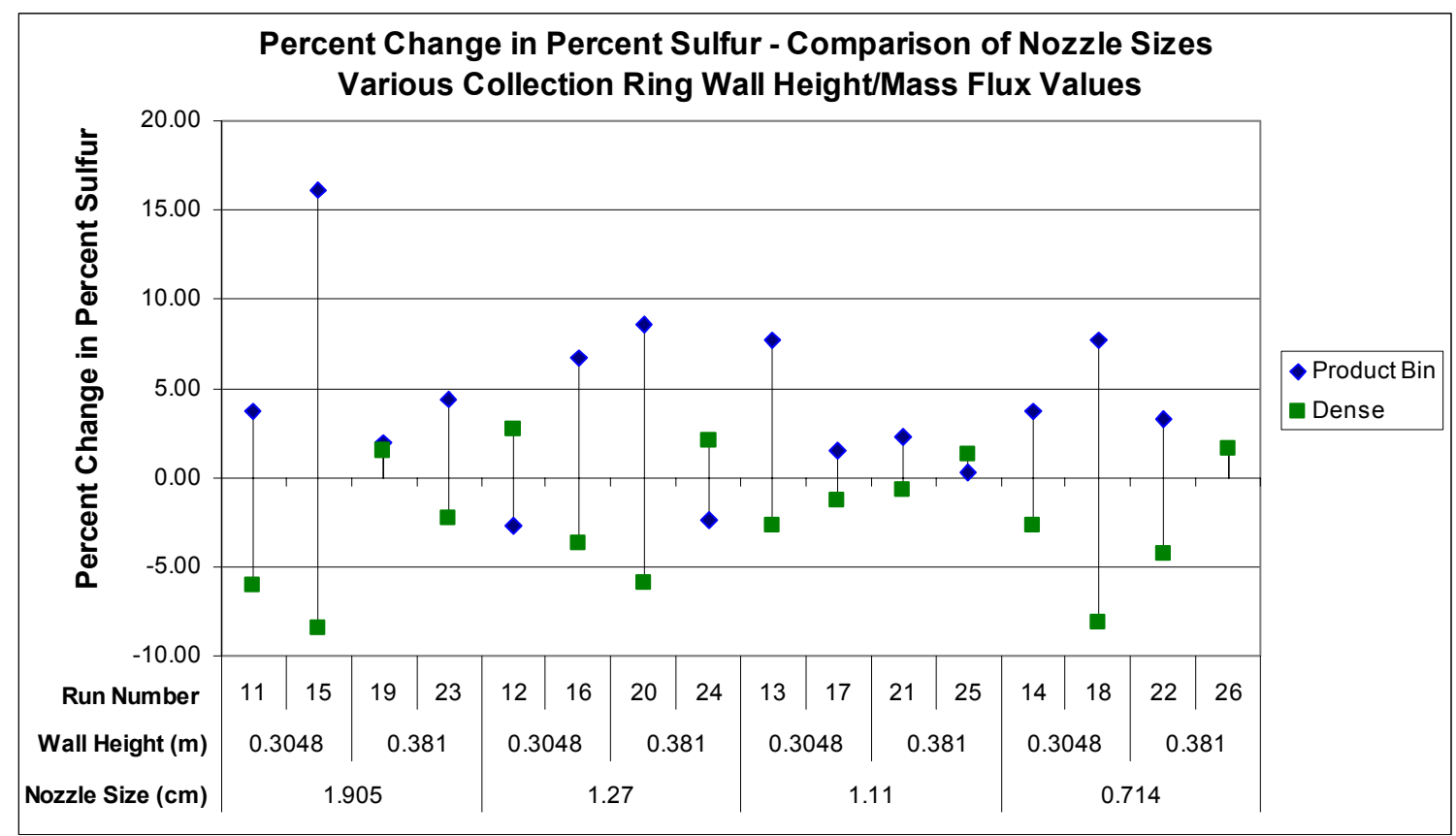

Figure 6.3.f Percent Change in Percent Sulfur Comparison for Nozzle Sizes

Figure 6.3.f shows a comparison of the different nozzle sizes for the separation of pyritic laden coal from clean coal. The highest separation efficiency comes from the $1.905 \mathrm{~cm}$ nozzle with the low collection ring wall height.

It is determined for the best possible separation efficiency when trying to separate mineral matter from coal that there are several combinations that can be used. If a lower collection ring wall height is used, a large particle entrance into the riser should be used. If a higher collection ring wall height is used, a smaller nozzle size or particle entrance into the riser should be used. It has also been determined that when using the lower collection ring wall height a higher mass flux rate should be used. Contrasting from that, if a higher collection ring wall height is used, a low mass flux rate should be used with the system.

Figure C.7 in Appendix C shows a coal spectrum overlay for the initial and dense and product collection bins. The sample was taken and placed in the SEM 
discussed in Section 3.3.7 to achieve the overlay. It is shown the dense bin contained the most sulfur, while the product bin contained less sulfur. These results are not in agreement with those taken from the test runs. Such a small amount of material is used in this analysis that it is not able to represent the full samples, and is therefore not used to evaluate the results.

\subsection{Coal Particle Size Distribution}

Some of the coal tests had very low separation efficiencies. It was determined if the pyrite remained embedded in the smaller coal particles, instead of the larger ones, that they could possibly have ended up in the product collection bin. An initial coal sample used in the experiments was sent for a particle size analysis. The results are shown in

\section{Figure 6.4.a.}

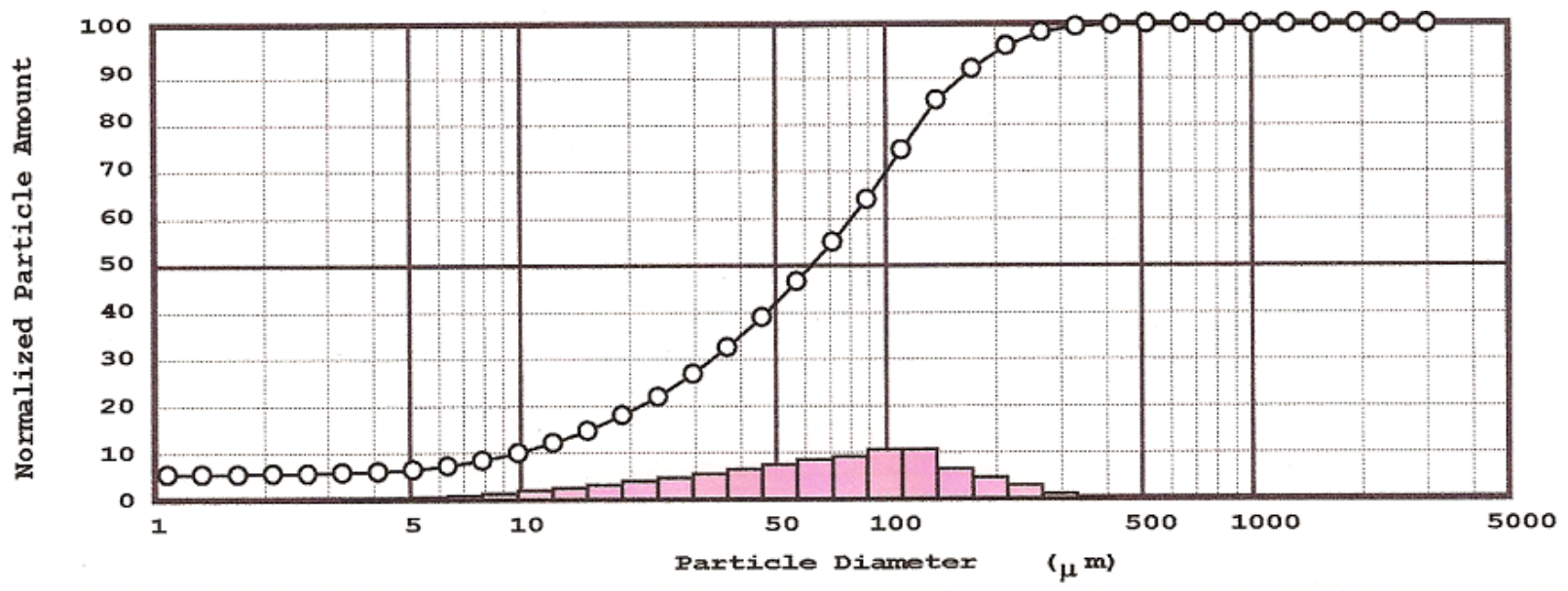

Figure 6.4.a Particle Size Analysis and Distribution

Figure 6.4 a shows that most of the coal sample lies approximately between the 75 to 120 micron size range. If more of the lift force was applied to the larger particles that did not have pyrite in them, the smaller pyrite laden particles would then exit out the top of the riser. Since most of the particles are found to be smaller, this is one possible explanation as to why the separation process was not as efficient for these experiments. 


\section{Chapter 7: Separation of Crushed Pyrite From Coal}

\subsection{Separation of Pure Crushed Pyrite from Coal}

A third separation project was undertaken to observe the efficiency of the CFB to separate pure pyrite from coal. Coal and Pyrite particles have a large density difference, thus making them a prime candidate for separation in the riser system. The problem with this, however, as described earlier is that pyrite particles are not independent of coal particles as found naturally. To solve this problem pure pyrite particles, of the same size as the coal, were placed into a mixture of Kingwood coal used in earlier testing. This would allow coal and pyrite particles of the same size to be passed through the riser for separation, since the materials were now independent from one another.

Two test runs were completed, each using the same amount of coal and pure pyrite. It was desired to see how the base riser system with no modifications would be able to separate the pyrite from the coal; therefore no nozzles or added ring collection height pieces were used. This would allow a baseline assessment of how efficiently the system could separate the two materials.

\subsection{Problems with the Kingwood Coal Used}

The Kingwood coal that was used for testing had been previously cleaned. This created a "worst case" scenario for the previous separation projects; however, it would allow an optimal case to be created for this project. The coal used had an initial sulfur percentage of around $0.75 \%-1.0 \%$, meaning it had close to that amount of pyrite. Generally, the most unclean coal used today is around 3\% - 4\% pyrite. To replicate this, crushed pyrite was added to the coal mixture to have that percentage of pyrite. This 
would also allow several different analysis methods to be completed to check the separation efficiency.

\subsection{Added Pyrite}

Pure pyrite chunks approximately 0.25 inches in diameter were taken and run through a jaw and roller crusher to make the particles the correct size. The pyrite was then run through American Standard sieves with mesh sizes of 105 to 210 micron. These are the same sieves the Kingwood coal was passed through, thus giving the pyrite and the coal particles the same size range. Assuming the Kingwood coal used had a pyrite quantity of around $1.0 \%$, approximately $3.0 \%$ needed to be added to bring the mixture to the desired $4.0 \%$.

Approximately 10 pounds of the Kingwood coal was used for each test. This means 0.3 pounds (136.07 grams) of crushed pyrite was added to each mixture. Each coal mixture was then taken and thoroughly stirred to ensure the pyrite particles were evenly distributed within the coal mixture.

\section{$\underline{7.4 \text { Test Conditions }}$}

The test conditions for separating disconnected pyrite from clean coal were decided upon from the previous coal test run results. The test conditions are described further in Section 4.1.4. It was decided that no nozzles would be used, and the 0.3048 meter collection ring wall height would be used. The mass flow was set at $0.5 \mathrm{lb} / \mathrm{min}$.

\subsection{Analysis of Results}

To analyze the results, three different methods were used. The first method used was to place a sample from the dense and product collection bins underneath an optical microscope at $25 \mathrm{x}$ to see if individual pyrite pieces could be seen. The second method of 
analysis was to take approximately 100 grams, in two sets, from each collection bin and put through a sink-float test. The coal and pure pyrite mixture was then placed in Dibromoethene with a specific gravity of 2.6. This would allow any pyrite in the mixture to sink out and be collected. The pure pyrite from each collection bin was then weighed and dived by the initial mass of coal and pyrite mixture placed in the Dibromoethene. This was used to find the percentage of sulfur collected for each bin. The third analysis method was to send a small sample, for each run, from each collection bin, to the analytical chemical lab in the NRCCE to be tested on the ICP machine. The lab analyzed the percent of sulfur in the sample, and the iron as well. Pyrite is known to contain mostly sulfur and iron, so it was used as a method of double checking that the results were as perceived.

\subsection{Discussion of Results from Separating Pure Pyrite from Coal Tests}

\subsubsection{Results from Optical Microscope}

The first method of analysis was to take a representative sample from the dense and product collection bins and look at them under an optical microscope. The magnification was set at $25 \mathrm{x}$ so the individual pieces of pure pyrite can be seen. Figure 7.6.a shows the product collection bin, while Figure 7.6.b shows the dense collection bin.

As shown in the figures, the product bin only contained one small piece of visible pyrite. The dense bin, however, shows several large pieces of pure pyrite among the coal. The results were very desirable; however, the sample taken does not necessarily represent either of the collection bins fully. It was therefore decided to pursue other manners of analyzing the test data. 


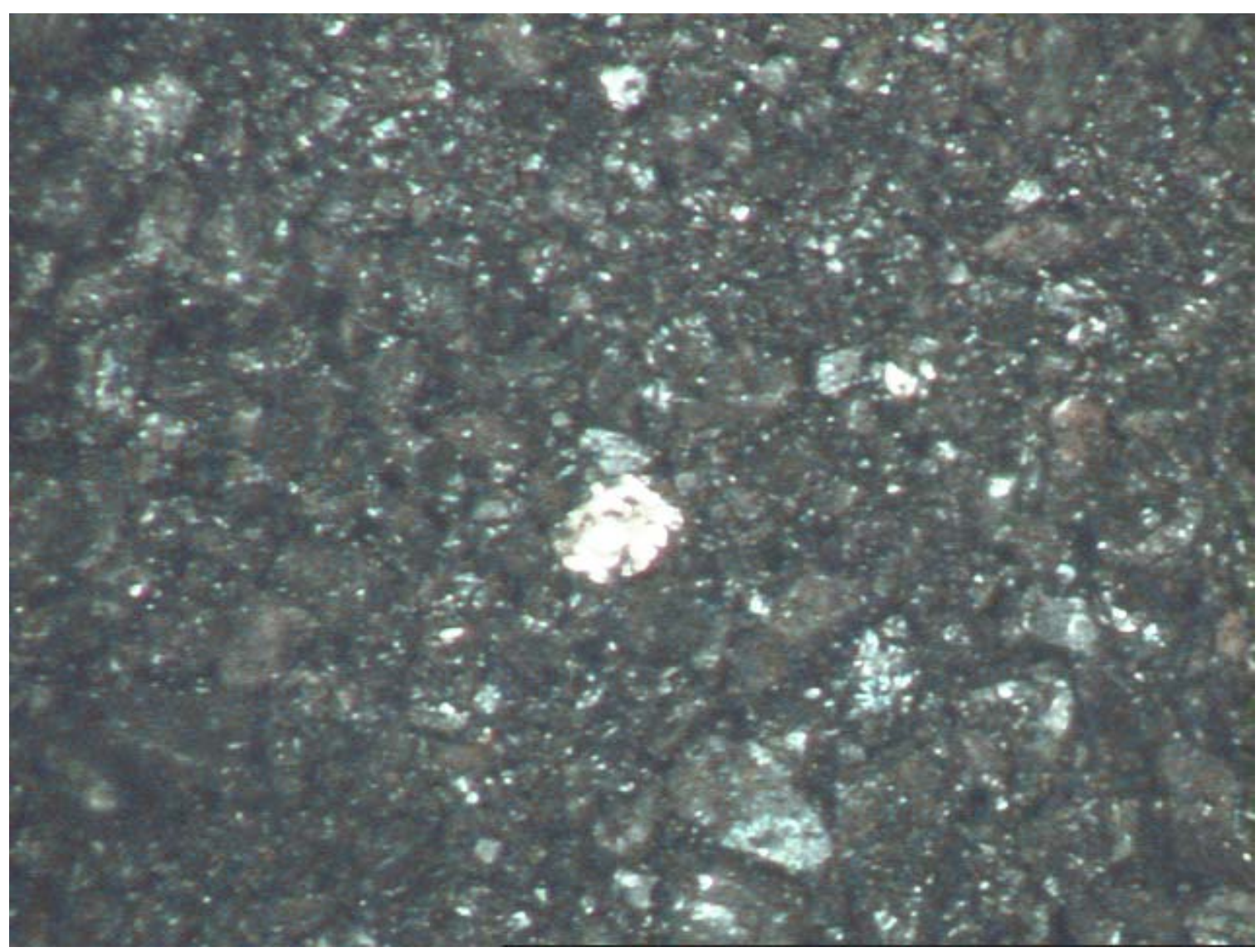

Figure 7.6.a Pure Pyrite from Product Collection Bin 


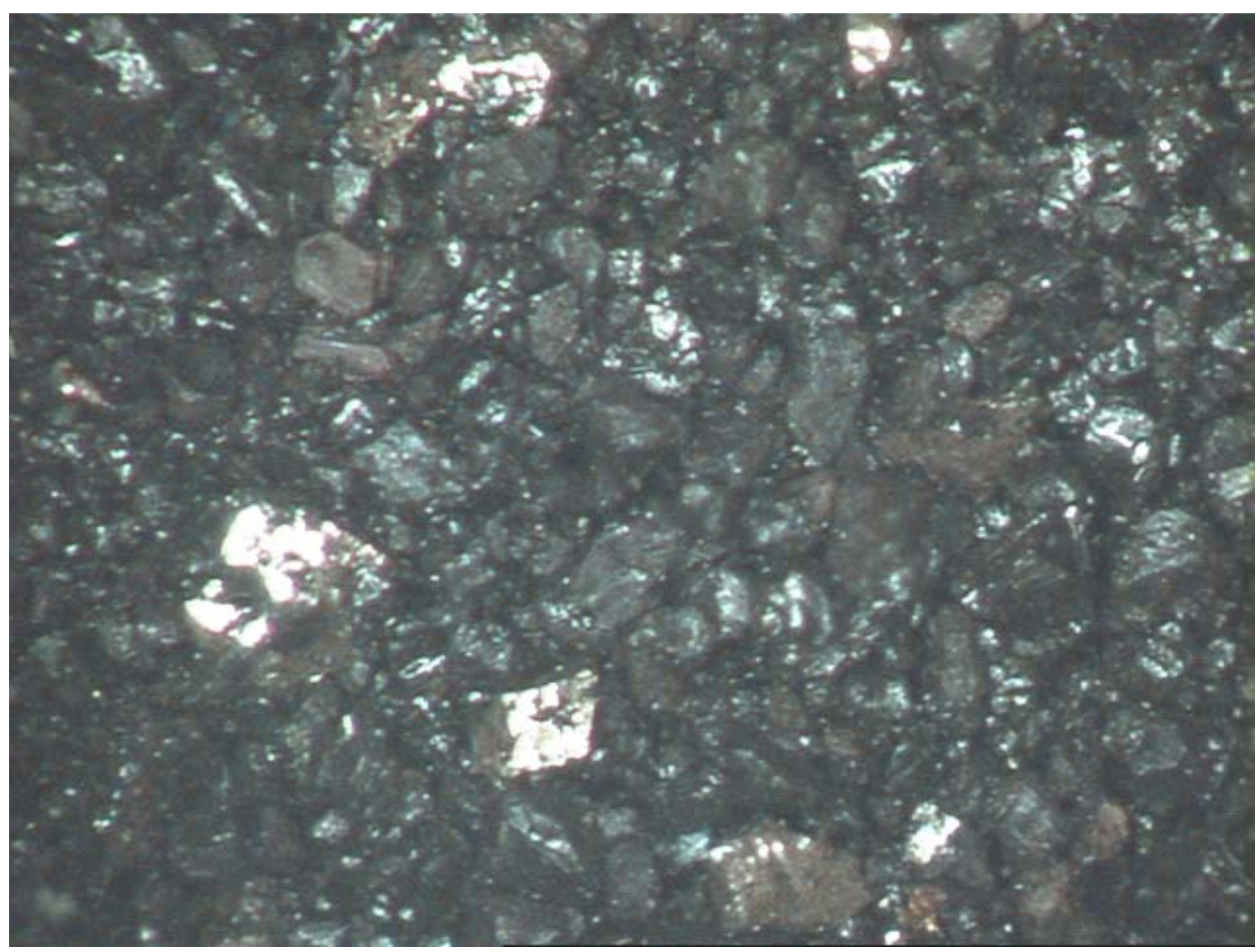

Figure 7.6.b Pure Pyrite from Dense Collection Bin

\subsubsection{Sink-Float Analysis}

Approximately two samples, 100 grams from each collection bin, for each run, were put through a sink float test. The results from this test are shown in Table 7.6.a.

\begin{tabular}{|c|c|c|c|c|}
\hline \multicolumn{5}{|c|}{ Sink-Float Test Results - Pure Pyrite from Coal - 105-210 microns } \\
\hline $\begin{array}{c}\text { Run } \\
\text { Number }\end{array}$ & Sample & $\begin{array}{c}\text { Initial } \\
\text { Weight } \\
\text { (grams) }\end{array}$ & $\begin{array}{c}\text { Pure Pyrite } \\
\text { Weight } \\
\text { (grams) }\end{array}$ & $\begin{array}{l}\text { Percent of } \\
\text { Pure Pyrite }\end{array}$ \\
\hline \multirow{4}{*}{1} & Product 1 & 100.2 & 1.78 & \multirow{2}{*}{$25.30 \%$} \\
\hline & Product 2 & 99.8 & 1.47 & \\
\hline & Dense 1 & 101.3 & 6.64 & $7470 \%$ \\
\hline & Dense 2 & 100.2 & 6.74 & $14.10 \%$ \\
\hline \multirow{4}{*}{2} & Product 1 & 100.4 & 1.47 & \multirow{2}{*}{$22.20 \%$} \\
\hline & Product 2 & 100.1 & 1.38 & \\
\hline & Dense 1 & 100.3 & 6.53 & \multirow{2}{*}{$77.80 \%$} \\
\hline & Dense 2 & 99.9 & 6.57 & \\
\hline
\end{tabular}

Table 7.6.a Sink-Float Results from Separation of Pure Pyrite from Coal 
As shown in the table, $77.8 \%$ and $74.7 \%$ of the pure pyrite was collected for the dense collection bins for each run, respectively. The results are very satisfactory.

\subsubsection{Chemical Lab Analysis}

Samples from each collection bin, for each run, were also sent to the NRCCE

chemical analytical lab to be processed on the ICP machine. The initial coal sample, which contained 4\% pyrite, and samples from each bin were analyzed. Three samples for each of these items were processed to ensure accurate results. The results from the test runs can be viewed in Table 7.6.b.

\begin{tabular}{|c|c|c|c|c|c|}
\hline \multicolumn{6}{|c|}{$\begin{array}{c}\text { Chemical Lab Analytical Results for Sink-Float Tests - Crushed } \\
\text { Pyrite from Clean Coal - 105-210 micron size range }\end{array}$} \\
\hline $\begin{array}{l}\text { Run } \\
\text { Number }\end{array}$ & Sample & $\begin{array}{c}\% \\
\text { Sulfur }\end{array}$ & $\%$ Iron & $\begin{array}{l}\text { Average } \\
\% \text { Sulfur }\end{array}$ & $\begin{array}{l}\text { Average } \\
\% \text { Iron }\end{array}$ \\
\hline \multirow{3}{*}{ Initial 1} & Initial 1 & 3.97 & 2.65 & \multirow{3}{*}{4.37} & \multirow{3}{*}{2.83} \\
\hline & Initial 2 & 4.59 & 2.88 & & \\
\hline & Initial 3 & 4.54 & 2.95 & & \\
\hline \multirow{3}{*}{ Initial 2} & Initial 4 & 3.88 & 2.48 & \multirow{3}{*}{4.21} & \multirow{3}{*}{2.79} \\
\hline & Initial 5 & 3.89 & 2.51 & & \\
\hline & Initial 6 & 4.86 & 3.39 & & \\
\hline \multirow{3}{*}{1} & Dense 1 & 6.24 & 3.97 & \multirow{3}{*}{6.74} & \multirow{3}{*}{4.29} \\
\hline & Dense 2 & 6.86 & 4.38 & & \\
\hline & Dense 3 & 7.12 & 4.51 & & \\
\hline \multirow{3}{*}{2} & Dense 4 & 5.96 & 4.20 & \multirow{3}{*}{6.53} & \multirow{3}{*}{4.01} \\
\hline & Dense 5 & 7.04 & 3.70 & & \\
\hline & Dense 6 & 6.58 & 4.14 & & \\
\hline \multirow{3}{*}{1} & Product 1 & 1.86 & 1.22 & \multirow{3}{*}{1.84} & \multirow{3}{*}{1.11} \\
\hline & Product 2 & 1.82 & 1.07 & & \\
\hline & Product 3 & 1.85 & 1.05 & & \\
\hline \multirow{3}{*}{2} & Product 4 & 2.07 & 1.17 & \multirow{3}{*}{2.08} & \multirow{3}{*}{1.30} \\
\hline & Product 5 & 2.13 & 1.31 & & \\
\hline & Product 6 & 2.04 & 1.42 & & \\
\hline
\end{tabular}

Table 7.6.b Analytical Chemical Lab Results from Separation of Pure Pyrite from Coal

As shown in the table, in the first test run the dense bin contained approximately $6.74 \%$ and $6.53 \%$ pure pyrite. The product collection bin in return contained $1.84 \%$ and 
$2.08 \%$ pure pyrite particles. The results agree with the results from both the optical microscope and sink-float analysis.

\subsection{Conclusions from Pure Pyrite from Clean Coal Separation Tests}

The results from removing pure crushed pyrite from clean coal were very satisfactory. The results prove that using a circulating fluidized bed for such separation projects are a viable option. Although results were good, they are not able to fully represent how run-of-mine coal would separate in the riser. Having the pyrite being completely disconnected from the clean coal aided in the process. It is recommended that further research be completed with such a mixture exploring other test variables to see how they affect the separation efficiency. 


\section{Chapter 8: Conclusions and Recommendations}

\subsection{Conclusions}

The riser system located has been found to be a feasible device for particle separation based on density difference. The current research was a limited investigation to see if the separation efficiency of the riser could be improved. Funding for the project was very minimal, allowing very few modifications to be made. With proper funding a more complex examination of the riser and its capabilities could be completed.

Throughout this research, the geometry of the CFB riser system has been configured to allow the most efficient separation possible. Different variables have been investigated to see how it would affect the separation process. One of the main variables in testing was to change the particle entrance into the riser by use of a nozzle. This was done to try and take advantage by varying the velocity profile of the gas and particles in the riser. Another variable was to change the collection ring wall height to determine how it would affect separation, and to observe if it would allow a higher mass flux of material in the riser without allowing the particle bed to bubble over into the dense collection bin.

The riser system was first used to separate materials of the same size range with a large difference in densities. Play sand and steel shot particles were sieved to a range of 250 to 500 microns. The mixture used was optimal due to both the sand and steel shot particles being cleanly separable from one other, as well as having a large difference in their densities. The combination of sand and steel shot was run through the riser using different gas velocities for the distributor plate and transport tube, varying particle entrance into the riser, and with different collection ring wall heights. Using the various 
changes to the system yielded very desirable collection efficiency and mass fraction values. Dense particle mass fraction values for the tests were found to be over $90 \%$ for all test performed. The dense particle collection efficiency values were also found to be very high, ranging from $70 \%$ to $91 \%$, with most values falling in the mid $80 \%$ range. It was found that varying the gas velocity through the nozzle/distributor plate did not affect the results. The other variables proved to be of greater influence, which led to a $50 \%$ split of the gas for the coal tests for the nozzle/distributor flow. It was determined for the best dense mass fraction rates that a medium sized nozzle of $1.27 \mathrm{~cm}$ should be used. It was also found that for the best collection efficiencies the smallest nozzle possible should be used, a $0.714 \mathrm{~cm}$ nozzle in this case, with the highest collection ring wall height, which was 0.381 meters.

The second portion of this research project involved using the CFB system to separate pyritic laden coal from clean coal. The material used was sieved down to a size range of 105 to 210 micron, to allow the pyrite to be liberated from the coal matter. Different variables were investigated such as the nozzle size, collection ring wall height, and mass flux of the coal into the system. The material was then taken from the dense and product collection bins and analyzed by a chemical lab to check for sulfur content. It was found that some separation did occur for the system, but the results were opposite of those anticipated. Due to the mixture being very inhomogeneous in nature, it is unknown where the pyrite laden coal lies in the size range. Since most of the pyritic coal was found in the product collection bin, it is most likely the pyrite laden coal was found in the smaller particle sizes. For the test runs completed, the greatest percent change in sulfur was close to $25 \%$ for the dense and product particle collection bin. Overall, percent 
change in sulfur values tended to be between $2 \%$ and $10 \%$, meaning some separation did occur, but not enough to use this configuration of the system effectively on a large scale. As shown in Figure 6.3.e, on a whole the 0.3048 meter collection ring wall height provides better separation efficiency when trying to separate pyritic coal from clean coal. Figure 6.3.f shows the highest separation efficiency comes from the $1.905 \mathrm{~cm}$ nozzle with the low collection ring wall height. It was also observed that higher mass flux values provided better separation efficiency in the riser.

The third portion of research completed was to try and separate pure crushed pyrite from clean coal in the circulating fluidized bed. It was found by chemical lab results that for the first test run the dense bin contained approximately $6.74 \%$ and $6.53 \%$ pyrite. The product collection bin in return contained $1.84 \%$ and $2.08 \%$ pyrite particles. The sink-float tests showed that approximately $75 \%$ of the pyrite was collected in the dense particle collections bin, while around $25 \%$ was collected in the product collection bin. As with the sand and steel shot tests, the results prove the CFB riser system is capable of separating particles when they are not bound to each other, and have dissimilar densities. Further work and research should be completed to further advance the separation efficiency of riser system.

\section{$\underline{8.2 \text { Recommendations }}$}

The circulating fluidized bed riser system has been now been in use for 4 years for three various research projects. Although still operable, several changes need to be made to allow the continued use of the riser.

The data acquisition system used for the riser system was hooked up to pressure taps and load cells to take readings. Although the system worked accurately, the 
computer interface is somewhat difficult to use. A new data acquisition system should be installed and connected to the riser to allow data to be collected with ease.

The particle injector does not connect well with the feed hopper. The joint had to be taped and connected with PVC glue on several occasions to ensure a proper seal.

New joints throughout the riser system should be devised stemming from the top of the riser to the product/filter collection bins. The joints now are currently hoses with PVC pipes and hose clamps holding them together. The joints would often form leaks or fall off during or after testing in which they would need to be re-connected and/or tightened.

The feed hopper of the system was re-designed for this research project to allow for easier loading procedures. This feed hopper contains plastic PVC joints, as well as rubber boots with hose clamps to adjoin it to the particle injector. The joints would often release when the feed hopper reached 10 psi or greater. This would end the testing process and create a large mess, as well as a potential health hazard. The feed hopper should be re-designed with a pressure relief valve so that it will not reach its failing point.

Some material would sometimes be left in the transport tube as it would settle out of the gas flow. Once the test was completed, it would take a very long time for this material to be emptied from the feed system into the riser. To fix this problem, it is recommended the transport tube would have some form of aeration to allow the particle not to settle from the air flow. This would also help to ensure the proper transport of the material from the injector into the riser.

The joints of the riser are made of acrylic plastic with acrylic flanges as well. The joints are held together with acrylic glue and long wood screws. A cork gasket is used 
throughout where the joints are found. The joints near the dense collection bin and above the distributor plate would often leak small amounts of air. The joints should be redesigned using a better gasket material, or with a better means of sealing.

Coal is very non-uniform in nature. Kingwood coal was used to investigate the potential for separation of pyritic laden coal from clean coal. Samples from the dense and product collection bins were sent to the analytical chemical lab for testing on the ICP machine. It is feared the small sample sizes were non-uniform in nature. Only $0.05 \mathrm{mg}$ of coal was used in the ICP analysis. With the combined non-uniformity of coal and small sample size, the data produced had a large range of values. Although three samples were taken, per bin, to average the results, it would still benefit to have a more definitive means of testing which would represent the entire product/collection bin sample.

Another large problem found with the riser is the flow rate of solids into the riser. The flow is currently controlled pneumatically and through the use of a ball valve on the feed hopper. The mixture in the feed hopper would often need to be pressurized slightly to start the flow of particles into the riser. A screw feed type system would be much easier to use and allow a known flow rate of particles to enter the system. The current method for achieving the desired flow rate of solids into the riser is by running several tests and just "getting a feel" for controlling the flow. This led to the material entering into the system much too quickly, or slowly, in which case the test had to be re-run.

Another problem found was gathering the desired size range of materials. The screens used for sieving the coal, play sand, and steel shot are not able to handle a large amount of material at one time. To allow larger amounts of material to be used, the large screens and shaker system need to have better capacity. Some of the large screens have 
holes and tears in them which allow material to pass through that should not. If dealing with a large quantity of material where size is not of great importance the screens would be adequate. In this case, however, it was deemed necessary to use the smaller sieves which proved to be very time consuming.

Previously mentioned are recommendations that would allow the system to operate with better efficiency and less maintenance. For future projects using the riser, it would be necessary to be appropriately funded to complete many of the changes. It is recommended if a great deal of research is to be completed using a circulating fluidized bed, that appropriate funds could be found to allow a new riser system to be constructed. 


\section{$\underline{\text { References }}$}

Almond R., R. (2005). Small Particle Separation in a Circulating Fluidized Bed Riser

System. Masters thesis, West Virginia University.

Anjorin, V.A.O., Tang, H., Morgan, A.J., and Barton, I.E. (2003). An Experimental and numerical investigation into the dispersion of powder from a pipe. Experimental Thermal and Fluid Science. Vol. 28, 45-54.

Chen, Q., \& Yang, Y. (2003). Development of dry beneficiation of coal in China. Coal Preparation, 23. 3-12.

Danielson, John A. (1967). Air Pollution Engineering Manual. Cincinnati : U.S. Dept. of Health, Education, and Welfare, National Center for Air Pollution Control; for sale by the Supt. of Docs., U.S. Govt. Print. Off., Washington, 1967.

Doctor, R.D., Anderson, J.L., Garvey, D.B., Livengood, C.D., and Farber, P.S. (1983).

The Impact of Coal Cleaning as a Sulfur-Reduction Strategy in the Midwest. U.S. Environmental Protection Agency.

Eichhorn, R. \& Small, S. (1964). Experiments on the lift and drag of spheres suspended in a Poiseuille flow. Journal of Fluid Mechanics. Vol 20, part 3, pages 513-527.

Fan, L.S., \& Zhu, C. (1998). Principals of gas-solid flow. New York, New York. Cambridge University Press.

Herhal, Albert J. \& Minnucci, Chris. (1990). Assessment of Physical Coal Cleaning Practices for Sulphur Removal. Science Applications International Corporation, Norristown, PA.

Holt, Elmer C. \& Deurbrouck, A.W. (1977). Coal Cleaning with Scrubbing for Sulfur Control. Washington : Environmental Protection Agency, Office of Research and Development, Office of Energy, Minerals and Industry ; Springfield, Va.

Johnson, E.K., \& Regester, J.L., \& Kang, B.S.-J. (2005). Fluidized bed riser as a dry particle separation system. Minerals \& metallurgical processing. Vol. 22 No.3 130-134.

Komnitas K., Stouraiti C., Paspaliaris I. (2001). Sulfur Removal From Coal Beneficiation Wastes. $7^{\text {th }}$ CEST Conference. Syros, Greece.

Lain, S., \& Garcia, J.A. (2006). Study of four-way coupling on turbulent particle-laden jet flows. Chemical Engineering Science Vol. 61. 6775-6785.

Leith, D. (1982). "Cyclones" in: Hetrsroni, G. (Ed.), Handbook of multiphase systems. New York: McGraw-Hill. 
Levy, Y. and Lockwood, F.C. (1981). Velocity Measurements in a Particle Laden Turbulent Free Jet. Combustion and Flame. Vol. 40: 333-339.

Luttrell, G.H., \& Venkatraman, P., \& Yoon, R.-H. (1998). Removal of hazardous air pollutant precursors by advanced coal preparation. Coal Preparation, 19. 243-255.

Moran, J.C., \& Glicksman, L.R. (2003). Mean and fluctuating gas phase velocities inside a circulating fluidized bed. Chemical Engineering Science, 58. 1867-1878.

Regester, J.L. (2004). Separation of small particles due to density differences in a CFB riser system. Masters thesis, West Virginia University.

Saffman, P.G. (1965). The lift on a small sphere in a shear flow. Journal of fluid mechanics, 22. 385-400.

Saffman, P.G. (1968). Corrigendum to "The lift on a small sphere in a shear flow." Journal of fluid mechanics, 31. 624.

Schlichting, H. (1979). Boundary layer theory. ( $7^{\text {th }}$ ed.). New York: McGraw-Hill.

Shuen, J.-S., Chen, L.-D., and Faeth, G.M. (1983). Evaluation of a Stochastic Model of Particle Dispersion in a Turbulent Round Jet. American Institute of Chemical Engineers. Vol. 29, No.1.

Shuen, J.-S., Solomon, A.S.P., Zhang, Q.-F., and Faeth, G.M. (1985). Structure of Particle-Laden Jets: Measurements and Predictions. American Institute of Aeronautics and Astronautics. Vol. 23, No. 3.

Speight, James G. (2005). Handbook of Coal Analysis. . Hoboken, New Jersey: John Wiley and Sons.

Stiller, A. (2007) Personal Interview. 28 February.

Yamamoto, F. et al. (1991). Particle lift and drag in high Reynolds number linear shear flow. Gas-Solid Flows, 121. 191-195.

Yang, H., (1995) "Experimental Study on the Hydrodynamics in the Riser of a Circulating Fluidized Bed.” Dissertation, West Virginia University. 


\section{$\underline{\text { Appendix A }}$}

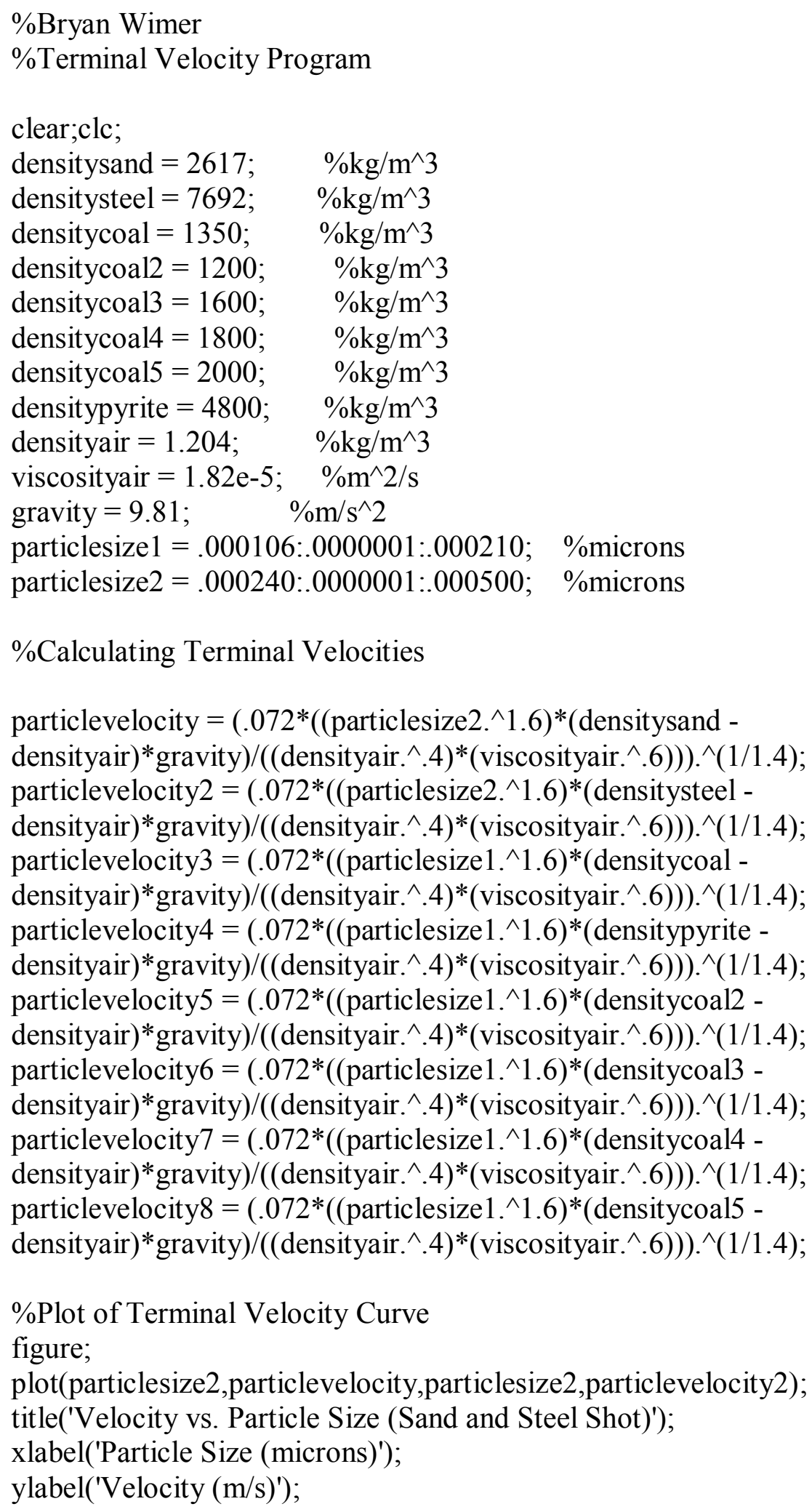




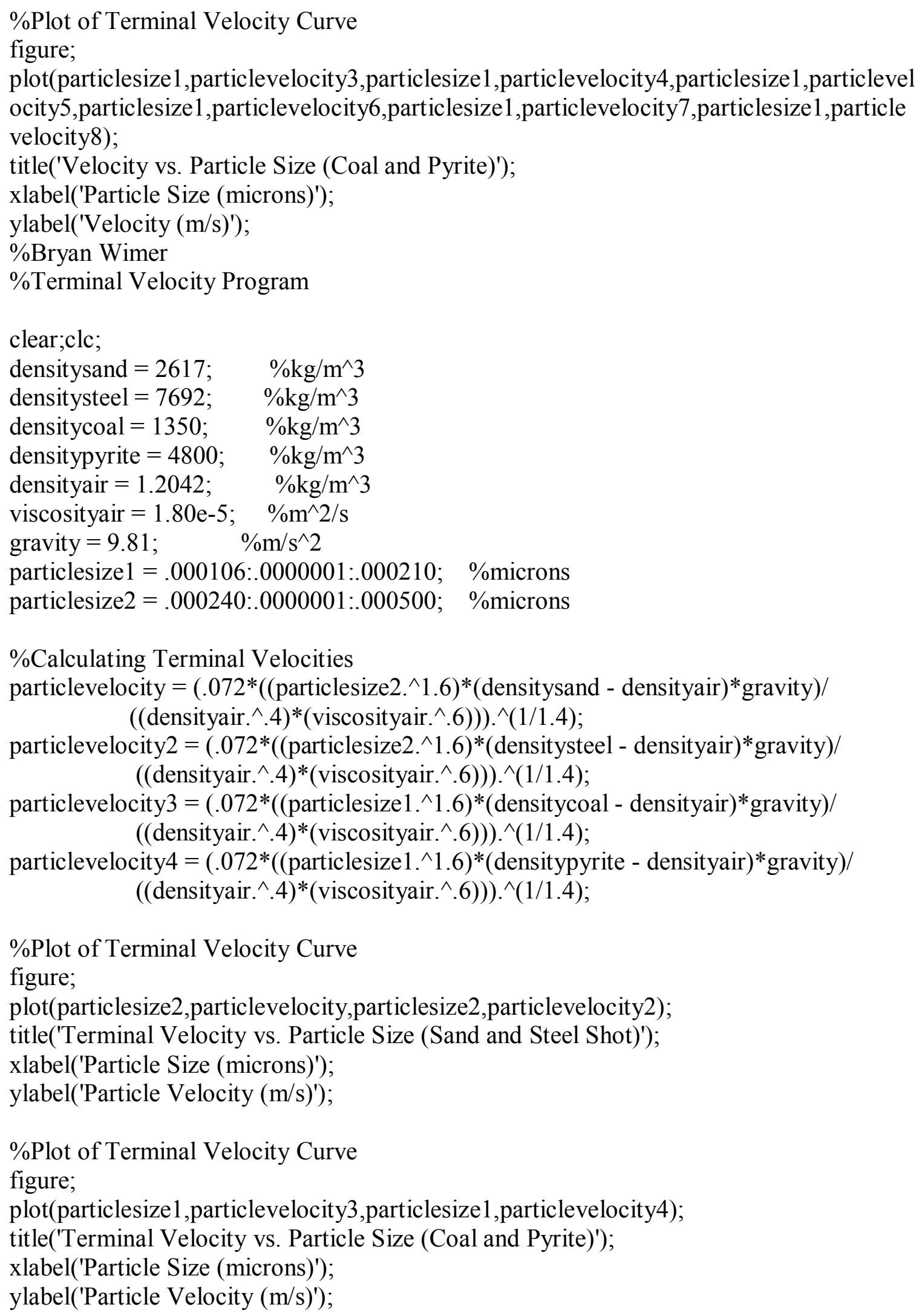




\section{Appendix B}

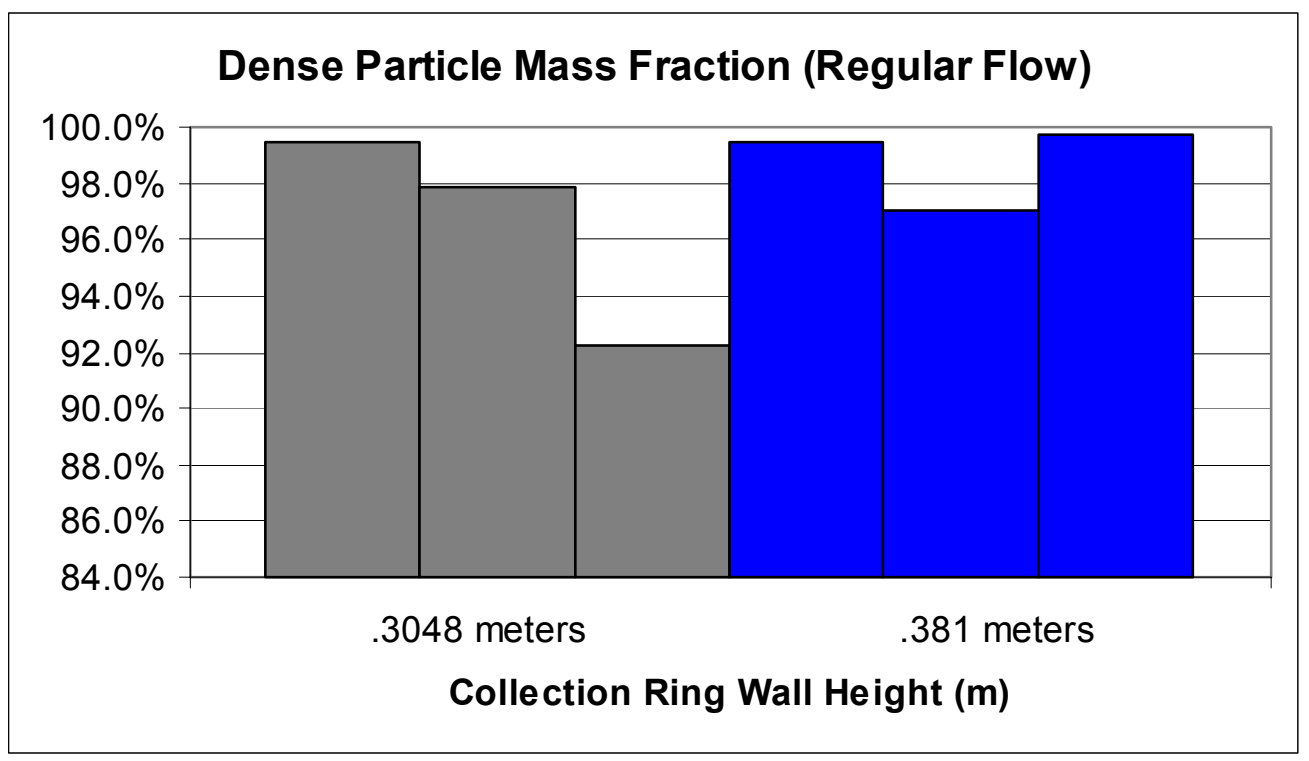

Figure B.1 Dense Particle Mass Fraction as a Function of Collection Ring Wall

Height (Regular Flow)

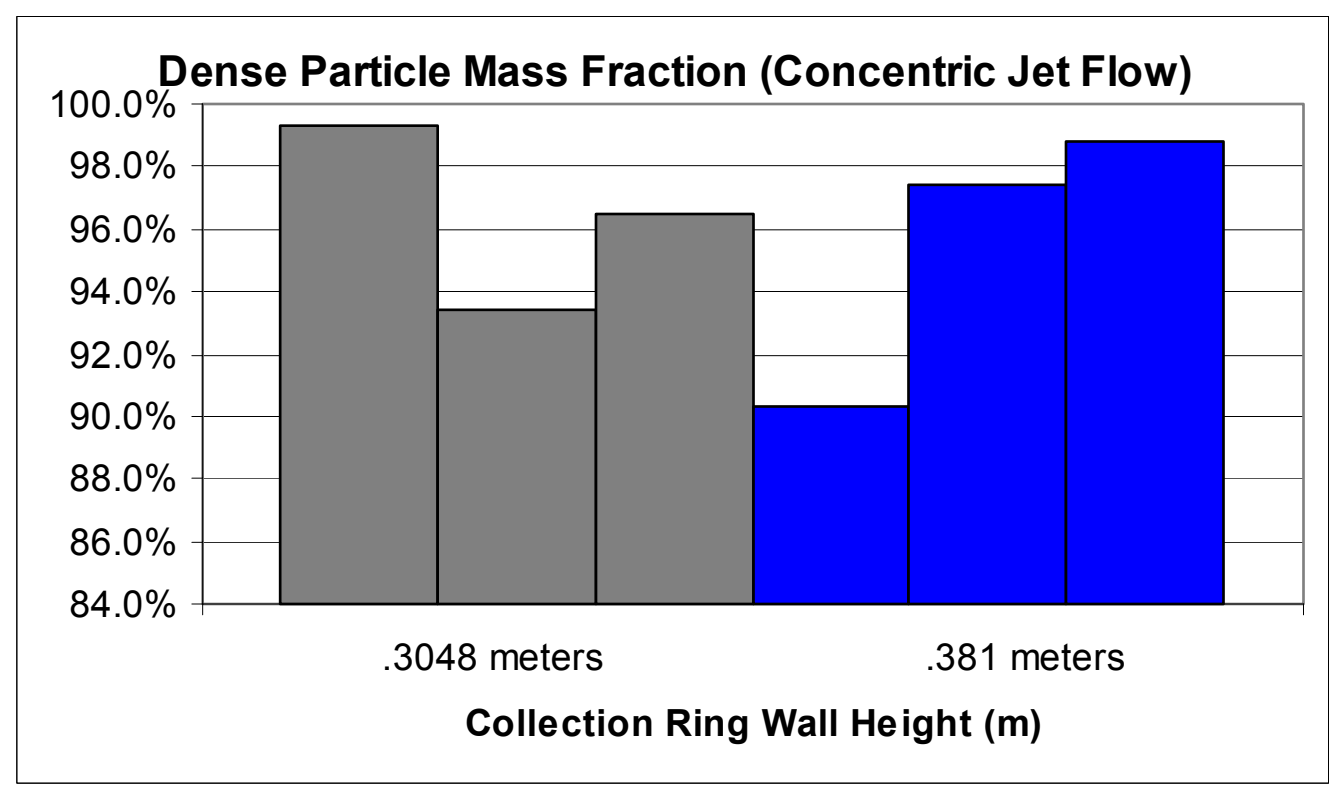

Figure B.2 Dense Particle Mass Fraction as a Function of Collection Ring Wall Height (Concentric Jet Flow) 


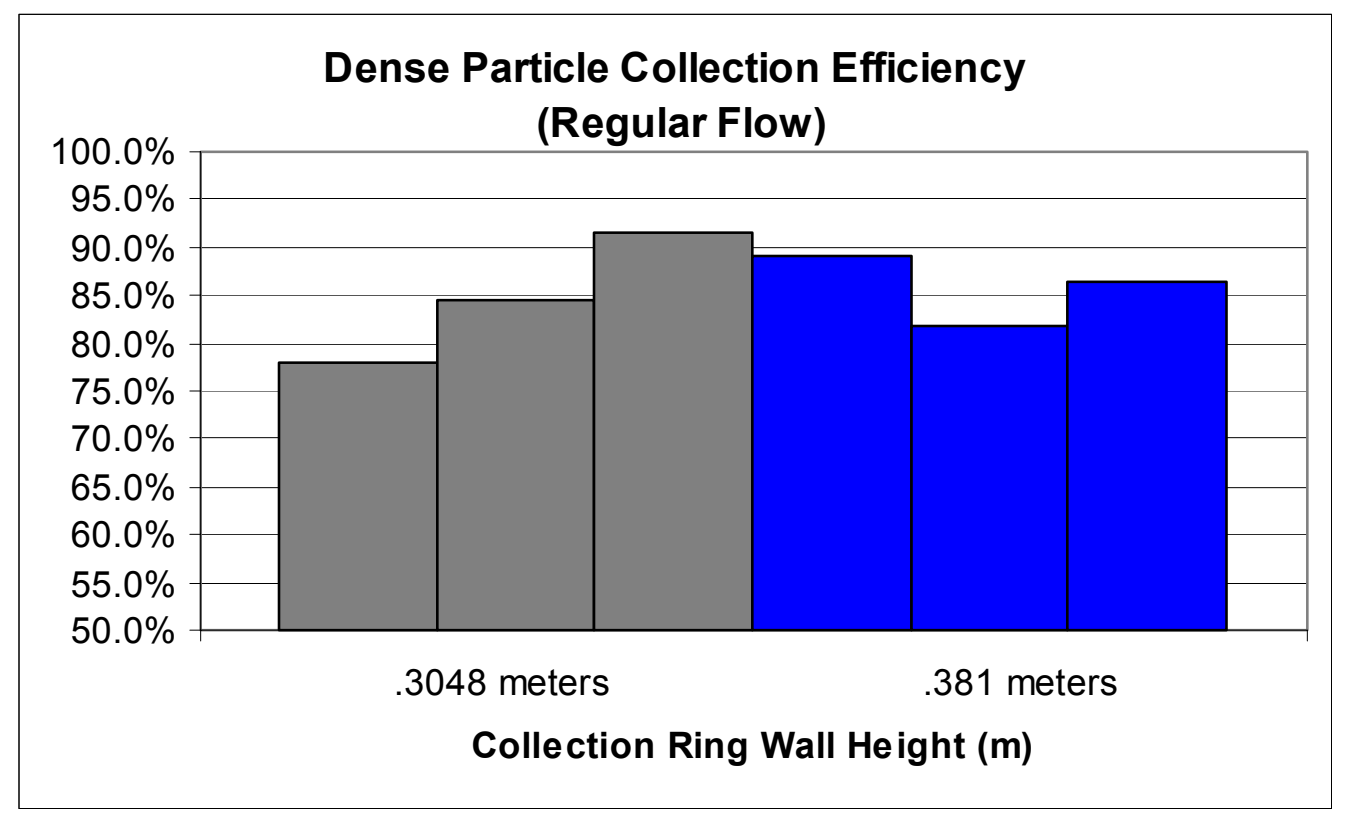

Figure B.3 Dense Particle Collection Efficiency as a Function of Collection Ring Wall Height (Regular Flow)

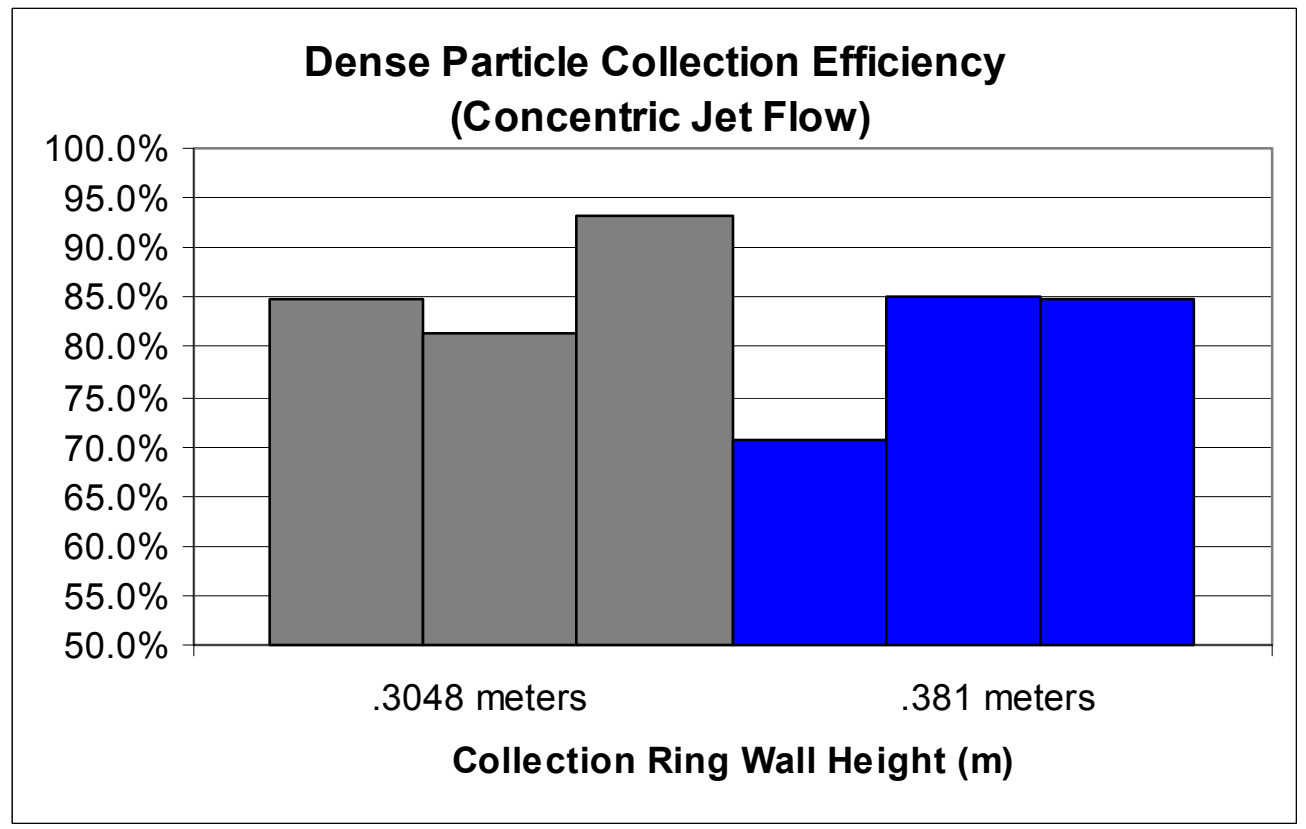

Figure B.4 Dense Particle Collection Efficiency as a Function of Collection Ring Wall Height (Concentric Jet Flow) 


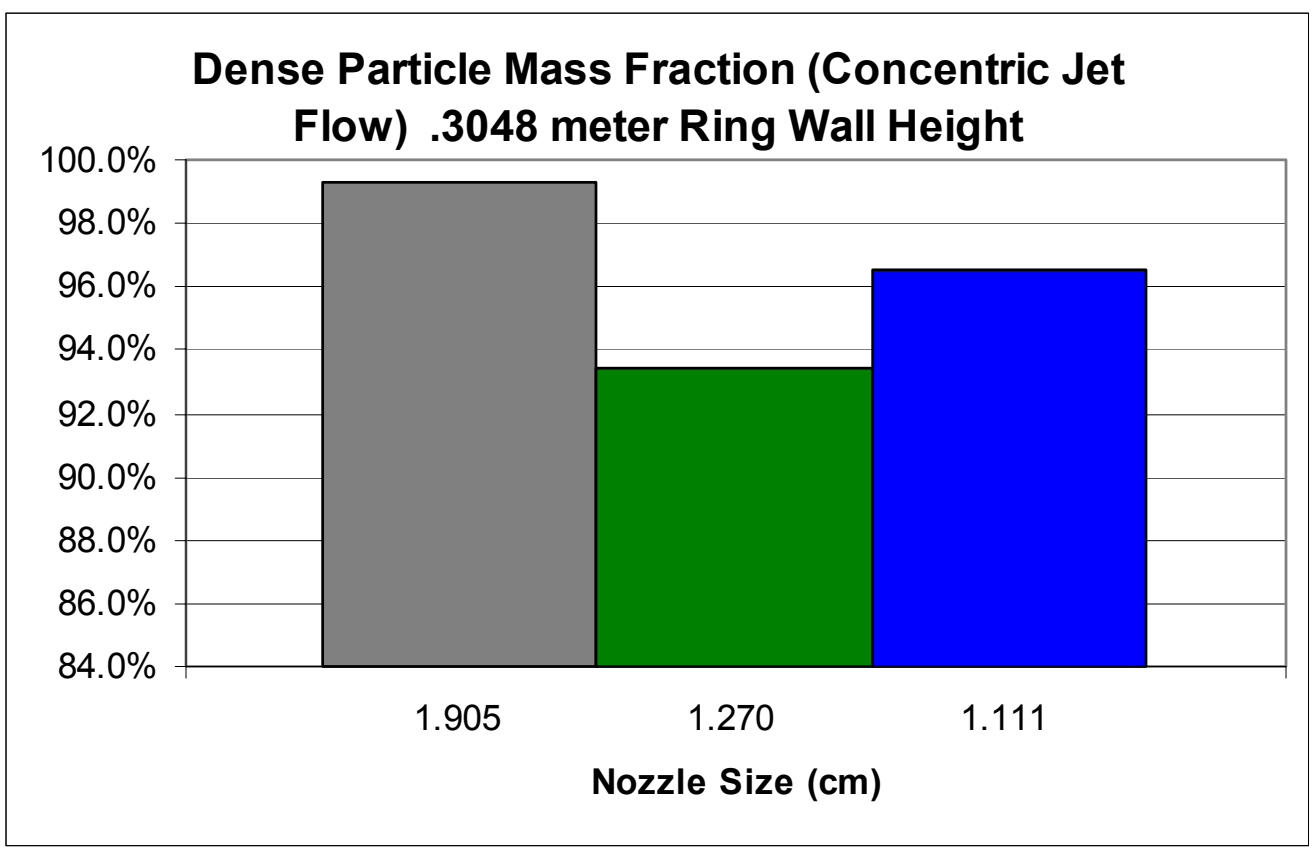

Figure B.5 Dense Particle Mass Fraction as a Function of Nozzle Size - .3048 meter Ring Wall Height - (Concentric Jet Flow)

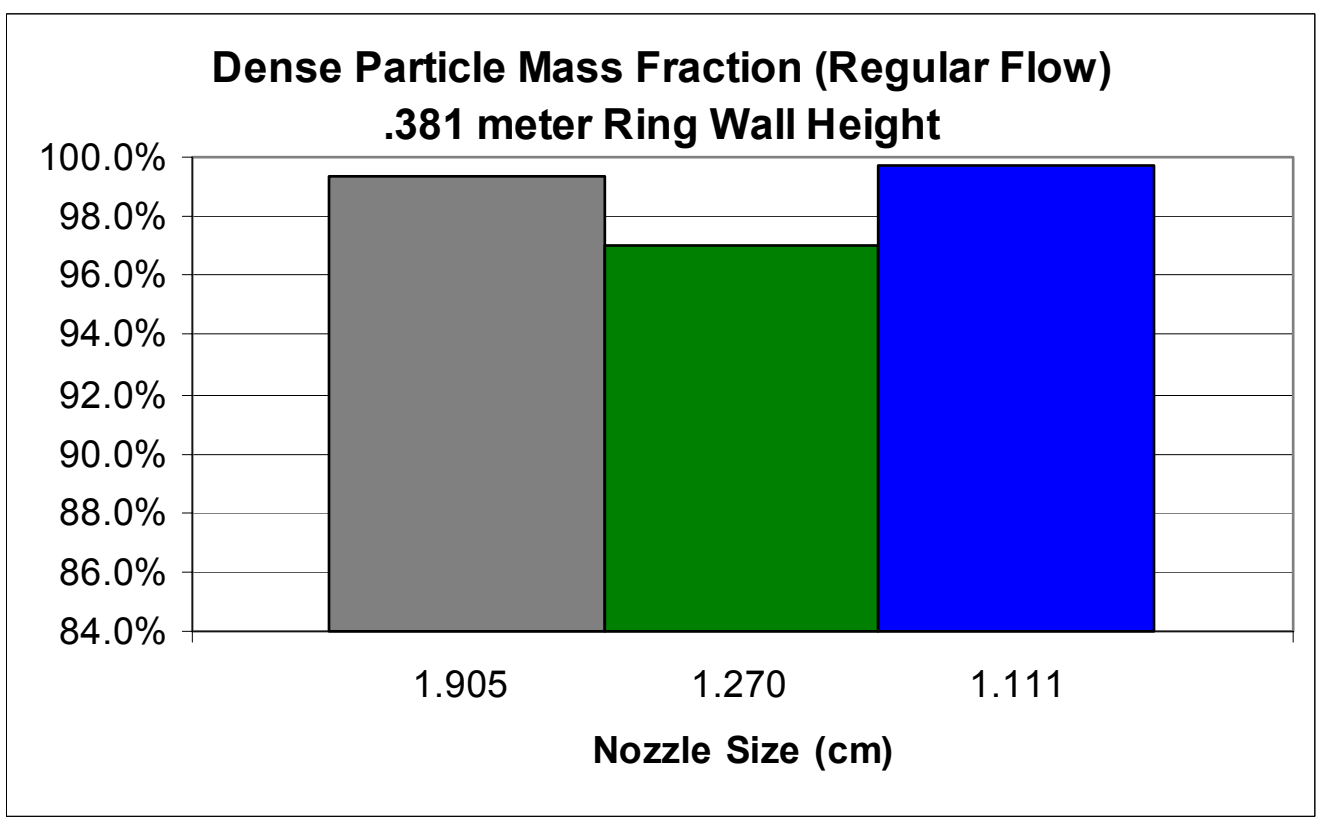

Figure B.6 Dense Particle Mass Fraction as a Function of Nozzle Size - .381 meter Ring Wall Height - (Regular Flow) 


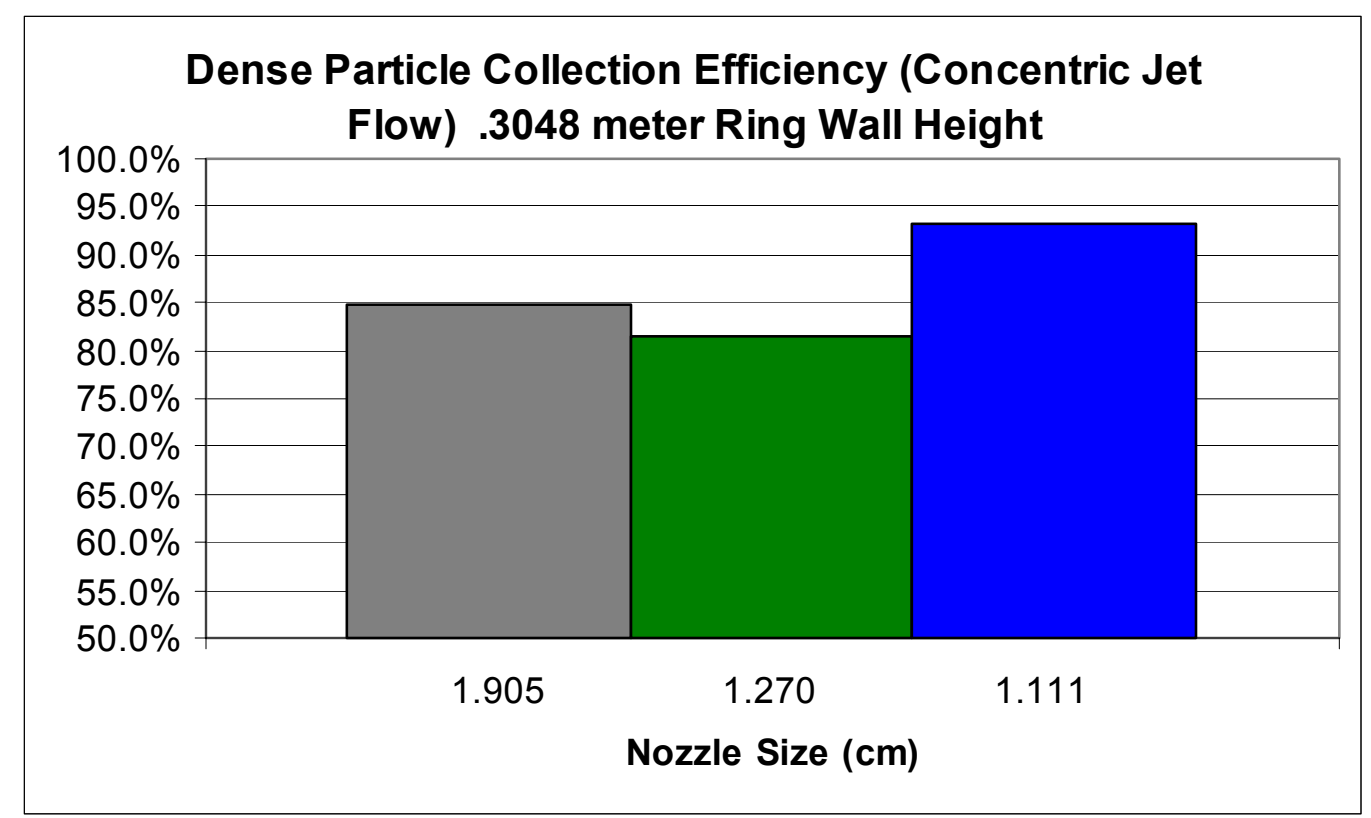

Figure B.7 Dense Particle Collection Efficiency as a Function of Nozzle Size - . 3048 meter Ring Wall Height - (Concentric Jet Flow)

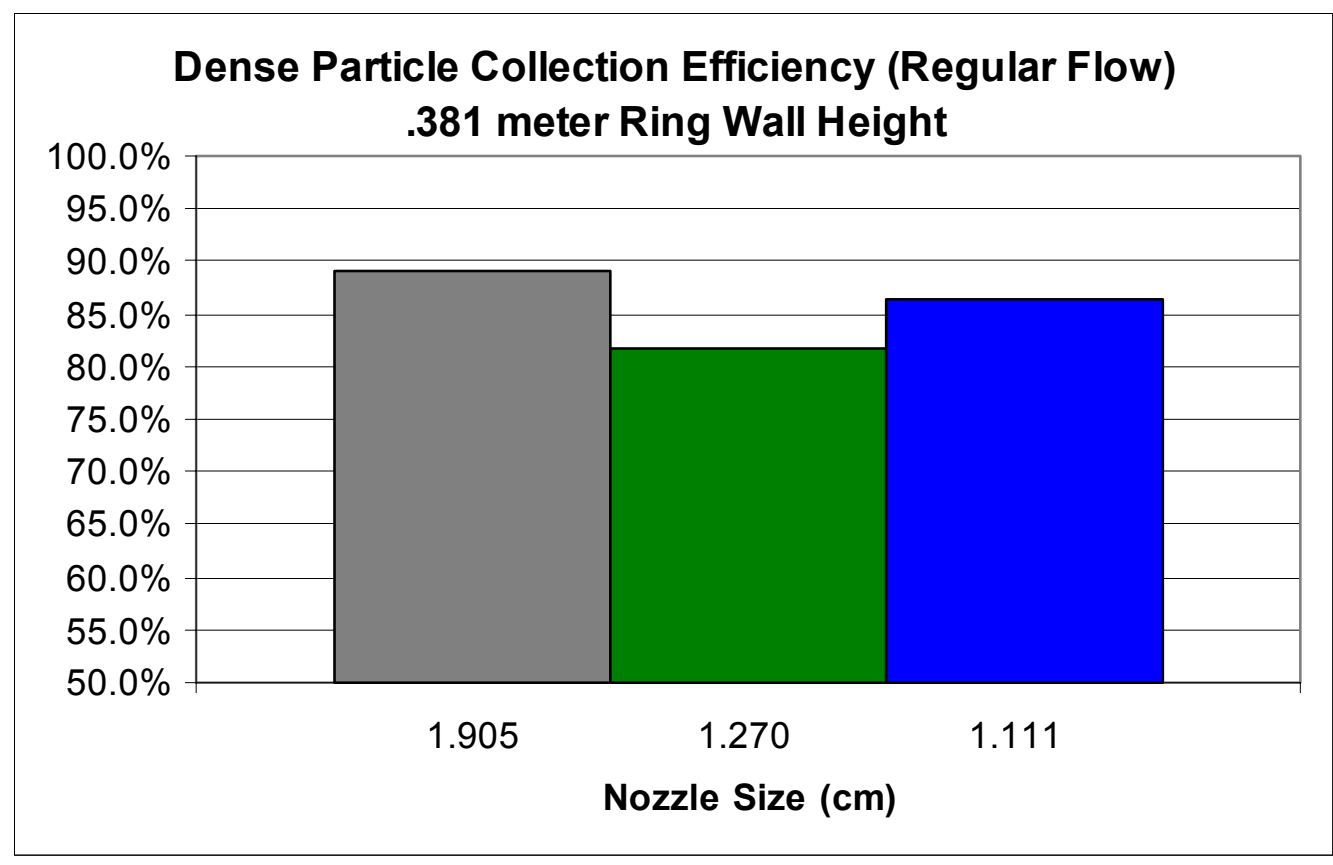

Figure B.8 Dense Particle Collection Efficiency as a Function of Nozzle Size - .381 meter Ring Wall Height - (Regular Flow) 


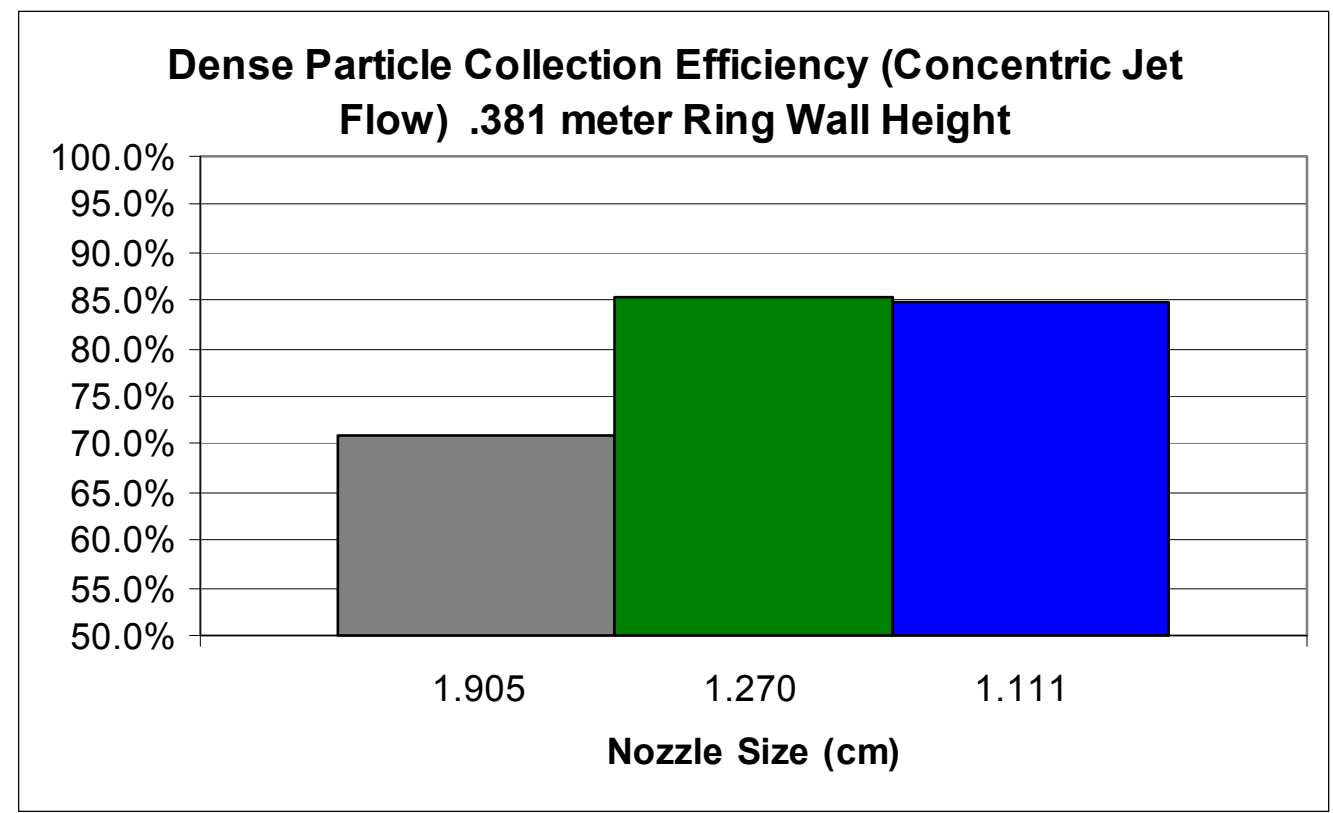

Figure B.9 Dense Particle Collection Efficiency as a Function of Nozzle Size - .381 meter Ring Wall Height - (Concentric Jet Flow)

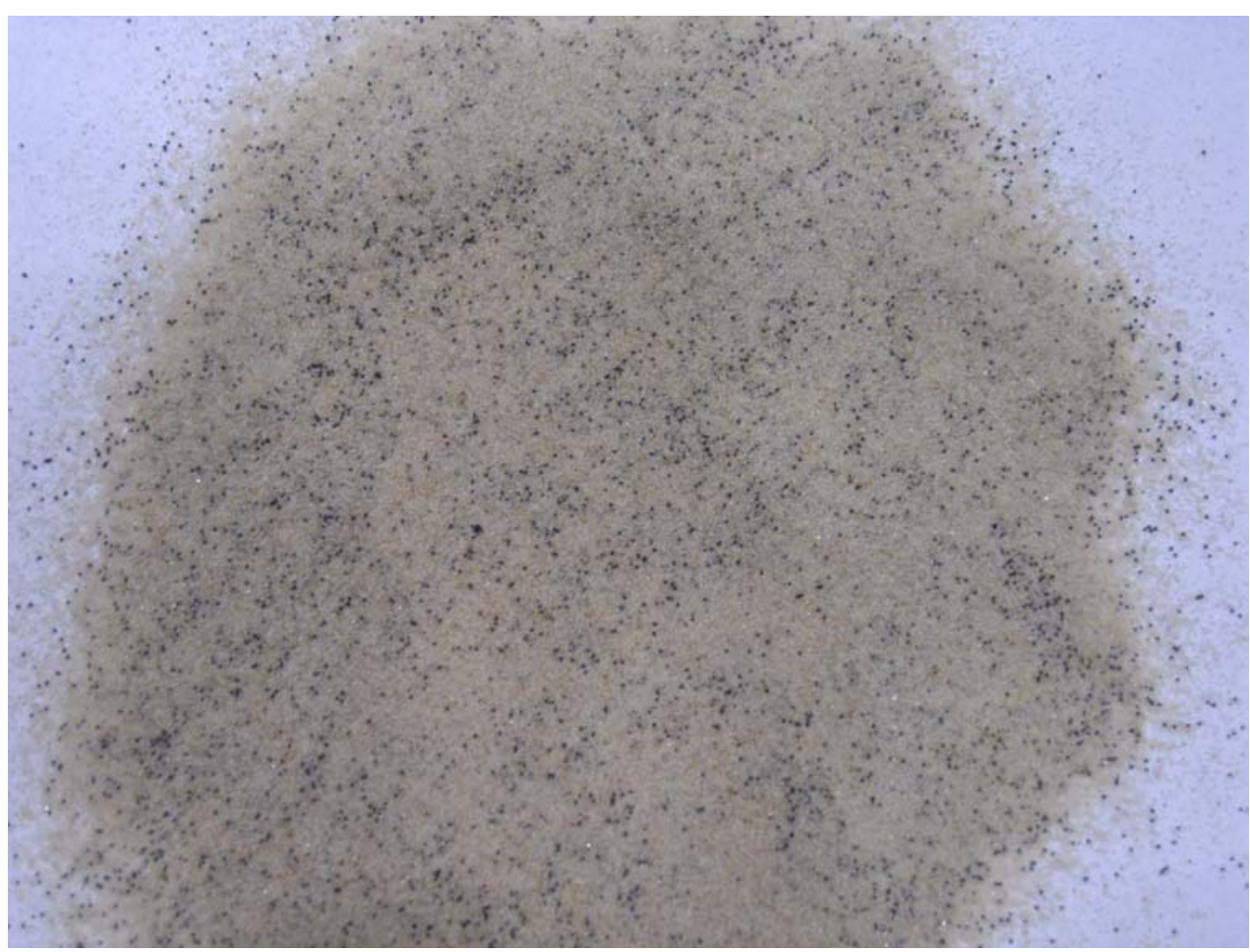

Figure B.10 Picture of Sand and Steel Shot Mixture before Separation 
Figure B.11 Picture of Sand and Steel Shot from Product Bin - Post Separation

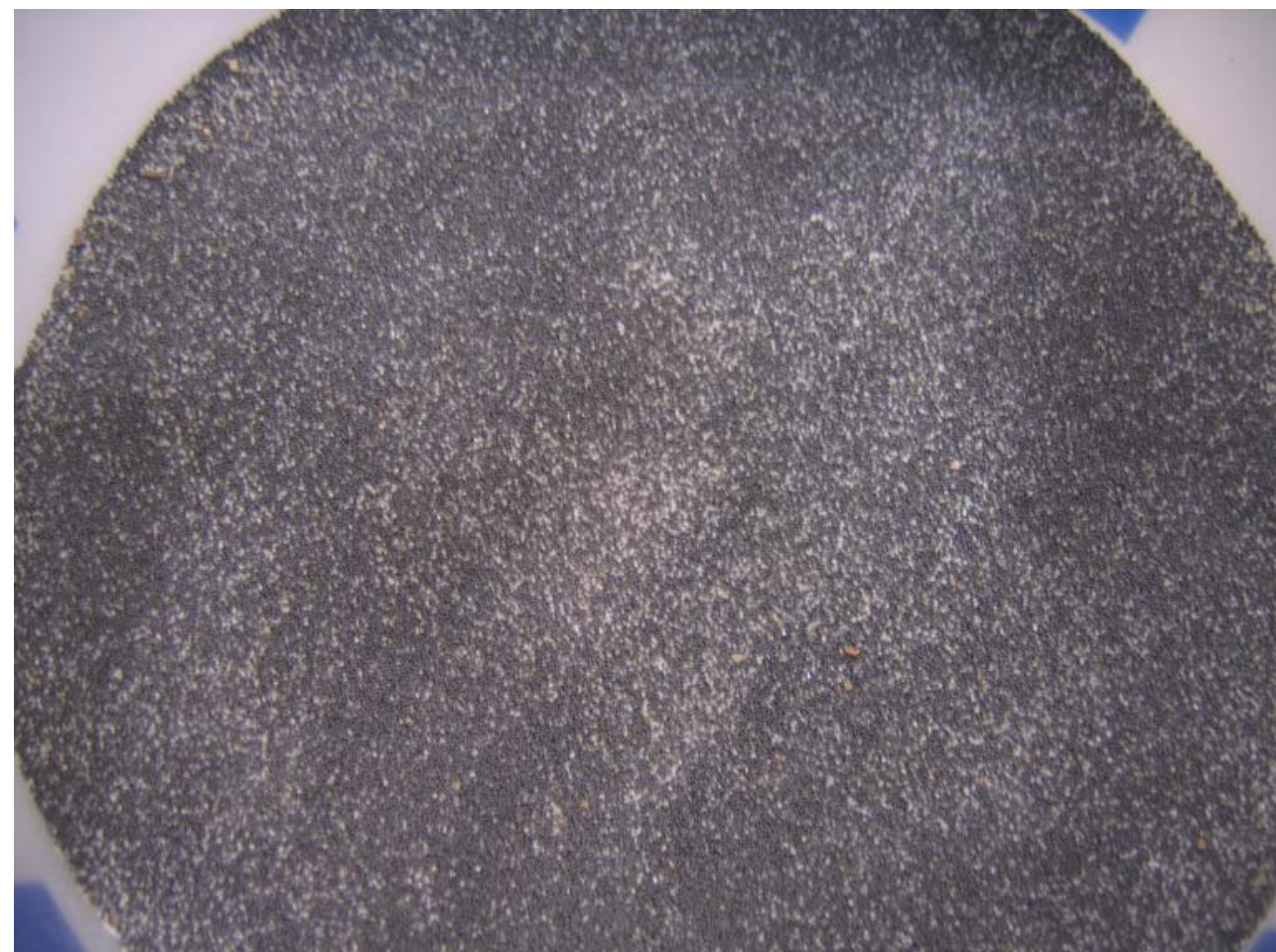

Figure B.12 Picture of Sand and Steel Shot from Dense Bin - Post Separation 
$\underline{\text { Appendix C }}$

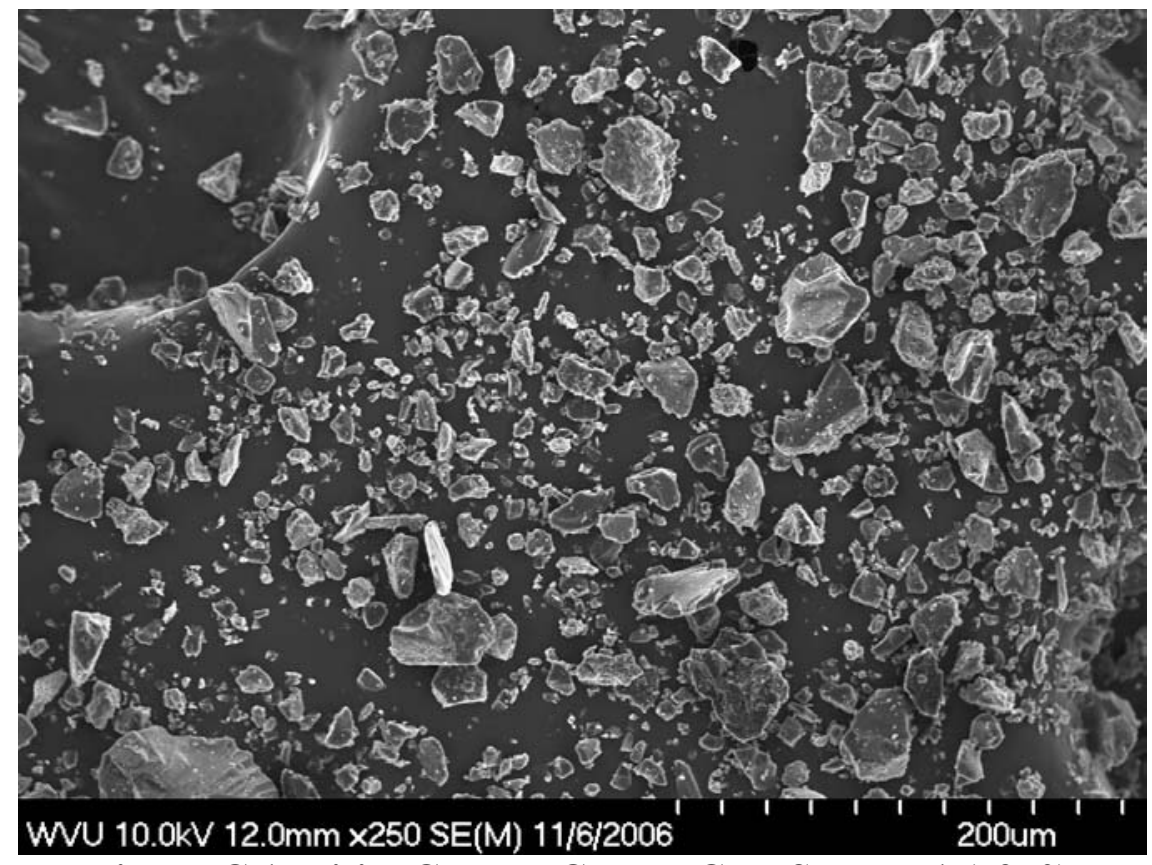

Figure C.1 Initial Carbon Coated Coal Sample 1 (x250)

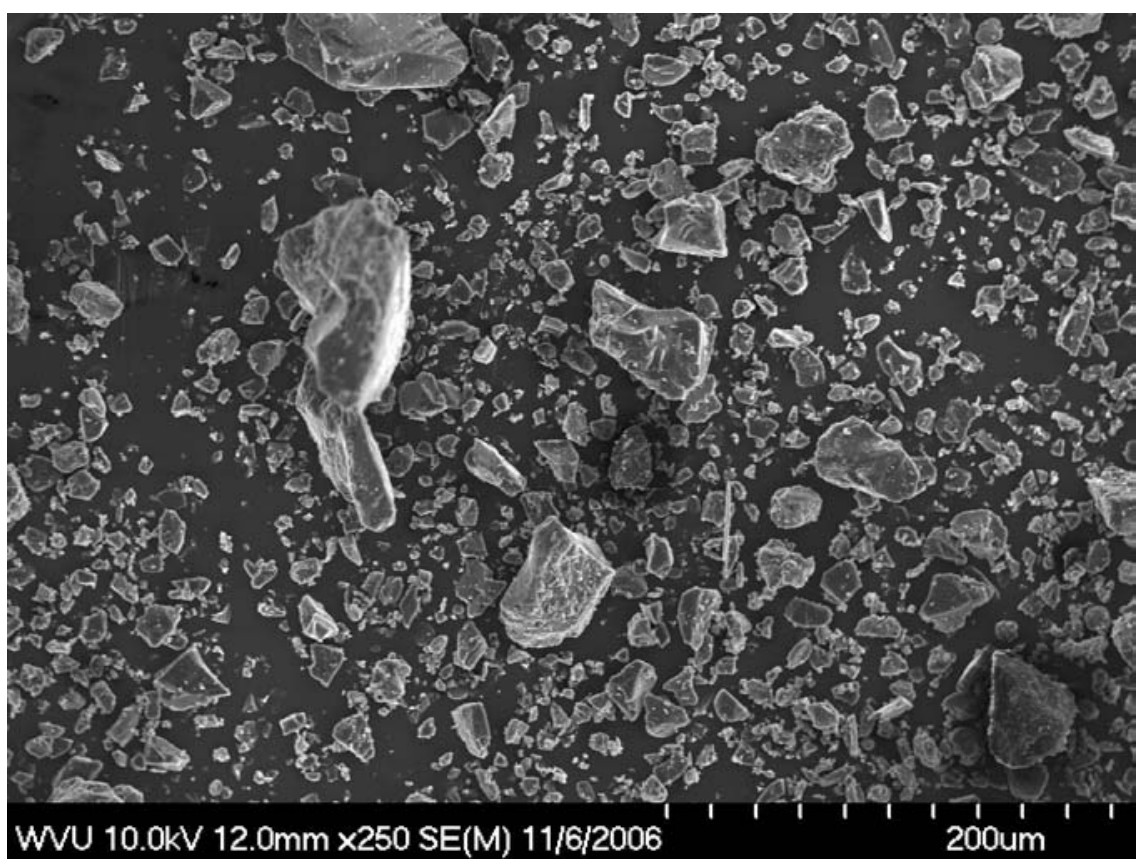

Figure C.2 Initial Carbon Coated Coal Sample 2 (x250) 


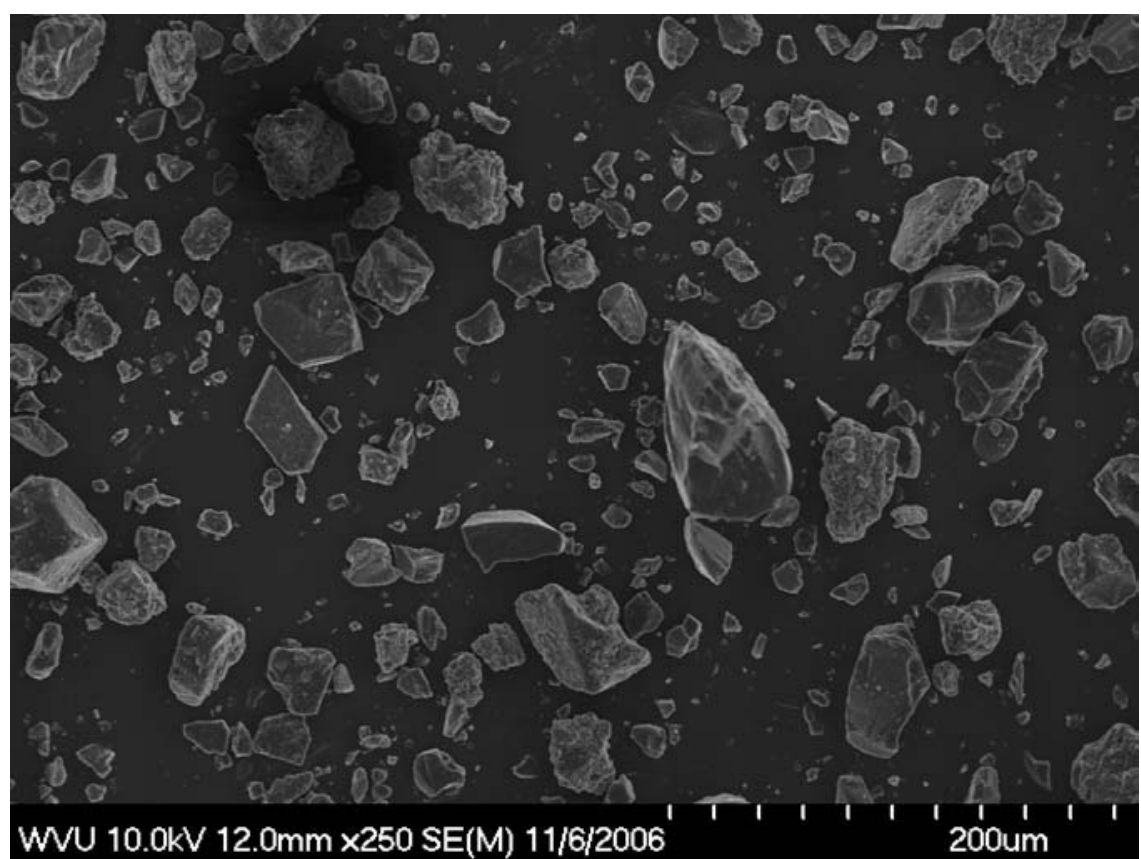

Figure C.3 Dense Bin Carbon Coated Coal Sample 1 (x250)

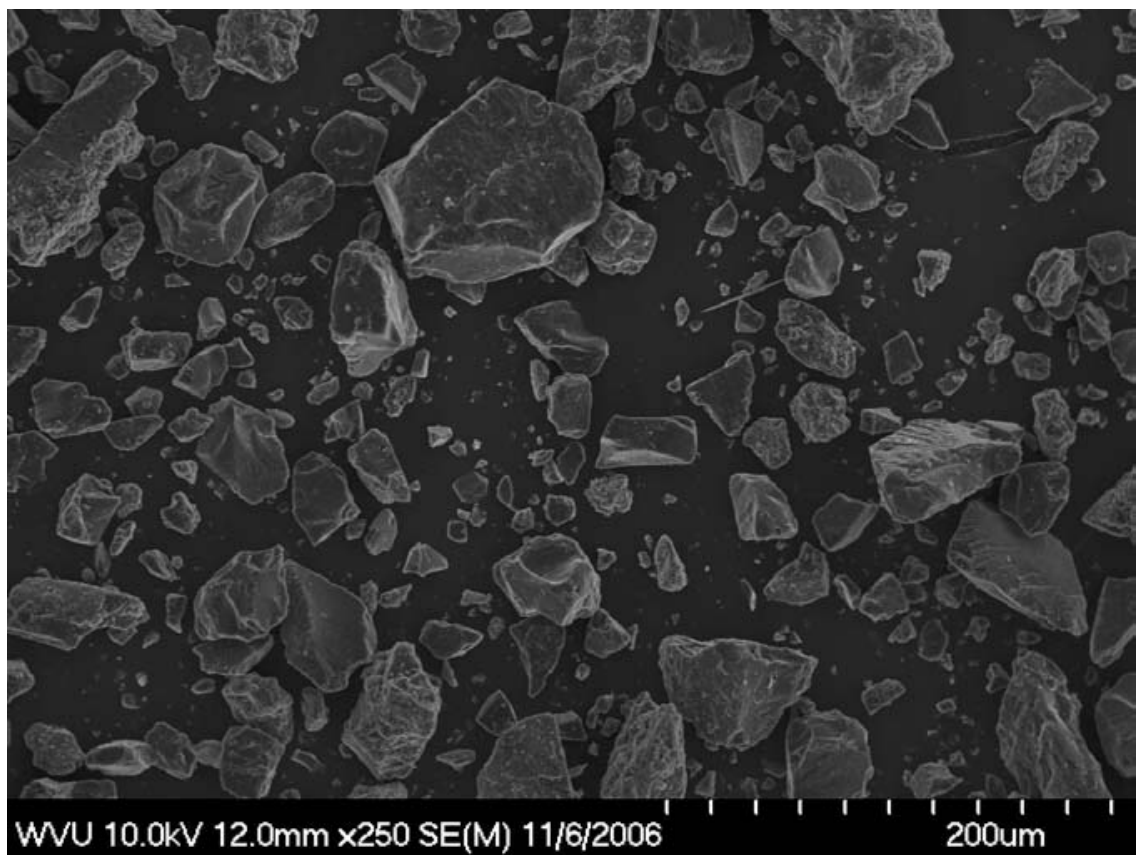

Figure C.4 Dense Bin Carbon Coated Coal Sample 2 (x250) 


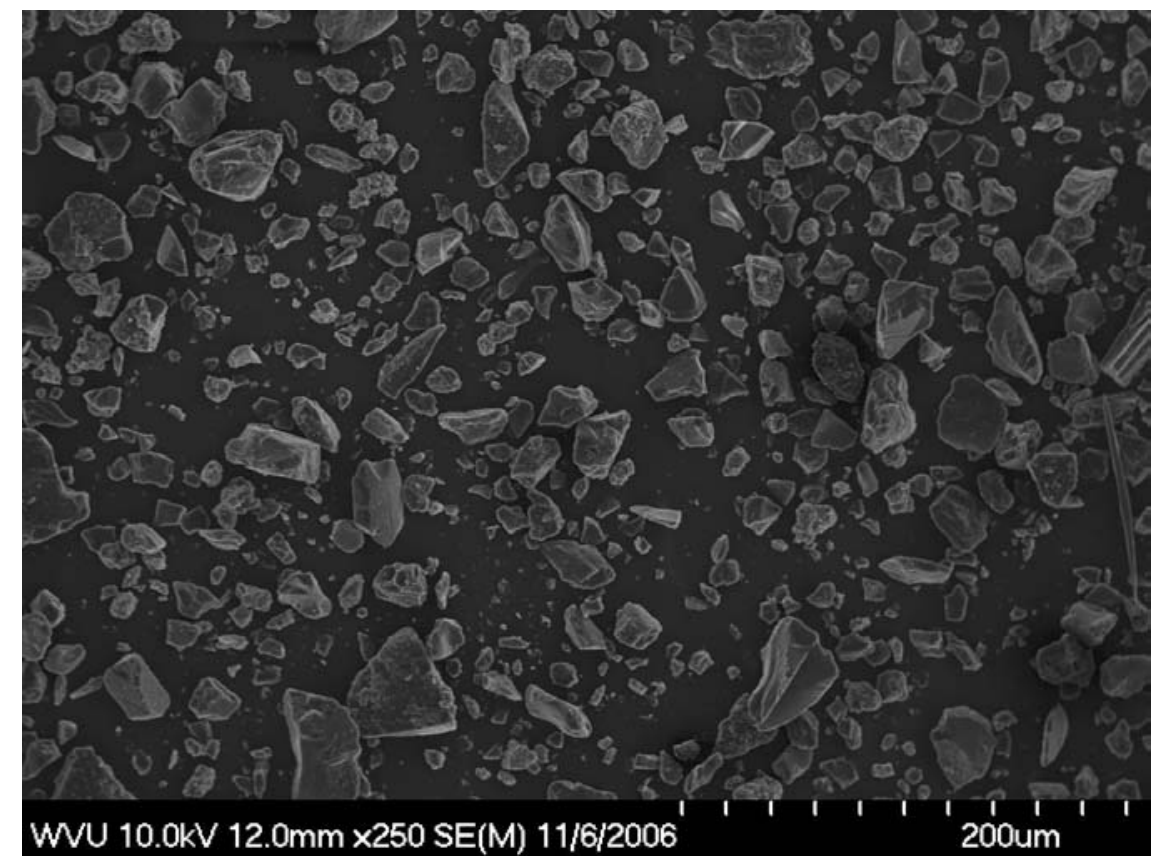

Figure C.5 Product Bin Carbon Coated Coal Sample 1 (x250)

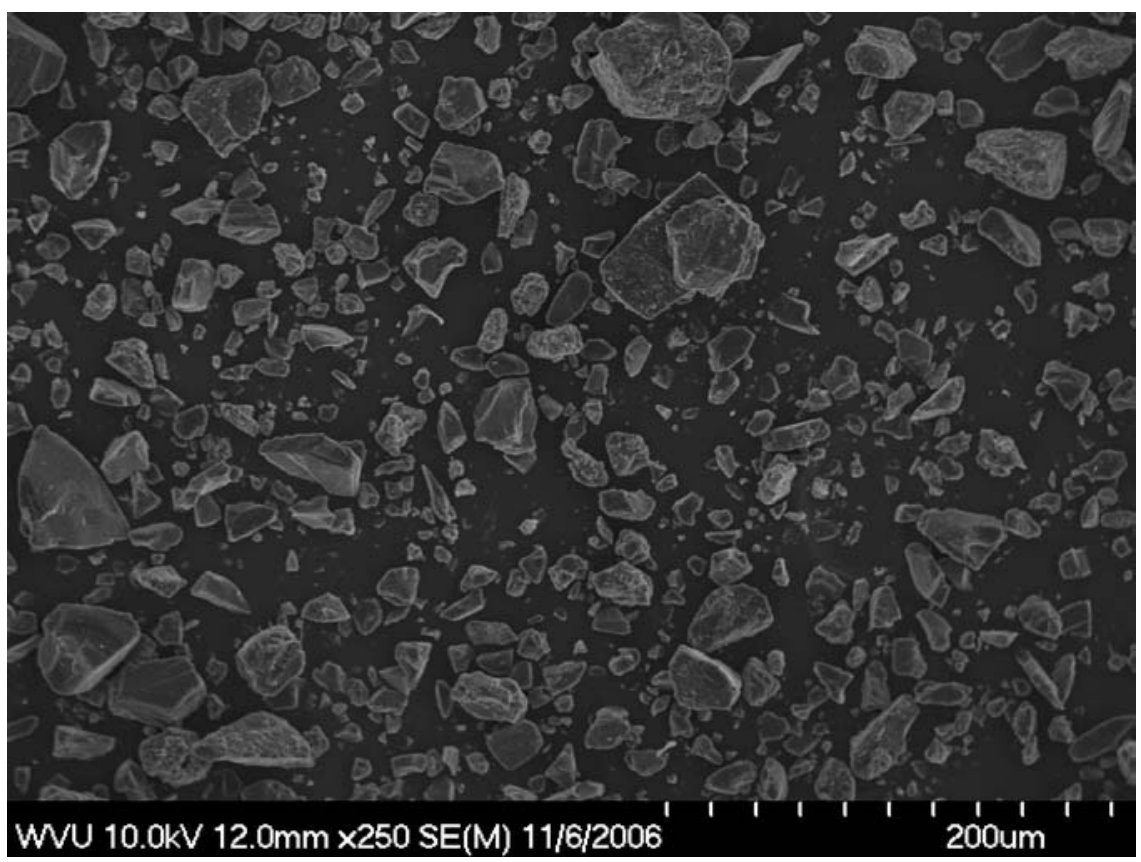

Figure C.6 Product Bin Carbon Coated Coal Sample 2 (x250) 


\section{Coal Spectrum Overlay for Dense, Product, and Initial Samples}

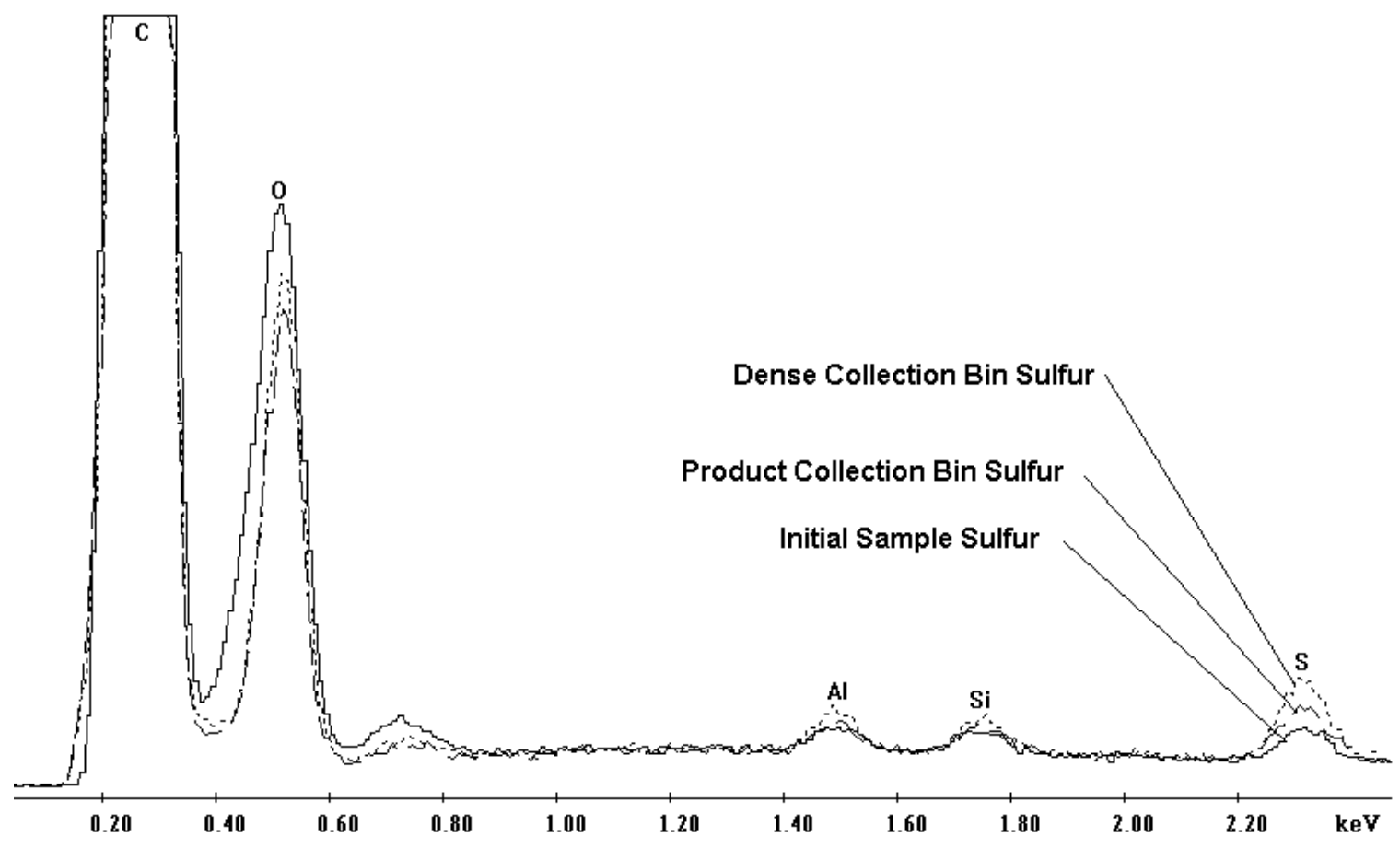

Figure C.7 Coal Spectrum Overlay for Initial, Dense, and Product Samples 


\section{$\underline{\text { Appendix D }}$}

\section{D.1 Riser Start Up/Shut Down Procedure}

\section{D.1.1 Riser Start-up Procedure}

1. Check to Ensure all Cables to Data Acquisition System are Connected

2. Turn on the computer

3. Turn on the power source to the pressure transducers

4. Make sure all valves are closed

5. Attach Dense Particle bin

6. Check to ensure closure of Product bin valve

7. Check that filtration system is secured to cyclone exhaust

8. Check all other System Connections

9. Open DAPView

10. Start data acquisition

11. Open main airflow valve

12. Check for any air leaks

13. Open distributor flow valve to desired level according to flow meter

14. Open pneumatic flow valve to desired level according to flow meter

15. Open valve to pressurize feed hopper if needed

16. Check System for any leaks, or any vibrations

17. Open Feed Hopper ball valve to start solid mixture flow

18. Check to ensure DAPView is reading data correctly and check all other instrumentation to take readings

\section{D.1.2 Riser Shutdown Procedure}

1. Close tank pressurization valve

2. Close off ball valve to feed hopper to ensure no particles will be trapped in the Transport Tube area (Must do after tank pressure is turned off!!!)

3. Close distributor flow valve

4. Close pneumatic flow valve

5. Close main air flow valve

6. Stop DAPView

7. Save DAPView data from run and mark down other data

8. Detach Dense Particle bin and empty contents

9. Empty small cap from distributor base to check for particles

10. Empty Product bin by opening ball valve and empty contents

11. If using paper filtration system - remove filter bags and replace with fresh bags 